\title{
Effects of faculty senate's site-based management practice on restructuring schools to facilitate inclusion
}

\author{
Holly Ann Pae \\ West Virginia University
}

Follow this and additional works at: https://researchrepository.wvu.edu/etd

\footnotetext{
Recommended Citation

Pae, Holly Ann, "Effects of faculty senate's site-based management practice on restructuring schools to facilitate inclusion" (1999). Graduate Theses, Dissertations, and Problem Reports. 3135.

https://researchrepository.wvu.edu/etd/3135

This Dissertation is protected by copyright and/or related rights. It has been brought to you by the The Research Repository @ WVU with permission from the rights-holder(s). You are free to use this Dissertation in any way that is permitted by the copyright and related rights legislation that applies to your use. For other uses you must obtain permission from the rights-holder(s) directly, unless additional rights are indicated by a Creative Commons license in the record and/ or on the work itself. This Dissertation has been accepted for inclusion in WVU Graduate Theses, Dissertations, and Problem Reports collection by an authorized administrator of The Research Repository @ WVU.

For more information, please contact researchrepository@mail.wvu.edu.
} 
Effects of Faculty Senate's Site-Based Management Practice on Restructuring Schools to Facilitate Inclusion

\author{
Holly A. Pae \\ Dissertation submitted to the College of Human Resources and Education \\ at West Virginia University \\ in partial fulfillment of the requirements \\ for the Degree of \\ Doctor of Education \\ in \\ Special Education
}

Dr. Thomas P. Lombardi, Chair

Dr. Gretchen Butera

Dr. Diane T. Woodrum

Dr. Phyllis Durden

Dr. Ernest Goeres

Department of Education Theory and Practice

Morgantown, West Virginia

1999

Keywords: Inclusion, School Reform, Site-Based Management

Copyright 1999 Holly A. Pae 


\begin{abstract}
Effects of Faculty Senate's Site-Based Management Practice on Restructuring Schools to Facilitate Inclusion
\end{abstract}

Holly A. Pae

The national reform agenda charges schools to address the needs of all students. Unlike prior movements these reform goals have influenced the broader context of education's activities to embrace the principle and practices invested in the Individual with Disabilities Education Act. In response states have developed policies that promote inclusive education. Yet despite these initiatives, students with disabilities continue to receive limited attention in the school reform literature. The purpose of this study was to examine how these contexts of reform serve special education's interests.

Using a multiple case design this study examined the relationship between the school's inclusion level and their site based management participatory characteristics. Four case sites were participants: two had a high percentage of student receiving special education services and two had a low percentage as determined by state records. The study used four data collection strategies at each site: observation, content integration plan analysis, teacher survey, and teacher interview. A pattern-matching analysis developed four case study profiles by examining the embedded units within each case. The study then treated each case as units of analysis to inform a larger case. This pattern-matching examination determined if a predicted pattern was produced (i.e., whether schools with higher perceived participatory role in decision making achieve a different level of inclusive practices then that of schools with lower perceived participatory role in decision making).

The impetus for change was largely attributed to how the larger system initially redefined the teachers' positions within the organization. Faculty senates in schools with higher levels of integration made different types of decisions than that of faculty senates in schools with lower levels of integration. They had fewer faculty senate committees, spent a majority of their meeting time in discussion with the principal, and engaged in decision making regarding teacher related concerns. Faculty senates in schools with lower levels of integration had more faculty senate committees, spent their meeting time discussing teacher driven proposals, and engaged in decision making regarding student related concerns. 


\section{Acknowledgments}

My sincere appreciation goes to my committee, Dr. Thomas Lombardi, chair, Dr. Gretchen Butera, Dr. Diane Woodrum, Dr. Phyllis Durden, and Dr. Ernest Goeres, for their support that made the completion of this dissertation a reality. This work and my doctoral program would not have been completed without their encouragement, support, and assistance.

I would also like to thank the faculty and staff from the four schools who participated in this study. I am grateful for how they welcomed me into their community and took a genuine interest to openly share their thoughts and understandings about their schools.

I extend a special thanks to John Foshay, Dr. Laura Reissner, Dr. Joan Henderson, Sally Brannan, and Missy Reed for their technical assistance and sincere regard in helping me succeed. I am indebted to their friendship and for the countless ways they faithfully shared in my happiness.

I give the deepest appreciation to my family for their unconditional love and belief that life holds the opportunity to make dreams come true. I would especially like to thank my sister, Nancy, for all of her support and for being my biggest fan. Finally, this endeavor would not have been accomplished if it were not for my parents and the value that they place on education. Their devotion and appreciation of learning have been a great inspiration to my personal and professional goals. I love you and thank you. I dedicate this to you. 


\section{Table of Contents}

Acknowledgments $\quad$ iii

List of Tables $\quad$ ix

Chapter I: Introduction $\quad 1$

$\begin{array}{ll}\text { Statement of the Problem } & 6\end{array}$

$\begin{array}{ll}\text { Purpose of Study } & 6\end{array}$

$\begin{array}{ll}\text { Research Questions } & 7\end{array}$

Chapter II: Review of Literature $\quad 8$

Riding the Waves of Educational Reform 9

Educational reform of the 1980s: The first wave 9

Educational reform of the 1980s: The second wave 13

Educational reforms of the 1980s: The teachings of the past 16

$\begin{array}{ll}\text { Educational reform of the 1990s: The third wave } & 18\end{array}$

Educational Reform: Valuing Special Education as a Change Agent 20

$\begin{array}{ll}\text { Educational reform: The new goal } & 20\end{array}$

Educational reform: The special education policy 22

Educational reform: The special education philosophy 24

Educational Reform: The Bureaucratic Challenge 26

Educational reform: The bureaucratic barriers $\quad 29$

Educational reform: The bureaucratic conflict 31

Educational Reform: Building Inclusive Schools in West Virginia 33

Current educational reform: The strategy and goals 33

Current educational reform: The West Virginia experience 35

Current educational reform: The strategic plan 36

Current education reform: The implications $\quad 40$

Chapter III: Methods

$\begin{array}{ll}\text { Subjects } & 44\end{array}$ 
Instrumentation $\quad 45$

$\begin{array}{ll}\text { Artifacts } & 46\end{array}$

$\begin{array}{ll}\text { Survey } & 46\end{array}$

$\begin{array}{ll}\text { Observation } & 50\end{array}$

$\begin{array}{ll}\text { Interviews } & 51\end{array}$

$\begin{array}{ll}\text { Procedures } & 52\end{array}$

Data Analysis and Presentation $\quad 53$

Case Study Profiles and Cross Case Analysis $\quad 54$

Chapter IV: Data Analysis and Results 56

$\begin{array}{ll}\text { Gemrock School } & 57\end{array}$

$\begin{array}{ll}\text { Observation } & 57\end{array}$

$\begin{array}{ll}\text { Staffing } & 58\end{array}$

$\begin{array}{ll}\text { Collaboration } & 59\end{array}$

$\begin{array}{ll}\text { Student involvement } & 61\end{array}$

$\begin{array}{ll}\text { Faculty Senate } & 62\end{array}$

$\begin{array}{ll}\text { Strategic Integration Plan } & 64\end{array}$

$\begin{array}{ll}\text { Teacher Survey } & 70\end{array}$

$\begin{array}{ll}\text { Teacher Interview } & 75\end{array}$

$\begin{array}{ll}\text { Integration plan effects on school practice } & 75\end{array}$

$\begin{array}{ll}\text { Staffing and collaboration } & 76\end{array}$

$\begin{array}{ll}\text { Training } & 76\end{array}$

$\begin{array}{ll}\text { Student and community involvement } & 77\end{array}$

$\begin{array}{ll}\text { Heterogeneous grouping } & 77\end{array}$

$\begin{array}{ll}\text { Placement decisions } & 78\end{array}$

$\begin{array}{ll}\text { Faculty Senate } & 78\end{array}$

$\begin{array}{ll}\text { Case Summary Profile } & 79\end{array}$

$\begin{array}{ll}\text { Lucas School } & 83\end{array}$ 
$\begin{array}{ll}\text { Observation } & 83\end{array}$

$\begin{array}{ll}\text { Staffing } & 84\end{array}$

$\begin{array}{lr}\text { Collaboration } & 85\end{array}$

$\begin{array}{ll}\text { Student involvement } & 87\end{array}$

$\begin{array}{ll}\text { Faculty Senate } & 88\end{array}$

$\begin{array}{ll}\text { Strategic Integration Plan } & 90\end{array}$

$\begin{array}{ll}\text { Teacher Survey } & 97\end{array}$

$\begin{array}{ll}\text { Teacher Interview } & 102\end{array}$

$\begin{array}{ll}\text { Integration plan effects on practice } & 102\end{array}$

$\begin{array}{ll}\text { Staffing and collaboration } & 103\end{array}$

$\begin{array}{ll}\text { Training } & 103\end{array}$

$\begin{array}{ll}\text { Student and community involvement } & 104\end{array}$

$\begin{array}{ll}\text { Faculty Senate } & 105\end{array}$

Faculty Senate impact on teacher morale 106

$\begin{array}{ll}\text { Resource versus consultation teacher's role } & 106\end{array}$

$\begin{array}{ll}\text { Case Summary Profile } & 107\end{array}$

Bucknell Middle School $\quad 111$

$\begin{array}{ll}\text { Observation } & 111\end{array}$

Staffing 113

$\begin{array}{ll}\text { Collaboration } & 114\end{array}$

$\begin{array}{ll}\text { Student involvement } & 115\end{array}$

$\begin{array}{ll}\text { Faculty Senate } & 117\end{array}$

$\begin{array}{ll}\text { Strategic Integration Plan } & 118\end{array}$

$\begin{array}{ll}\text { Teacher Survey } & 124\end{array}$

$\begin{array}{ll}\text { Teacher Interview } & 129\end{array}$

$\begin{array}{lr}\text { Staffing and collaboration } & 129\end{array}$

$\begin{array}{ll}\text { Training } & 131\end{array}$ 
Student and community involvement

Faculty Senate

IEP responsibilities

Special education team stigma

Case Summary Profile

Observation

Staffing

Collaboration

Student involvement

Faculty Senate

Strategic Integration Plan

Teacher Survey

Teacher Interview

Staffing and collaboration

158

Training

Student and community involvement

Faculty Senate

Heterogeneous grouping

Inclusion plan effects

Case Summary Profile

Observation

Strategic Integration Plan

Teacher Survey

Teacher Interview 
Team affiliation influences student involvement 182

Faculty Senate Decision Making 183

Integration Plans not cause for changes in special education $\quad 184$

Administrative decisions prescribe change model 185

$\begin{array}{ll}\text { Research Questions } & 185\end{array}$

Chapter V: Discussion and Recommendations 192

$\begin{array}{ll}\text { Findings } & 194\end{array}$

$\begin{array}{ll}\text { Conclusions } & 200\end{array}$

$\begin{array}{ll}\text { Limitations } & 201\end{array}$

$\begin{array}{ll}\text { Implications } & 202\end{array}$

Reference 205

Appendices

A School Demographic Protocol 222

$\begin{array}{lll}\text { B Strategic Plan Protocol } & 224\end{array}$

$\begin{array}{ll}\text { C Teacher Survey } & 230\end{array}$

C-1 Teacher Survey Factor Component 233

D Teacher Interview: School-Based Planning Team Members 237

E Teacher Interview 243

G Content Analysis Protocol 247

$\begin{array}{ll}\text { Curriculum Vitae } & 249\end{array}$ 
List of Tables

$1 \quad$ Gemrock School Special Education Class Assignment 61

2 Gemrock School Mission Component Analysis 64

3 Gemrock School Mission Content Analysis 65

4 Gemrock School Goal Analysis 66

$5 \quad$ Gemrock School Need Analysis $\quad 67$

6 Gemrock School Objective and Activity Analysis 68

$7 \quad$ Gemrock School Evaluation Analysis $\quad 69$

8 Gemrock School Theme Analysis 70

9 Gemrock School Professional Practice Factor Analysis $\quad 71$

10 Gemrock School Site Based Management School Climate Factor Analysis 72

11 Gemrock School Collaborative Teaming Factor Analysis 73

12 Gemrock School Student Involvement Factor Analysis $\quad 74$

13 Gemrock School Teacher Survey's Teacher Mean by Factor 74

14 Lucas School Special Education Delivery Model 88

15 Lucas School Mission Statement Components 91

16 Lucas School Mission Content Analysis 92

17 Lucas School Goals Analysis 93

$18 \quad$ Lucas School Objective and Activity Analysis 94

19 Lucas School Evaluation Analysis 95

20 Lucas School Theme Analysis 97

21 Lucas School Professional Practice Factor Analysis 98

22 Lucas School Site Based Management School Climate Factor Analysis 99

23 Lucas School Collaborative Teaming Factor Analysis 100

24 Lucas School Student Involvement Factor Analysis 101

25 Lucas School Teacher Survey's Teacher Mean by Factor 101

26 Bucknell Middle School Special Education Delivery Model 116 
27 Bucknell School Mission Component Analysis

28 Bucknell School Mission Statement Analysis

29 Bucknell School Goal Analysis

30 Bucknell School Objective and Activity Analysis 122

31 Bucknell School Evaluation Component Analysis 123

32 Bucknell School Theme Analysis $\quad 124$

33 Bucknell School Professional Practice Factor Analysis $\quad 125$

34 Bucknell School Site Based Management School Climate Factor Analysis 126

35 Bucknell School Collaborative Teaming Factor Analysis 127

36 Bucknell School Student Involvement Factor Analysis 128

37 Bucknell School Teacher Survey's Teacher Mean by Factor 128

38 Arnold School Special Education Class Assignment 145

$39 \quad$ Arnold School Mission Component Analysis 148

$40 \quad$ Arnold School Mission Statement Analysis 149

41 Arnold School Goal Analysis $\quad 149$

42 Arnold School Need Analysis $\quad 150$

43 Arnold School Objective and Activity Analysis 151

44 Arnold School Evaluation Component Analysis 152

45 Arnold School Theme Analysis 153

46 Arnold School Professional Practice Factor Analysis 154

47 Arnold School Site Based Management School Climate Factor Analysis $\quad 155$

48 Arnold School Collaborative Teaming Factor Analysis 156

$49 \quad$ Arnold School Student Involvement Factor Analysis 157

50 Arnold School Teacher Survey's Teacher Mean by Factor 157

51 Case Site Student and Teacher Populations 169

52 Case Site Student and Teacher Special Education Population 170

53 Case Site Special Education Delivery Model by Teacher Placement 171 
54 Case Site Student Percentage in Separate Settings 171

55 Case Site Teacher Team Membership $\quad 172$

56 Case Site Demographic Summary 173

57 Case Study Mission Content Analysis $\quad 174$

58 Case Study Goal Content Analysis $\quad 175$

59 Case Study Need Content Analysis 176

60 Case Study Objective and Activity Content Analysis 177

$\begin{array}{lll}61 & \text { Case Study Theme Analysis } & 178\end{array}$

62 Analysis of Variance Test for the Teacher Survey Factors 180

63 Case Study Teacher Survey Factors Means by Rank Order 180

64 Faculty Senate Decision Percentage by Category 184 


\section{Chapter I}

In the words of Bob Dylan, "The times, they are a-changing" and the American public schools provide an excellent place to witness the effects of the change process in action. Throughout its history American public education has enacted policy and changed practice in an effort to achieve goals of equity and excellence in schooling. The Soviets' launch of Sputnik and fierce economic competition from abroad has led to policies focused on academic excellence. Other forces as commitment to social justice and racial equality have resulted in policy intended to achieve equity. While these shifts in perspective enable schools to make progress toward important goals, one emphasis often overlooks or crowds out other concerns. As a result, achieving equity and excellence in education has become a tug of war. One goal competes with the other.

"What is needed," according to Kirst (1984) "is a policy that fights for both goals, excellence and equity, while balancing the claims of each" (p. 17). As early as 1800s, Thomas Jefferson argued that if America was to remain democratic and avoid tyranny public education had to be excellent: it had to produce thoughtful citizens. If America was to remain a free society, one in which positions of power were open to all on the basis of merit, public education also had to be equitable (Gutek, 1991). In terms of reform, to strive for excellence, without equity, runs the risk that only a segment of the student population achieves higher learning outcomes. It inadvertently limits the diversity of ideas contributed to the learning process and thereby jeopardizes the quality of the excellence achieved. On the other hand, equity, without excellence create the danger that a narrowed opportunity will result in mediocrity. Inherent to these conditions' outcomes, therefore, is the notion that equity and excellence are a necessary part of each of the achievement of the other.

Gerber (1996) suggests schools can achieve equity and excellence in one of two ways. "Either achievement variance will decrease by increases in achievement in the lower half of the distribution or mean achievement will rise without increases in variance in the higher half of the distribution" (p. 171). In essence education must provide practices that shift the entire 
performance distribution upward (see also Brown \& Saks, 1981; Gerber \& Semmel, 1985; Gerber, 1988; Bacdayan, 1994). To accomplish this, a system must be created that addresses individual variability and opportunity through practices that simultaneously strive to achieve excellence. This model thereby imagines a restructured education system in which every participant of schooling, professionals as well as students, will engage in activities that increase the performance of all students.

In West Virginia, and across the country, current efforts to merge general and special education interests through site-based management activities embody principles that detail such a model. Through state legislation, faculty at the local school level is responsible for developing a strategic plan to support inclusive practices. Specifically they are to compose plans that detail how their school manages the appropriate placement of students with special needs into the regular classroom. Framed within the broader contextual language of national policy, these plans charge teachers to envision a more dynamic view of schooling. Teachers are to strive to improve achievement of all children. By designing such a system, the plans make it necessary for teachers to rethink schooling in terms that support a child centered paradigm.

Ironically the movement to create inclusive schooling is not new. In special education a long history has attempted to achieve this goal. Yet, the primary reason why inclusion has yet to radically change education lies in the fact that education viewed inclusion as an answer to the wrong question. Rather than viewing inclusion as a catalyst to change education, the inclusion movement evolved as a separate movement disconnected from the national reform agenda's goals. Systematic decisions about inclusion thereby limited inclusion as an answer to the question of how to improve the effectiveness of what schools are already doing; not how to transform what schools do. Consequently questions about student placement remained dependent upon whether their individual needs fit within the scope of general practice. This perspective, in turn, limited choices about instructional adaptations by confining them to existing knowledge and bureaucratic tendencies of practice. As a result, inclusion did not evolve as a system wide 
effort. Rather schooling viewed it as an end in itself and maintained it as secondary to general education's concerns.

The national goal of reforming an education system so that all students can reach more challenging performance standards, however, now puts the potential of inclusion in a very different light. The question is no longer how to use inclusion to do the same thing better. Now the question is how to use inclusion to change practices to reach new goals: as a catalyst for change and as a tool in creating, implementing, managing, and communicating a new concept of teaching and learning and a system that supports it. Ultimately it provides educators with the ability to reconstruct education from the vantage point Skrtic (1991a, 1991b) refers as the dark side: from the institutional practices that have emerged to contain failures of the system. By challenging the barriers that caused special and general practices to separate and evolve into two semi-distinct fields, teachers can begin a change process that permeates the depths of education's foundation.

The vision outlined by the Individual with Disabilities Education Act (IDEA) provides the underpinnings to this endeavor. By definition, this policy mandates schools to provide students with disabilities a Free and Appropriate Education (FAPE) in the Least Restrictive Environment (LRE). Of significance, these principles and their supporting practices are not only different from, but contradict the bureaucratic practices of schooling (Skrtic, 1991a; 1991b). For example, in traditional convention of schooling:

The curriculum is delivered to groups of students by a single teacher. The content is organized sequentially so that students of the same chronological age progress through or learn the same material at the same pace. (Pugach \& Warger, 1993 p. 128)

This model characterizes schooling as being both highly structured and standardized by a finite repertoire of practices. As Skrtic observes (1995) "Students whose needs fall outside the standard practices must be forced into them, or forced out into another unit that can" (p. 759). Under IDEA, on the other hand, the student's need drives the curriculum's orientation whereby the teacher's delivery of curriculum address and accommodates individual needs. Unlike standard 
practice, this focus makes necessary for teachers to problem solve, exercise creativity and embed novelty into their instructional practices.

The charging of faculties to design strategic plans for the inclusion of students with special needs, as in West Virginia, represents a new emphasis. The attempt is to encourage and assure that teachers adopt IDEA's principles on a systemic level. Teachers are to develop plans similar to an Individual Education Plan (IEP) that are to address the entire system as well as the individual student need. The goal thereby is to create a more unified system where teachers share a common mode of practice. To achieve this, the special and general educators must confront their differences and change conventional methods of practice. As Stainback and Stainback (1996) observe, such practices may recreate education into a new system that will have three interdependent practical parts: support networking (organizational component); collaborative consultation, and teaming (procedural component); and cooperative learning (instructional component).

From an organizational perspective, inclusive practices challenge teacher's relative autonomy that is commonplace in American education to date and makes necessary for the coordination of teams and individuals that support each other (Stainback \& Stainback, 1990a, 1990b, 1990c, 1996; Villa \& Thousand, 1990). Through collaborative associations, teachers must interact together in order to effectively meet students' unique and diversified needs. These procedures thereby challenge teachers to question standardization of practice and to seek new instructional approaches. From the new knowledge that results, teachers "create a classroom learning atmosphere in which students of varying abilities and interests can achieve their potential" (Stainback \& Stainback, 1996, p. 4). In sum, inclusive practices change education's organizational and instructional mode of operation into model of schooling that not only promotes excellence, but also simultaneously assures equity.

To initiate this change process, West Virginia employs a combined top down bottom up strategy approach. Legislative mandates from above have articulated the goals while site based management activities from below implement and define these goals in relation to their school's 
individual situations. Unlike previous top down mandates, the emphasis is upon creating a new system. The intent is to encourage teachers to enter a realm of uncertainty and challenge. Sitebased management activities advance these conditions by providing a change process that aligns and reinforces itself with the tenets it is attempting to achieve. It models the process it hopes to elicit. Because the student's needs guide their decision making process, planning for inclusion encourages teachers to individually examine their practices and discern methods that contribute to school wide goal achievement. This orientation, in turn, makes necessary for an interactive, collaborative mode of operation to occur in and outside the classroom.

Of significance, the notion equity and excellence transcend all aspects of the reform process in West Virginia. First, by sharing teacher expertise, site based management provides each faculty member an equal opportunity to shape and define best practice. Second, by seeking practices that address the needs of all students, the goal assures that all teachers create an atmosphere that strives to achieve equity and excellence for their students. Together, these practices strive for excellence in a manner that gives parity to the concerns of the individual student as well as to the individual teacher. Of consequence, this parity not only introduces new practices that challenge the traditional conventions of schooling, but provides education with a comprehensive and coherent model for achieving deep structural reform.

Viewed from a wide angle lens, West Virginia's reform efforts typify how American public education is undergoing a new sort of change. Until recently, "the predominant focus of the reform movement had been on excellence, as evidenced by the virtual absence of the education of children with disabilities in the reform proposals" (Paul \& Rosselli, 1995, p. 188). Now the national reform goals have since shifted and emphasize an agenda that embraces the concerns of all children. The shift acknowledges special education as part of the national reform agenda. According to Lipsky and Gartner (1996a), "Across the United States, states have developed policies that have, to a greater and lesser degree, promoted inclusive education for students with disabilities" (p. 782). Of interest, therefore, is the extent to which the reform goals 
afford the broader context of education's concerns to embrace the principles and practices invested in IDEA.

\section{$\underline{\text { Statement of the Problem }}$}

In the past two decades numerous studies have examined the effects that inclusion has upon education. Much of research literature has focused on the attitudes and behavior of teachers (Braaten, Kauffman, Braaten, Polsgrove \& Nelson, 1988; Kauffman, Cullinan \& Epstein, 1987; Myles \& Simpson, 1992; Schumm \& Vaughn, 1991; Scruggs \& Mastropieri, 1996; Semmel, Abernathy, Butera \& Lesar, 1991), while other studies have examined the effects of inclusion on student achievement and socialization (Banerji \& Dailey, 1995; Burello \& Wright, 1993; Chase \& Pope, 1993; Christmas, 1992; Fuchs \& Fuchs, 1994; Jenkins \& Horner, 1989; Logan, Bakeman, \& Keefe, 1997; McLesky \& Waldron, 1995; Wang \& Walberg, 1988; Zigmond, Jenkins, Fuchs, Deno \& Fuchs, 1995). The context of much litany has also described and debated inclusion's advantages and disadvantages (Lieberman, 1996; Lipsky \& Gartner, 1991; SaponShevin, 1992; Stainback \& Stainback, 1996, Will, 1986). However, as Duchnowski, Townsend, Hocutt and McKinney (1995) conclude, "The database on restructuring and inclusion is relatively small" (p. 373, see also Rossman \& Salzman, 1994). Even though students who are at risk have received some attention in school reform initiatives (Murphy, 1991), students with disabilities have received little systemic examination of reform's impact on their schooling. Reform activities discussed in the effective schools literature also fails to clearly address this population (Lilly, 1987; Pugach \& Sapon-Shevin, 1987). Of consequence, we know little about how the Individual with Disabilities Education Act (IDEA) and effort to support inclusive schooling impact education when presented within the general context of school reform.

\section{Purpose of Study}

This study's purpose is to understand the relationship between the school's level of inclusive practices and the participatory characteristics of the school's site-based management. The question is whether the fundamental principles implied by West Virginia's effort to shift to site base management and charging of faculty senates to develop school models to support 
inclusive schools present a real catalyst for changing educational practice. This study, therefore, focuses on the relationship between the ends (goals and objectives of the policy of inclusion), means (systemic changes the schools made to achieve these goals and objectives), and the actual outcomes (inclusive practices and faculty participatory decision making).

\section{$\underline{\text { Research Questions }}$}

I. What systemic changes did school's faculty senates make in their restructuring efforts to foster practices for inclusion?

II. To what extent did these changes result in increased decision-making for teachers regarding the inclusion of students with disabilities?

III. What is the relationship between schools' inclusion ratios and faculty's perceived role of participatory decision making involvement?

IV. To what extent does the general and special education teacher's perceptions agree regarding their involvement in the special education delivery decision making process? 


\section{Chapter II}

\section{$\underline{\text { Review of Literature }}$}

American public education has witnessed, participated in and perpetuated reform in nearly all aspects of schooling. While efforts to change or reform education is not new and has occurred throughout American public education, the scope and momentum of recent efforts are unparalleled to prior movements (Odden \& Marsh, 1988). Since the onslaught of reform reports of the early 1980s, schools have undertaken a sustained effort to fix, restructure, and rethink America's public educational practices. Over a relatively short period of time, change strategies have swung back and forth on a top down, bottom up pendulum. These experiences consequently helped shape our knowledge of change process and opened new insights into the dynamic complexities of schooling. When viewed from a wide-angle lens, these rapid changes enable us to see streams of continuity that reflect how reform attempts to achieve equity and excellence in schooling.

The purpose of this chapter is to present the argument that current reform efforts as manifested in West Virginia, provide, unlike previous endeavors, a real catalyst for changing American public education practice. West Virginia's shift to site-based management and charging of faculty senates to develop models to support inclusive schools presents a new paradigm. By merging special and general education interests through a site-based management approach, reform creates a process to confront assumptions that are inherent to America's educational practice. This, in turn, enables schools to achieve real change that penetrates beneath the surface level. Recognizing that theory and practice may not always go hand in hand, it seems that a study of West Virginia's reform efforts and their theoretical implications provides an excellent opportunity to capture meaningful insight into the complexities reform faces when striving for deep levels of change.

To achieve this purpose, the first section, Riding the Waves of Educational Reform, reviews the characteristics of the national reform efforts during the 1980s. This review provides the reader with a simple understanding of the impact top down and bottom up change strategies 
has had upon restructuring education. After establishing this context, the section then describes the locus of current reform efforts occurring on a national level. The intention is to demonstrate how current efforts adopt and or combine change elements from the past while at the same time shift toward new concerns previously neglected.

The second section, Educational Reform: Valuing Special Education as a Change Agent, establishes a framework for recognizing how features of the Individual with Disabilities Education Act (IDEA) contained within recent reform initiatives champion significance. Because IDEA has been part of educational policy since 1975, the focus of this discussion is two-fold:

First a review of IDEA's provisions in relation to its implementations reveals how it introduced a new educational practice and philosophy and second uncovers how dynamic systems of education thwart the fundamental purpose of the Act to change the nature of schooling. Because IDEA in essence challenges education's belief structure and organizational practices, this section discusses how it provides school reform a prescription for achieving comprehensive change.

The third section, Educational Reform: Building Inclusive Schools in West Virginia, describes West Virginia's current reform efforts. It unpacks the information presented in the first two sections to examine why the movement to merge special and general education through sitebase management presents an authentic catalyst for achieving educational reform. By drawing inference from the 1980's waves of reform discussion, the first half of this section demonstrates how today's combined change approach overcomes the shortcomings top down and bottom up strategies previously experienced. It then relates how IDEA is the catalyst to this change process' achievement. The second half of this section provides a detailed description of West Virginia's strategic inclusion plan components. The purpose of this discussion is to demonstrate how these plans facilitate inclusive schooling expected effects upon school reform.

\section{$\underline{\text { Riding the Waves of Educational Reform }}$}

Educational reform of the 1980s: The first wave. The three year span from 1983 to 1986 encompasses what educators commonly refer to as the 'first wave' of school reform. According to Underwood (1989), the fundamental condition or crisis that gave life to this movement was the 
'crystallization' of the belief that the United States was technologically falling behind other industrialized countries. Numerous reports described the failure of American public schools. Most noteworthy of these was the National Commission on Excellence in Education's report, $\underline{A}$ Nation at Risk: The Imperative for Educational Reform (1983). This report had an immediate and profound impact upon school restructuring by capturing the attention of the American public about whether schools were effectively producing the work force needed to maintain America's competitive edge:

Our nation is at risk. Our once unchallenged preeminence in commerce, industry, science, and technological innovation is being overtaken by competitors throughout the world.... If an unfriendly foreign power had attempted to impose on America the mediocre educational performance that exits today, we might well have viewed it as an act of war. (National Commission on Excellence in Education, 1983, p. 5)

Soon after its publication, approximately thirty other reports called for a variety of reforms and proposals for change (Bierlein, 1993; Jordan \& McKeown, 1990). These reports include: Action for Excellence, (Education Commission of the States, 1983); Educating Americans for the 21st Century, (National Science Board Commission, 1983); and Making the Grade, (Twentieth Century Fund Task Force on Federal Educational Policy, 1983). In an early survey of these reports, the Education Commission of the States identified sixteen national reform commissions, and noted that more then 175 state task forces were simultaneously considering educational reform issues (Education Commission of the States, 1983; Guthrie \& Koppich, 1993). Furthermore, all fifty states subsequently adopted at least some of recommendations and or reform packages based on prescriptions from these commissions' reports (for data on state level initiatives between 1983 and 1985 see Education Week, February $11,1985)$.

The emphasis of these reports primarily focused upon changing external factors by prescribing 'top-down' mandates for instituting higher standards. Initiatives sought to increase excellence by: requiring more rigorous graduation and teacher certification requirements (e.g., 
National Commission on Excellence, 1983); outlining curriculum changes, particularly with relation to math and science (e.g., National Science Board Commission, 1983; Twentieth Century Fund Task Force, 1983); and calling for more rigorous student assessments (National Commission on Excellence, 1983). As Guthrie and Koppich (1993) suggest, these efforts are characteristic of 'safe' reforms because they did not require anyone to do anything differently. The change activities principally consisted of policy alterations by proposing add-ons to the existing educational structure.

From a philosophical perspective, these reform activities viewed schooling "as part of the problem and part of the solution" (Guthrie \& Kirst, 1988, p. 4). The assumption was that schools were failing American youth due to poor instruction and resources, lack of expectation, and absence of teacher and student accountability measurement. Reformers therefore, targeted factors (i.e., curriculum, assessments, and standards) that states could change or manipulate by imposing highly mechanistic mandates composed mainly of centralized controls and standards (Boyd, 1987).

The major response of the 1980s is to emphasize the supervision and control of internal processes. Present reform efforts are characterized by a tightening of the organization and an increased supervision and evaluation for both teachers and students. (Sedlak, Wheeler, Pullin, Cusick, 1986, p. 175)

Following the implementation of this change strategy, researchers began to examine local response to these state education reform efforts by conducting survey studies (see Goertz, 1986, 1988; Grossman, Kirst, Negash, \& Schmidt-Posner, 1985; Kaye, 1985). Reports attempted to ascertain the degree to which states adopted national proposals. For example, Goertz's (1986) studies reported that forty-one states increased course work requirements for graduation; twentytwo states expanded or implemented student minimum competency-testing. In short, this surveyed data by in large demonstrated that states swiftly implemented policies reflecting the components and emphasis of the national reform agenda. 
The Center for Policy Research in Education (Furhman, Clune \& Elmore, 1986) and the Policy Analysis for California Education (Odden \& Marsh, 1987) conducted extensive in-depth, field research that investigated the quality of how top down reform proposal changed educational practices. These investigations, like the survey studies, also found that top down change strategy provided a short-term acceleration of state activity and highlighted certain directions. More specifically, the Center for Policy Research in Education's (1988) longitudinal study of five states (California, Georgia, Florida, Arizona, and Pennsylvania) concluded that: policy clarity was less crucial then predicted (e.g., despite ambiguities local districts responded to the spirit of nearly all policy elements); involvement in the policy development process was less crucial then predicted (e.g., educators saw the reform programs creating opportunities for them to accomplish many of their own objectives); local response was not symbolic but was substantive (e.g., several districts had begun to revamp local curriculum and instruction programs before state education reform began); and local response was remarkably uniform, with little apparent local resistance (Odden \& Marsh, 1990, p. 170-177).

Research however also suggested that the initial reform efforts only occurred on the surface. Firestone's (1990) review of these studies concludes that, "Policy reports can contribute to modest increases on almost any of the [policy comparison's] five dimensions [breadth, cost, depth, complexity, and redistribute impact], but they do not lead to real major changes" (p. 164). For example, the amount of student testing time, and the amount of time staff spent coordinating, administrating, and interpreting the various tests, increased substantially. However, study suggests that many school personnel not only saw this as a burden, but also did not find the information useful and there was no mechanism linking the information to a process of instructional improvement (see also Corbett \& Wilson, 1990; Lutz \& Maddirala, 1988; Neill \& Medina, 1989; Wise, 1988). Other critics suggest that the integrity of top down change strategies "diminish the morale of school-site personnel, thereby crippling efforts at real improvement" (Davidson, as cited in Murphy \& Beck, 1995, p. 81; see also McNeil, 1986). 
In sum, reviews of this era's accomplishments conclude that top down mandates helps facilitate the restructuring state and local policy, but they, alone, can not assure that schools carry out such changes in the classroom. They are an oversimplified response to a complex problem. As Goodlad (1992) observes, "Top down, politically driven education reform movements are addressed primarily to restructuring: they have little to say about educating" (p. 238). Senge (1990) explains that these shortcomings in essence reflect an 'illusion of being in control': The perception that someone "up there" is in control is based on an illusion: the illusion that anyone could master the dynamics and complexity of an organization from the top. (p. 290)

The Policy Analysis for California Education (1986) study's concludes, top down mandates can "initiate and nurture these [change] processes, it cannot mandate their outcomes" (p. 3).

Educational reform of the 1980s: The second wave. In the latter part of the 1980s, 1986 to 1989 , a second wave of reform evolved as attentions turned to improving the role of the teacher. Teacher empowerment became the new slogan and triggered such initiatives as sitebased management, school choice, business partnership, along with continued emphasis on excellence (Guthrie \& Koppich, 1993; Lavely \& McCarthy, 1995). As in the first wave, the activities and reports of educational reform commissions defined to a great extent the direction reform efforts took during this period. Several of these reports included the publication of the: Carnegie Forum on Education and the Economy, A Nation Prepared: Teachers for the 21st century (1986); the Holmes Group, Tomorrow's Teachers (1986); the National Governors' Association, Time for Results (1986); the National Commission on Excellence in Educational Administration, Leaders for American Schools (1987); and the Committee for Economic Development, Investing in Our Children and Children in Need $(1985 ; 1987)$.

These reports, like their predecessors, stressed the theme of a need to improve schools in order to enhance America's economic competitiveness. However, unlike the previous reform wave, these recommendations called for a 'bottom-up' approach that focused upon improving the roles and responsibilities of teachers. Reports asserted that bureaucratic structure of schools, 
characterized by standardized, highly regulated environments, were ill-suited to enable educators to achieve desired outcomes. As a result, they called for and recommended changes in the organization and operation of American schools. These recommendations stressed three broad areas of emphasis (Murphy, 1990, p. 28): (1) the professionalism of teaching (e.g., Tomorrow's Teachers, 1986); (2) the development of decentralized school management systems (e.g., Leaders for American Schools, 1987); and (3) the promotion of higher-order thinking and problem-solving skills (e.g., A Nation Prepared: Teachers for the 21st century, 1986; Time for

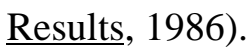

From these recommendations, schools began to substantially alter their governance structure to facilitate school improvement (David, 1991; Ingwerson, 1990; Lally, 1991; Van Meter, 1991). The adoption of site-based management models became a national trend (see, Etheridge, Horgan, Valesky, Hall \& Terrell, 1994; Struaber, Stanley, Wagenknecht, 1990). In practice, site-based management became a process of decentralization. Schools became the primary unit of management and educational improvement as a redistribution of decision-making occurred. Early as 1989, a survey by the American Governors' Association indicated that thirty states had adopted or were implementing state-level initiatives to promote such reform efforts (David, 1989a).

The philosophy guiding these efforts differed greatly from the first wave of reform. Rather then viewing elements within the system as the problem, reformers of this period saw the system itself as the problem and therefore, proposed initiates to restructure school's organizational framework. They believed that capitalizing on the energy and creativity of individuals at the local school site would cause change to happen.

While previous reports called for leadership, it was generally at the state level; now the cry is for local involvement and reforms that improve what happens in the classroom itself. (Green, 1987, p. 4)

The underpinning of this argument is the assumption that educational decisions will improve and educators will more likely implement them if they, the persons closest to the effects of the 
decision, are the ones making them. Reforms thereby restructured schools to increase teachers and the community's participation in such decision making activities as: developing educational priorities and or programs; allocating building resources; and selecting applicants for positions, all in a manner to best meet the unique needs of their school's student population (David, 1989b).

Research examining the effectiveness of site-based management as a change strategy consistently reports positive outcomes with regard to increasing teacher participation (see Taylor \& Bogotch, 1994; Taylor and Teddlie, 1992; Weiss, 1992; Wohlsetter, Smyer \& Mohrman, 1994). However, the extent to which decision making sought change did not appear to relate to their instructional practice. For example, in a study that compared 33 schools (16 pilot schools implementing site-based management programs and 17 non pilot schools from the same district), Taylor and Teddlie (1992) found that teachers in the pilot schools reported higher levels of participation in decision making, but no difference in their use of teaching strategies. They wrote, "Teachers in this study did not alter their practice . . increasing their participation in decision making did not overcome the norms of autonomy so that teachers would feel empowered to collaborate with their colleagues" (p. 10). Similarly, Taylor and Bogotch's (1994) study concludes:

The main findings that emerge from the study are that: (a) Several dimensions of decision participation exist; ... (c) Teachers' participation does not produce statistically significant effect on outcomes for teachers or students in this district; and (d) teachers in both participation groups report feeling decisionally deprived on all 19 decision items. (p. 309)

Several studies speculate as to why site based management engenders these shortcomings. Wohlsetter, Smyer \& Mohrman (1994) state that, "This study has not shown that high involvement in actively restructuring schools leads to performance outcome improvements . .. [due to] site based management's not placing enough emphasis upon achieving instructional and learning goals" (p. 284). In another study, Hallinger, Murphy and Hausman (1991) suggest that site based management does not necessarily lead to improved instructional practice because 
even though participants in their sample were highly in favor of restructuring, they "did not make connections between new governance structures and the teaching-learning process" (p. 11).

Educational reforms of the 1980s: The teachings of the past. Despite the relatively short period of time, the two distinct reform models that education experienced during the 1980s produced several insights to our knowledge about change. For example, we know from studies that the top down change model provides an effective method for disseminating reform mandates (Goertz, 1986, 1988; Grossman, Kirst, Negash, \& Schmidt-Posner, 1985; Kaye, 1985), whereas, the bottom up reform model provides an effective method for increasing teacher participation (Taylor \& Bogotch, 1994; Taylor and Teddlie, 1992; Weiss, 1992; Wohlsetter, Smyer \& Mohrman, 1994). Yet, we also learn that their ability to achieve substantive changes in pedagogy (teaching strategies) and in the way teachers worked together on instructional matters (collaboration) proves to be elusive (Hallinger, Murphy \& Hausman, 1991; Taylor \& Bogotch, 1994; Taylor and Teddlie, 1992; Wohlsetter, Smyer \& Mohrman, 1994). In short, the degree to which these reform strategies achieve systemic change is problematic and remains cursory at best.

Top down strategies are flawed because there is too much to control (Fullan, 1994). They are: too linear in that they do not acknowledge the complexity of schooling; accomplished in only providing add-ons to the existing structure without changing conventional practice; and short sighted in not recognizing the important role of the educator as being the key person who ultimately determines the fate of change. In as much the bottom up approach enables local schools to fill in these gaps, practice shows that schools do not necessarily take productive action. Stacey (1992) best summarizes this problem:

The whole point of flexible structures and dispersed power is to enable those below the top level in the management hierarchy to detect and take action to deal with a large number of changes affecting an organization that operates in a turbulent environment. This is supposed to enable the organization to learn about its environment and so adapt to that environment faster than its rivals do. However, studies have shown that widening 
participation and empowering people by no means guarantees that organizational learning will improve. (p. 175)

These shortcomings reflect that "policy and administrative structures are uncoupled from the central task of the enterprise: teaching and learning" (Elmore, 1993, p. 50). Because site based management represents an attempt to reform education by altering its governance structure, it runs the risk of becoming treated as ends in itself rather than as means to improved learning for students (Murphy, 1991). Furthermore, it assumes that people can or will initiate change in the absence of external stimuli and that the involvement or redistribution of decision-making translates into a change of power or influence (Duttweiler \& Mutchler, 1990; Malen, Ogawa \& Krantz, 1989; Tyack, 1993).

As Pascal (1990) observes, "Change flourishes in a 'sandwich': when there is consensus above, and pressure below, things happen" (p. 126). An effective reform strategy, therefore incites change by "maximizing the productive mix of top down pressure, incentives and responsiveness on the one hand, and bottom up initiatives, development, and accountability on the other hand" (Fullan, 1994). Through the combination of each, reform creates a more comprehensive and coherent model for change. The framework from above guides the central direction of change and protects the core values it intends to achieve. The decision making from below provides flexibility and encourages teacher ownership in facilitating the translation of goals into a local context.

These insights consequently influenced the reform strategies of the 1990s to move away from an either-or paradigm to embracing this combined approach. Today, efforts for reform couple the mandates from above with decentralized practices. As Peters and Waterman (1982) suggest, this enables a change model to have "simultaneous loose-tight properties" (p. 15). That is, in addition to being both centralized and decentralized, this change strategy is also distinguished by "the co-existence of firm central direction and maximum individual autonomy" (p. 318). As the following section describes in more detail, this combined approach is significant because it, unlike the reform initiative's of 1980s, maintains a congruency between its goal (the 
purposes of change) and its reform strategy (how schools implement change). By creating this new focus, current reform efforts simultaneously reinforce its change strategy with the tenets it is attempting to achieve.

Educational reform of the 1990s: The third wave. When the American school reform efforts entered the 1990s a new wave for change began to emerge. Using Murphy's (1990) metaphor from the vernacular of transportation, the first wave of reform sought to "fix the old clunker" (p. 22) whereas the second wave sought to, "get a new car" (p. 26). Murphy (1990) describes today's efforts as seeking to, "rethink the entire view of transportation" (p. 29). According to Olson (1989), the emphasis of the third wave of reform is taking new directions by replacing the uncoordinated and unconnected series of previous approaches for educating children with an integrated inter-organizational, inter-professional service model. The focus is now on rethinking how to best structure delivery of services for children rather then on the work and governance structures of adults. While concerns of earlier efforts centered on helping children, their primary activities proposed changing conditions that they believed would lead to improved situations for students: the first wave focused on the educational system by proposing add-ons to the existing structure, the second wave on teachers by reorganizing the structure to promote professionalism. The focus of third and current reform wave, on the other hand, is directly on children and creation of "child policy" (Kirst, 1987; Murphy, 1990) rather than of school or teacher policy.

Ysseldyke, Algozzine and Thurlow (1992) attribute President Bush's education summit in 1989 and subsequent release of American 2000: An Education Strategy as the initial impetus in developing this third wave of reform (see also, Danielson \& Malouf, 1994; Lipsky \& Gartner, 1996). At this summit the National Governors' Association Task Force on Education worked with the President to recommend specific national educational goals. In 1994, Congress embraced their recommendations by enacting, Goals 2000: Educate America Act (PL. 103-227) to establish a national education strategy based on six goals:

1. All children in America will start school ready to learn; 
2. The high school graduation rate will increase at least $80 \%$;

3. Students will leave grades 4,8 , and 12 having demonstrated competency in challenging subject matter in the five core subjects (English, math, science, history, and geography);

4. U.S. students will be first in the world in science and math achievement;

5. Every adult American will be literate and will have knowledge and skills to complete in a global economy; and

6. Every school in America will be free of drugs and violence and will offer a disciplined environment conducive to learning. (U.S. Department of Education, 1991, p. 61-65)

While several educational circles criticized and raised concern toward the adoption of these goals (see Kauffman \& Hallahan, 1993; Thurlow, Ysseldyke \& Greenen, 1995), the occurrence of these debates has had a significant impact upon the development of future or current policy. Disagreements forced a new kind of dialog where professionals from a variety of educational circles together began to discuss and view education in terms that included issues surrounding students who do not fit the norm. The language or reference to "all" children and "every" American used in the six goals triggered this phenomenon.

This inclusive perspective consequently introduced a new kind of emphasis that radically departs from the focus of prior initiatives. For example, in the first wave's attempt to raise standard by establishing: more required core courses; higher graduation requirements; and narrower accountability measures, as means to enhance America's economic competitiveness fostered the assumption that students can meet this challenge merely as a result of this strategy implementation. In other words, this strategy approach targeted change applicable to students in the top half of the performance continuum (Shaw et al., 1990) and thereby excluded students whose abilities do not fit within this model. America 2000 Educate America Act's use of the words all and every, on the other hand, shifts the emphasis to acknowledge that schools must address the needs of every child. 
Unlike previous top down efforts these initiatives thereby insist that schools deal with all components of the educational system. Rather than imposing add-ons, the goal is to build a restructured, interfaced coordinated service delivery system that deals more effectively with student diversity (Schrag, 1993). From a bottom up change perspective, this emphasis provides the educator's site based participation with a new focus. Because reform calls upon them to address the diversity of student need, educators must consider ideas that directly relate to their own instructional practice. This in turn reinforces and allows for the change mandated from above to occur. "When reform efforts are designed as coherent packages with mutually reinforcing parts, they will have a greater impact" (Firestone, Fuhrman \& Kirst, p. 355, 1990). Of significance, therefore, is that current reform efforts achieve a cohesion by creating a model in which each part, the reform strategy and goal, advance the other's achievement.

In sum, Danielson and Malouf (1994) explain that the basis of the initiatives embodied in Goals 2000 rests upon a "systemic approach to educational change characterized by restructuring, local autonomy, reduction in centralized control and 'red tape,' and encouragement and supports for local innovation accompanied by local accountability for results" (p. 18). The federal role in current reform activities therefore provides direction and accountability measures, while the role of state and local levels simultaneously seeks to define, plan and implement these goals in a manner that appropriately responds to their local needs and conditions. Today's reform strategy, therefore includes a combined top down, bottom up approach. Mandates send schools guiding principles that favor decentralized practices that, in turn enable schools to tailor their efforts to meet the goals espoused. Similar to the immediate and swift policy adoption found in the first wave of reform, thirty-seven states, one territory (America Samoa), and the District of Columbia has launched America 2000 initiatives (Schrag, 1993).

Educational Reform: Valuing Special Education as a Change Agent

Educational reform: The new goal. In comparison to other reform movements, the effort to achieve educational goals for all students posits a potentially far reaching level of change in education. Of significant consequence, this emphasis opened a genuine window of opportunity to 
bridge general and special education interests together. In response to clarifying the meaning of the words all and every, the National Association of State Directors of Special Education (1992) issued a position paper stating that America 2000 applies to ALL students, including those with disabilities. In 1993, the Senate Report on the Goals 2000 Legislation (Senate report 103-85 to accompany S. 1150) further articulated this by discussing how these six national goals directly apply to the needs of students with disabilities.

The committee intends that the exclusion of individuals with disabilities from any aspect of ... reform is unacceptable... [There is] an expectation that all students across a broad range of performance will be held to high standards if they are to realize their full potential. (U.S. Congress, 1993, p. 20)

Policy makers also noted a discrepancy between the intention of special education mandates and the way schools translate them into practice. "Students with disabilities ... must be an integral part of all aspects of education reform, including the application of the national education goals and objectives, the establishment of national and state content, performance, and opportunity-tolearn standards" (U.S. Congress, 1993, p. 20). As a result these legislative documents and the debates surrounding the interpretation of this national policy, caused a significant breakthrough in turning the national education reform's attention to students with disabilities.

Prior to this time Federal direction regarding the need of students with disabilities occurred primarily through anti discrimination or entitlement legislation. While these policies remain, it is significant that the Federal government now reinforces these mandates through national reform efforts. In essence, PL. 94-142, the Education for All Handicapped Children Act, now renamed Individuals with Disabilities Education Act (IDEA) introduces practices that challenge the conventional operation and organization of schooling. Although this Act has existed within public education for over twenty years, systemic levels of reform have never before embraced its philosophical and pragmatic qualities. Instead, exploration of this Act's impact upon schooling reveals how education's bureaucratic and philosophical underpinnings served as obstacles to thwart its change agent capacity from effecting education's overall 
conventional practice. That fact that current efforts now acknowledge IDEA details a vision that has distinct possibilities for achieving advanced levels of change.

Educational reform: The special education policy. Hailed as a "Bill of Rights," the Individuals with Disabilities Education Act (IDEA), outlines a process whereby schools guarantee to all children, regardless of the severity of their disability, the same educational rights and privileges accorded their peers without disability: a "free appropriate public education" (Singer \& Butler, 1987, p. 125). To accomplish this, the Act outlines rights of individuals with disabilities and their families. Turnbull and Turnbull (1978) set forth these major principals of IDEA as:

(a) Zero Reject- or the right to be included in a free appropriate, publicly supported education system;

(b) Nondiscrimination Classification- or the right to be fairly evaluated and diagnosed so that correct educational programs and placement can be achieved;

(c) Individualized Appropriate Education- so that an education can be meaningful;

(d) Least Restrictive Educational Placement- or the right to normalization;

(e) Procedural Due Process- or the right to protest; and

(f) Participatory Democracy- or the right to participate in the educational process. (p. 4)

IDEA introduced a very different approach to how schools were to respond to students and their educational need. On a fundamental level, schools could no longer deny students with disabilities the access to education. When Congress passed PL. 94-142, it did so noting that schools denied at least one million students' enrollment solely on the basis of their disability and that they did not provide at least two million others an education appropriate to their needs (U.S. Congress, 1973). Congress overturned these practices by mandating that schools provide students a Free Appropriate Public Education (FAPE) in the Least Restrictive Environment (LRE). In a decade following, schools provided over 4.37 million students with services under the provisions of PL. 94-142. (U.S. Department of Education, 1987). As Gartner and Lipsky (1987) conclude, "by and large [program implementation] has been accomplished" (p. 371). 
While the principle of FAPE opened education's doors to students with disabilities, the LRE principle presented schools with a new model and method for determining how to provide appropriate educational services. Although the statute does not use or define LRE, one derives understanding of LRE principle from statutory and regulatory language that states:

To the maximum extent appropriate, handicapped children, including children in public or private institutions or other care facilities, are educated with children who are not handicapped, and that special classes, separate schooling, or other removal of handicapped children from the regular educational environment occur only when the nature or severity of the disability is such that education in regular classes with the use of supplemental aids and services can not be achieved satisfactorily. (Section 612, [5] D) LRE implies a preference for educating students with disabilities in the general classroom setting, but this preference is secondary to implementing an appropriate education. In other words, the LRE principle favors mainstreaming, inclusion, integration, but also recognizes that at times, an individual may require a more restrictive educational setting to meet specialized needs. To accommodate these various needs the Act requires schools to provide a full continuum of educational settings. The continuum ranges in degree of restriction. Such settings, listed from least restrictive to most restrictive may include: regular classroom; special classroom; special school; home instruction; instruction in hospitals and institutions (Turnbull \& Turnbull, 1978).

Following a process described by the Act's legislation schools use the LRE principle as a guide for determining which placement option is most appropriate for meeting a student's individual need. A multi-disciplinary team first identifies student need by conducting an evaluation. This team then uses this information to develop an individualized education plan (IEP) to detail the students' present levels of performance, educational goals and short term instructional objectives. From the written plan of instruction schools determine: where the student will receive their education; how the instruction accommodates their individual need; and who is responsible for the implementing program. Once implemented, the IEP then serves as a 
source of instructional accountability. Ultimately because it specifies how a school individualizes instruction to meet the student's need, the IEP illustrates how schools achieve FAPE in the LRE.

Educational reform: The special education philosophy. From a goal strategy perspective, IDEA philosophically and pragmatically creates a contingency requiring educators to conduct an ethical deliberation of schooling (Paul \& Ward, 1996; Stainback \& Stainback, 1992; 1990). Of significance, neither IDEA nor its regulations delineate how schools are to determine LRE and FAPE (Yell, 1995). Instead the Act directs a process in which the role of professional opinion and evaluation of a student's individual need derives the outcome. As a result, it is the beliefs of those responsible for instruction that greatly influence how their schools will deliver special education services. Because schools must seek to provide placement in the regular classroom while at the same time tailoring the individual's placement and program to meet their individual needs, IDEA forces educators to examine the efficacy of their program options. In essence, placement decisions call upon educators to question the meaning of schooling by defining the extent to which general education is able to address the needs of students with disabilities (see Kauffman \& Hallahan, 1995; Lieberman, 1996).

Despite the fact that the law's contents and the types of services that schools provide have remained the same, beliefs about appropriate special education placement have changed. For example, schools in the 1950s, placed most children receiving special education instruction in special classes (Meyen, 1995). Today the special class remains a service delivery option, but far fewer schools place students there (U.S. Department of Education, 1990; 1995). As such these changes provide testimony of how special education engenders the opportunity for educators to reshape and rethink their beliefs about schooling. In both cases, placement decisions focus upon educational need, but the beliefs about placement had changed. Viewed from a wide angle lens, the meaning and implication of the FAPE and LRE, as they are played out in placement decisions provide educators an opportunity to invoke their beliefs in a manner that ultimately reorients education's philosophical underpinnings of practice. 
IEP placement decisions and special education reform have occurred separate from general education reform for the most part. Instead, the deliberation for defining LRE and FAPE has evolved within the context of two major, closely related reform movements in special education: the Regular Education Initiative (REI) followed by its successor, the Inclusion Initiative (Paul, Rosselli \& Evans, 1995). In each of these initiatives, the prevailing theme was a call to encourage greater social and academic integration of students with disabilities by placing them in the general education classrooms (Sage \& Burrello, 1994). As noted by Paul, Rosselli \& Evans (1995) however, these movements occurred at a time when most reports driving national reform emphasized the necessity of general education's commitment to excellence (see also Ysseldyke, Algozzine \& Thurlow, 1992). At the same time, criticism of general education was becoming more widespread (Keogh, 1988). Under such conditions, it is not surprising that, "There [were] no clamoring masses anxious to teach students with unique abilities and special learning needs" (Ysseldyke, Algozzine \& Thurlow, 1992, p. 127).

As education entered the 1990s, the national reform goals have shifted. According Sailor, (1991) current initiatives now reflect that "Sufficient parallels exist between the general and special education reform agendas to suggest that the time may be at hand for a shared educational agenda" (p. 8). One similarity is that the child centered principles already existing within special education policy now are becoming the focus of national reform. Current initiatives call upon educators to examine their practices in a manner that embraces all children's concerns, including those with disabilities. Specifically Goals 2000 requires that a comprehensive study verify that practices of inclusion occur within school reform activities assisted under the Act. Also, in order for states to receive funding under Goals 2000 each must develop a comprehensive improvement plan for ensuring that all students can achieve the national educational goals. In sum, "all of these reform efforts need to be inclusionary, that is, they must focus on 'breaking the mold' to deal more effectively with the needs of all students, including those with disabilities" (Schrag, 1993 p. 211). 
This shared agenda champions significant possibilities. First, IDEA provides these efforts a proven effective framework for conducting an ethical deliberation about schooling. Second, the spirit of the Act's philosophical orientation about LRE, inclusion, integration makes necessary for educators to examine their practices and procures them with the opportunity and rationale to seek change. In short, IDEA furnishes the philosophical underpinnings to advance the current, third wave of reform's child centered focus and provides a method to accomplish its achievement.

Educational Reform: The Bureaucratic Challenge.

From a change perspective, IDEA also presents reform efforts with a model of practice that is not only different from, but contradicts the traditional bureaucratic configurations of schooling (Skrtic, 1991a, 1991b, 1995). In the same vein, our understanding of a bureaucracy enables us to recognize how schooling thwarts the vision detailed in IDEA. As a result, IDEA provides a model for school restructuring while at the same time identifies the barriers that prevent this from occurring. This lends current reform an insightful vantage point. By advancing IDEA through a national effort, it forces reform to acknowledge and overcome the obstacles IDEA previously faced. However, appreciation of these action's ramifications, requires one to first have an understanding about schooling from an organizational point of view. From this perspective, one can more easily recognize how IDEA's practices are different and thereby serve to inform current reform's ability to accomplish deep structural change.

Schools have bureaucratic characteristics and therefore, are rather inflexible structures. As Mintzberg (1979) describes they are "performance structures designed to perfect programs for contingencies that can be predicted, not problem-solving ones designed to create new programs for needs that have never before been encountered" ( p. 375). Because by definition a bureaucracy is: "a governmental structure characterized by specialization of functions, adherence to fixed rules and a hierarchy of authority" (Merriam-Webster's dictionary, 1990, p 188), it is a structure designed to enable an organization to produce standard outputs by implementing and 
regulating standard processes. Through this process the bureaucracy's purpose provides a model of operation that enables the organization to function in a stable environment (Robbins, 1983).

The organizational configuration of schooling falls within a continuum of two basic types of bureaucracy: machine and professional. The former commonly refers to the characteristics defined by Max Weber's (1947) classic analysis of organization (see Hoy, \& Miskel, 1991; Mintzberg, 1979; Robbins, 1983). Weber describes a machine bureaucracy as a structure that has high complexity, high formalization, and high centralization. A pyramidal hierarchy arranges positions, creates divisions of labor, and increases authority as one moves up in the organization. Each level represents units of expertise in which the organization breaks down each person's task into simple, routine, and well-defined functions. Rules and procedures establish a standard mode of operation that enable the organization to achieve its goals.

A professional bureaucracy, on the other hand, is a structure that has high complexity, but is less formalized and more decentralized then a machine bureaucracy. This condition is a result of a fundamental difference. In professional bureaucracies the organization's work requires the employment of individuals who have highly developed knowledge and skills. Because each person's responsibilities are complex and entail extensive specialized formal training, the professional bureaucracies decentralize the structure in which they work to provide individuals the discretion and autonomy to exercise their knowledge. Thus, the hierarchy of the organization exercises less regulation over their work. Instead, regulation or standardization comes from the worker's professional identity and training. "So whereas the Machine Bureaucracy relies on authority of a hierarchical nature-the power of the office-the Professional Bureaucracy emphasizes authority of a professional nature-the power of expertise" (Mintzberg, 1979, p. 351).

As Mintzberg explains, (1979) schools are more like professional bureaucracies. Teachers acquire expertise to perform specialized tasks. In order to exercise this knowledge, teachers are "loosely coupled" within the organization (Weick, 1983). In other words, the bureaucratic nature of schooling "weakly, infrequently, slowly or with minimal interdependence" ties the professional together (Weick, 1983, p. 20). This condition provides professionals with a 
relative autonomy to allow them to perfect and to maintain control over their own work. It also enables them to spend most of their time with students rather than working with others within the organization. Together these conditions decentralize authority. Educators work closely with their students, subject only to the collective control of their colleagues (Robbins, 1983).

Teachers also acquire specialized training for the purposes of performing a defined set of skills. For example, a science teacher learns how to teach science. It is faulty however to infer that because teachers undergo a tremendous amount of training that they have the abilities to accommodate variability or difference. Rather, as Skrtic explains (1991a) this "professional practice is circumscribed; it [training] provides professionals with a finite repertoire of standard skills that are applicable only to a finite set of contingencies or presumed client needs" (p. 164). As a result, their finite set of skills limits the degree in which they can adapt to change. Mintzberg explains:

The fact is that great art and innovative problem-solving require inductive reasoning, that is, the induction of new general concepts or programs from particular experiences. That kind of thinking is divergent-it breaks away from old routines or standards rather then perfecting existing ones. And that flies in the face of everything the professional bureaucracy is designed to do. (Mintzberg, 1979, p. 375)

Of consequence these conditions cause the classroom to be structurally non adaptable because professionalism ultimately results in convergent thinking (Skrtic, 1991b, 1995).

IDEA, on the other hand, provides a model that challenges these bureaucratic characteristics and replaces it with a mode of operation that changes conventional practice. First, IDEA redirects the instructional orientation of schooling to adopt a highly individualized child centered delivery model. Theoretically, teachers define instruction based on the needs of the student rather then upon their set realm of expertise. Second, IDEA promotes teaching practices premised upon problem solving abilities. In order to create individualized instructional programs, professionals must exercise creativity, flexibility, and novelty. The IEP process encourages teachers to remedy shortcomings found within conventional practice. Third, IDEA promotes 
collaboration. Through a multidisciplinary team approach, teachers share responsibility, and opinion in their development and implementation of an Individualized Education Plan (IEP). This configuration enhances the teacher's sense of being a team member, whereas their sense of relative autonomy thwarts their giving great attention to coordinating their work with their peers. In sum, IDEA invokes practices that cause a rudiment restructuring of education's organizational and instructional system.

Educational reform: The bureaucratic barriers. Unfortunately, up to this time the professional bureaucratic nature of schooling foiled a degree to which this new and different approach could affect the general operations of schooling. This is not to say that this mandate did not have a tremendous impact upon affecting the lives and education of students with disabilities. It has not, however, completely penetrated the fundamental structures of schooling into a new way of thinking. Instead, the federal mandates to provide a free and appropriate education to students with special needs, resulted in the creation of a semi-separate, parallel educational system. This limited the degree to which schools were capable, at large, to becoming immersed into a child centered, collaborative, problem solving mode of operation.

Referred to by Mintzberg (1979) as pigeonholing, the operation of schooling protects the classroom from being adaptable by sorting the students into an existing standard program. This process characterizes the two basic tasks of schooling: (1) "to categorize the client's [student's] need in terms of a contingency, which indicates which standard program to use, a task known as diagnosis; and (2) to apply or execute programs" (p. 352). This sorting process simplifies the school's response and achieves standard outputs thereby alleviating the need to use the enormous resources that would be necessary to treat every student as unique. As a result, when confronted with new and different needs, schools address these challenges and maintain stability by creating new additional sub units within the organization. Consequently, the structure does not change: it expands and rearranges itself to accommodate needs.

Weick's (1976) observation that, "schools are in the business of building and maintaining categories" (p. 8) typifies how schools or professional bureaucracies incorporate change. More 
poignantly, Segal (as cited in Skrtic, 1991a) explains that schools do not accommodate heterogeneity. Instead, they screen it out by forcing its students' needs into one of its standard programs, or by forcing them out of the system all together. An extreme example of this occurred when school segregation provided an education to children of different race or color as a sub unit. A more common daily practice occurs when schools assign students seeking ninth grade science with the ninth grade science teacher. Assignment to a category equates with meeting need. As long as the environment remains stable, the professional bureaucracy does not encounter problems. The organization or school consequently continues to prefect the skills and the given system of pigeonholes that sorts them (Mintzberg, 1979).

From a reform perspective, the FAPE and LRE mandate contained within IDEA challenge and yet also support this practice. On one hand, IDEA mandates that the school's decision about how to provide service rests upon satisfying student need not upon the needs of the program. Therefore, instead of the student need fitting the standard program, IDEA introduces procedures where the standard program must accommodate the student's need. As a result IDEA serves as a catalyst to change the organizational paradigm of schooling. Yet, on the other hand, the mandate for schools to provide a continuum of services also enables schooling to perpetuate their pigeonholing practices. Here the disability pigeonholing protects the organization from change by providing service options that traditional practices fail to achieve.

The fate of this pigeonholing process becomes suspect, however, in light of current reform initiatives. The Senate Report on the Goals 2000 legislation (Senate Report 103-85) directs state and local reform efforts to submit improvement plans that specify their strategies for meeting the national education goals. Within these plans, efforts must include services for students with disabilities as an integral component. As such, these directives mandate that schools to examine their practices with a regard to all children. This child centered perspective thereby unites special and general education with a common emphasis and penetrates the barriers created by their semi-dual existence. From a comprehensive list of states' restructuring activities, Schrag (1993) observes that these efforts call upon educators to create inclusive, collaborative 
instructional models. Of significance, therefore, is that this merging of practice challenges the ideas, practices, and assumptions of general as well as special education. Further as Skrtic (1991a) suggests, it "asks whether public education's institutional practices are consistent with its democratic ideal" (p. 150).

Educational reform: The bureaucratic conflict. From a philosophical perspective, calling upon educators to examine inclusive practices from a systemic perspective, creates special and regular educators' concerns to merge into a new kind of dialogue. In essence, it creates a dialogue that is an ethical deliberation. It impels teachers to examine their fundamental ideas about schooling and to reflect upon how these ideas affect student placement decisions. By establishing a common understanding, current initiatives create a window of opportunity for teachers to gain insight about their assumptions used to justify this process. As Skrtic (1991a, 1991b, 1995) suggests, this questioning of the validity of their assumptions exposes the purposes of pigeonholing and how it tends to serve general education.

Skrtic (1991a) summarizes the questionable assumptions educators typically use to justify the exclusionary practices as follows:

- disabilities are pathological conditions that students have;

- differential diagnosis is objective and useful;

- special education is a rationally conceived and coordinated system of services that benefits diagnosed students; and

- progress results from rational technological improvements in diagnostic and instructional practices. (p. 152)

With regard to the first assumption, Skrtic (see also Gartner \& Lipsky, 1987; Kauffman, Gerber, \& Semmel, 1984; Keogh, 1988; Pugach \& Lilly, 1984; Stainback \& Stainback, 1984 as cited in Skrtic, 1991a) supports the notion that some of the students' disabilities are pathological.

However, he also points out that several are not:

Because of a number of definitional and measurement problems, as well as problems related to the will or capacity of teachers and schools to accommodate student diversity, 
many students identified as mildly handicapped are not truly disabled in the pathological sense, a situation that is particularly true for students identified as learning disabled. (1991a, p. 155)

Similarly, this measurement and definition problem weakens or diminishes the second assumption that differential diagnosis is objective and or useful (Council for Children with Behavioral Disorders, 1989; Gerber \& Semmel, 1984; Hallahan \& Kauffman, 1977 as cited in Skrtic, 1991a). Whether schools classify students according to a pathological perspective (e.g., in terms of the presence or absence of biological conditions) or a statistical point of view (e.g., in terms of the relative position within a normal distribution), each procedure is subjective in terms of how one defines the boundaries of normality versus abnormality (Sage \& Burrello, 1994). The utility of this process therefore becomes of suspect. It implies that the process of categorization directly identifies a specific student's individual need. Furthermore, it gives the faulty suggestion that a student's disability label or classification indicates that there are disability-specific types of instruction.

From an organizational perspective, these criticisms reflect how the assumptions used to rationalize special education practices are not truths but rather are ideas that serve the bureaucratic organization of schooling.

Student disability is an organizational pathology, a matter of not fitting the standard programs of the prevailing paradigm of a professional culture, the legitimacy of which is artificially reaffirmed by the objectification of school failure as a human pathology through the instructional practice of special education. (Skrtic, 1991a, p. 169) By serving as a semi-parallel system, special education legitimizes the "deep structural flaws in traditional school organization" (Skrtic, 1991a, p. 175). By removing students from the general program, schools avoid the need to recognize anomalies or weakness in their conventional practice. Because schooling has no way to see that something is amiss, this condition in turn reinforces the validity of this prevailing practice. 
In sum, the faulty assumptions used to rationalize the need for a dual educational system, according to Skrtic (1991a, 1991b, 1995) deconstructs special education as an institutional practice by exposing the silences, inconsistencies, contradictions, and incompleteness of special education relative to the purposes they serve (see also Lipsky \& Gartner, 1996a, 1996b; Sage \& Burrello, 1994). The purpose here, however, is not to criticize special education practices but rather to demonstrate how this analysis serves as a vantage point for pointing out how the bureaucratic structure thwarts the special education's goals from being fully envisioned.

From a reform perspective, IDEA becomes more then a policy, but an impetus that challenges the fundamental foundation of education's practices. It thereby serves to illuminate our understanding of how to restructure schooling in a manner that achieves meaningful and authentic change. By creating an inclusive perspective, the principles of IDEA describe challenge teacher's relative autonomy and standardizing of practice. By adopting practices that inherently threaten the foundation of education's professional bureaucratic characteristics, these reforms ultimately achieve a restructured model of schooling.

Current Educational Reform: Building Inclusive Schools

Current educational reform: The strategy and goals. As argued throughout this paper, "Schools are currently fighting to transform the way they think and act" (Murphy \& Beck, 1995). As Sage and Burrello (1994) observe education is currently undergoing a paradigm shift: people are experiencing a change in way they view the world and thereby are in a process of creating new ideas. These efforts or ideas have resulted in redefining the characteristics (how they view and value participants in organizations); configurations (how they structure the organization); and practices of schooling (how they define and carry out the goals to actualize the ideals envisioned, Peters, as sited in Sage and Burrello, 1994).

In the first section of this paper, we examined how the 1980's waves of reform underwent two distinct change strategies. Consequently insights about these top down and bottom up approaches' strengths and weaknesses reveal that comprehensive change achievement makes a combined approach necessary. Yet as Evans and Panacek-Howell (1995) remind us, 
Success of restructuring efforts is dependent not only upon the effectiveness of the strategies employed, but also upon other factors (people, personalities, policies, procedures, atmosphere, and so on), that often serve as barriers or facilitators to implementing change. (p. 35)

A strategy's ultimate fate thereby rests upon how well its practices affect goal attainment. Prior reform efforts were often fragmentary and lacked cohesion by attempting to change education one piece at a time (Schrag, 1993). In some cases, they were also contradictory and sent conflicting messages about these changes' purposes by not aligning curriculum with other policy areas (Odden, 1991; Cohen \& Spilline, 1993). Ultimately the problem with previous movements is that they did not challenge, disrupt or alter the basic assumptions underpinning America's educational practice. As a result, change occurred only on the surface and after time became superficial at best. Schooling fundamentally remained the same. The reform initiatives of the 1990s, on the other hand, not only provide a new change strategy approach, but they also introduce a new goal that is unlike prior efforts. It is this combination has the potential to effect considerable change.

Schrag (1993) best summarizes, the two key features that distinguish current reform from previous educational change:

First, current policies focus on student performance, with the premise that all students can and must learn at higher levels. Second, current restructuring policy is long-term commitment to fundamental, systemic change. (p. 221)

As a result today's emphasis on improving achievement for all students: (not expressly articulated or emphasized in previous movements) current reform forces special education concerns into the national reform arena. As such, inclusive practices and perspectives advance change to become a comprehensive, multifaceted, systematic process. Efforts to redistribute and decentralize decision-making across all levels of education continue as a focus of school restructuring (Goertz, Floden \& O'Day, 1996). However of difference and significance is that 
this process now engages educators in defining practices in terms of achieving an inclusive agenda.

Current educational reform: The West Virginia experience. West Virginia's shift to sitebased management and charging of faculty senates to develop models to support inclusive schools demonstrates how education is currently undertaking new efforts to restructuring education. In 1990, the West Virginia Legislature enacted the Local School Involvement Act in order to shift to site-based management in West Virginia schools. This legislation provides for shared decision making by creating faculty senates, school curriculum teams and community representation on a local school improvement council. It opened the school organization to influence by parents and the business community through their appointment or election to the local school improvement council. In short, it established what Ornstein (cited in Conley, 1993) describes as an "administrative decentralization" site-based management model that features teacher control by delegating decision making down the ranks of the professional hierarchy to building-level educators. This initiative empower the individual schools, through school improvement councils, faculty senates, and curriculum teams where teachers are the majority, to make some decisions formally made by the central administration.

Four years later, West Virginia's Legislature enacted Senate Bill 1000 (School Laws of West Virginia in West Virginia Code, $§ 18-20-3,1995)$ charging each faculty senate with the responsibility for creating a strategic plan to support inclusive schooling. Specifically, each school's faculty senate was to create a plan that identifies and provides a strategic model to manage the appropriate placement of students with special needs into the general classroom. Through this bottom up, site-based management approach, strategic plans require faculty senates to encourage the involvement of others, such as the school improvement council, parents, and community members in the planning process. Because West Virginia established faculty senates in every school throughout the state, each school has their own faculty senate. Therefore, each strategic plan describes the particular need and characteristics of an individual school.

As Sapon-Shevin (1995) reminds us: 
Comprehensive school reform entails two components. The first is a firm vision of the way school could and should be. The ability to imagine schools otherwise, not stratified by ability, not beholden to a fixed curriculum, well staffed with innovative, engaging teachers who are themselves well supported, is the first requirement. But the second essential component of wide-ranging school reform, as opposed to program innovation or school tinkering, is a shared agenda: the understanding that fixing the school for some children must mean fixing the school for all children. (p. 70)

West Virginia's strategic plans present a model to accomplish this. Each school's plan was to include: (1) a mission statement; (2) goals; (3) needs; (4) objectives; and activities to implement the strategic plan; (5) guidelines for implementation of collaborative planning and instruction; and (6) training for all regular classroom teachers who serve students with exceptional needs in integrated classrooms (West Virginia Code, $§ 18-20-3,1995$ ). Of significance each of these elements is an interdependent part: together they function to create a successful, dynamic learning environment intended for all students.

Current educational reform: The strategic plan. To aide faculty senate's development of their plans, West Virginia Department of Education issued A Strategic Planning guide for West Virginia's Faculty Senates (1994). The Mission Statement provides the following:

Mission Statement: The school's mission statement should be developed or at least reviewed and revised, if necessary, by the whole faculty senate and other stakeholders, i.e., other persons involved in or affected by the strategic plan activities, such as the school improvement council and parents of students with disabilities. The mission statement is based upon the vision and beliefs of the stakeholders and tells what the school does, for whom it is done, and how it is done. (p. MG-2)

According to Schaffner and Buswell (1996), establishing a mission statement, based upon democratic, egalitarian principles of inclusion, belonging, and provision of quality education to all students, is the first and primary step for creating a quality inclusive school. Its purpose helps schools to define their goals in terms that address the needs of all students. Because faculty 
senates create these mission statements they provide teachers and community members with the opportunity to communicate and to gain a better understanding of the rationale for and the methods of, developing and maintaining an inclusive environment. Furthermore, a standard with which schools can evaluate educational practices is established (Schattman, 1992).

In addition to a mission statement, each strategic plan specifies goals to support the achievement of individual school's mission.

Goals: A needs assessment must be completed prior to developing goals. After the needs assessment is completed, the faculty senate and other stakeholders must prioritize the identified needs. The needs ranked as high priorities define the areas in which goals should be developed. . . . Goals are long-range and should be written for a three to five year period of time. (West Virginia Department of Education, 1994, p. MG-2)

The foci of these goals embrace all components of the educational process. These may include statements in regard to: obtaining technical assistants; establishing positive partnerships; providing training; and developing an accountability system (West Virginia Department of Education, 1994, p. B-2). The National Association of State Boards of Education (1992) recommends that the goals driving the education that schools provide to be "germane and relevant for each student, encompassing at the least three spheres of development: (1) the academic ... (2) the social and emotional ... and (3) personal and collective responsibility and citizenship.... (p. 12).

In order for schools to identify goals that are specific to their needs, the strategic plan process requires each faculty senate to conduct a needs assessment. To facilitate this process, the West Virginia Department of Education (1994) provides schools with a variety of sample instruments they may use to gain a better understanding of their needs. They recommend that this process include an assessment of both internal and external environmental factors. The internal organizational analysis examines the "human and organizational strengths and weaknesses of the school that will contribute to or restrict the realization of the mission statement" whereas the external analysis identifies the barriers and opportunities that may affect the ability of the school 
to achieve their mission (West Virginia Department of Education, 1994, p. C-2). This process therefore, is comprehensive and multifaceted.

After identifying the goals and needs, the legislation requires faculty senates to write objectives and activities to implement the plans relating to each goal. The objectives, by definition, are to be concise, observable and measurable statements of what the staff expects to achieve and serve the purpose of providing the intermediate steps necessary for accomplishing this. The activities, on the other hand, state what the school will do, specify the persons responsible for these actions and determine timelines for completion. Together, the objectives and activities of the plan must address, at least, the areas of staffing, collaboration, and staff development (West Virginia Department of Education, 1994). Each area of concern centers upon the methods of adaptation or supports necessary for student success in the classroom. Thus, the strategic plan specifically identifies practices the teachers must develop and implement to foster inclusive classrooms. The student's needs identified on the IEP, thereby drive and determine this initiative.

The faculty senates' plans also include an evaluation plan. As the other components described above, the evaluation is a comprehensive, multifaceted process. As Schaffner and Buswell (1994) observe, "Even support teams committed to including students can fail if they do not establish proactive processes to ensure efficient, effective and on going planning and monitoring for the students" (p. 55). The evaluation component provides a vital link to informing faculty senates about their efforts and the needs still remaining. While there is no specific format, the legislation requires faculty senates to include evaluation strategies that determine if and the extent to which the school meet their plan's objectives. Essentially these evaluations describe the "work in process to implement the strategic plan" (School Laws of West Virginia § 18-20-3, 1995 ) to thereby recognize and support the quality of systemic change as a long term and multistep process.

The last three components of the strategic plan address staffing, collaboration, and training concerns. With regard to staffing, the faculty senate must develop objectives and 
activities related to the correct implementation of the special education process, particularly the development and implementation of the IEP. Because the goal of inclusive schooling is to provide students an appropriate education in the least restrictive environment or classroom setting, the plans must include guidelines for the implementation of collaborative planning and instruction. According to the West Virginia Department of Education (1994),

These "guidelines" can take the form of objectives and activities that address the scheduling of common collaborative planning and instructional team for teacher to and other staff, establishing and maintaining effective communication among staff members, and the process for selecting and implementing collaborative models or approaches. (p. MG-4)

Finally, the training component identifies and provides teachers with opportunities to advance their skills and knowledge necessary for appropriately serving students with special needs in integrated classrooms. Such topics may include, collaborative planning strategies; delivery of instructional support serves; integrative curriculum development; family and school collaboration; and transitional planning (Fox \& Williams, 1991 as cited in West Virginia Department of Education's A Strategic Planning guide for West Virginia's Faculty Senates, 1994).Through staff developments the schools are to provide this training for all members of the staff including both regular and special educators.

In short, process for developing these strategic plans recognizes education as a complex system of several, interlocking pieces. Each component is interdependent with the others. They also address the needs of entire educational system so as to avoid becoming an "add-on" to the existing structure. The fact that faculty senates including all members of the school's administrative and teaching staff, causes these plans' decision-making process to involve and provide opportunities to address their concerns. This collaborative effort thereby enables each member to have a voice and ownership in determining the school's procedures and practices. As a result, these proposed changes penetrate the surface of schooling to effect the realities of what is occurring in each individual classroom. 
Current education reform: The implications. Because this is the first time a national reform effort has included emphasis or recognition to individuals with disabilities (Lavely \& McCarthy, 1995), exciting possibilities for achieving a new level of reform to arise. As such, West Virginia's combined top down and bottom up approach to restructure schooling to meet the needs of all students, including those with disabilities, provides an excellent vehicle to examine this undertaking. In the words of Goodlad and Lovitt (1983), "Although the mission enculturating all is at the core a moral one, it is now defined in part by legal terms" (p. v). Our responsibility therefore is to advance our knowledge about reform efforts in order to learn more about how to best ensure schools have a method to envision and practice the spirit of these charges.

In sum, the purpose of this literature review was to highlight how current reform's combined components champion a significance. By examining these key features, new ideas about the possibilities of change emerge. Below summarizes the factors and propositions contained therein:

$\underline{\text { Factors }}$

\section{$\underline{\text { Reform strategy. }}$}

- A top down change strategy provides an effective method for disseminating reform mandates (Goertz, 1986, 1988; Grossman, Kirst, Negash, \& SchmidtPosner, 1985; Kaye, 1985).

- A top down change strategy, alone can not assure that schools carry out such changes in the classroom (Firestone, 1990; Fullan, 1994; Goodlad, 1992; Policy Analysis for California Education, 1986).

- A bottom up change strategy provides an effective method for increasing teacher participation (Taylor \& Bogotch, 1994; Taylor and Teddlie, 1992; Wohlsetter, Smyer \& Mohrman, 1994; Weiss, 1992). 
- A bottom up change strategy alone does not lead to changes in classroom practice (Elmore, 1993; Hallinger, Murphy \& Hausman, 1991; Taylor \& Bogotch, 1994; Taylor and Teddlie, 1992; Wohlsetter, Smyer \& Mohrman, 1994).

Special Education as a change agent.

- From a philosophical vantage point, IDEA's principles and practice for providing a FAPE in a LRE create a contingency requiring educators to conduct an ethical deliberation of schooling (Kauffman \& Hallahan, 1995; Lieberman, 1996; Paul \& Ward, 1996; Stainback \& Stainback, 1990; 1992).

- From a pragmatic vantage point, IDEA's principles and practice for providing an IEP in a LRE create a contingency requiring educators to redefine the school's model of a professional bureaucracy (Skrtic, 1991a, 1991b, 1995).

\section{$\underline{\text { Propositions }}$}

$\underline{\text { Reform's inclusive agenda }}$

- Combined top down, bottom up strategies create a more comprehensive and coherent model for change (Firestone, Fuhrman \& Kirst, 1990; Fullan, 1994; Peters \& Waterman, 1982).

\section{$\underline{\text { Rationale }}$}

- Mandates from above guide the central direction of change and protect the core value it intends to achieve. Decision-making from below provides flexibility and encourages teach ownership to facilitate goal implementation (Fullan, 1994;

Peters \& Waterman, 1982).

- Today's student centered initiatives coupled with decentralized decision making create a comprehensive, multifaceted, systematic change process (Goertz, Floden and O'Day, 1996; Lavely \& McCarthy, 1995; Schrag, 1993).

$\underline{\text { Rationale }}$

- By adopting school wide student centered practices, teachers break their relative autonomy and make necessary for the coordination of teams and individuals to 
support each other (Duchnowski, Townsend, Hocutt, \& McKinney, 1995;

Stainback \& Stainback, 1990a, 1990b, 1990c, 1996; Villa \& Thousand, 1990).

- Student centeredness challenges teachers to question their standardization of practice and to seek new instructional approaches that create a classroom learning atmosphere in which students of varying abilities and interests can achieve their potential (Stainback \& Stainback, 1996).

From these pattern of ideas from above, it is logical to propose that the degree to which faculty senate members engage in developing strategic plans for inclusion correlates with the extent to which their practices reflect a change. Stated differently, schools with a higher perceived participatory role in decision making achieve a different level of inclusive practices then that of schools with a lower perceived participatory role in decision making. In order to examine this relationship, the following chapter describes a method of study intended for these purposes. 


\section{Chapter III}

\section{$\underline{\text { Methods }}$}

The purpose of this research was to conduct four case studies to understand the relationship between the school's level of inclusion and the participatory characteristics of the school faculty senate's site based management. The question was whether the fundamental principles implied by West Virginia's effort to shift to site based management and charging of faculty senates to develop school models to support inclusive schools presented a real catalyst for changing educational practice. This study, therefore, focused on the relationship between ends (goals and objectives of the policy of inclusion or integration), means (systemic changes the schools made to achieve these goals and objectives), and the actual outcomes (inclusive practices and faculty participatory decision making).

The following questions guided this study:

I. What systemic changes did school's faculty senates make in their restructuring efforts to foster practices for inclusion?

II. To what extent did these changes result in increased decision-making for teachers regarding the inclusion of students with disabilities?

III. What was the relationship between schools' inclusion ratios and faculty's perceived role of participatory decision making involvement?

IV. To what extent did the general and special education teacher's perceptions agree regarding their involvement in the special education delivery decision making process?

This study used quantitative and qualitative data collection methods. It organized these features by using a case study strategy. A case study, according to Yin (1984), is an empirical inquiry that:

(a) Investigates a contemporary phenomenon within its real-life context; when

(b) the boundaries between phenomenon and context are not clearly evident; and in which

(c) multiple sources of evidence are used. (p. 23) 
It is an approach that provides an understanding of a social phenomenon "by analyzing the many contexts of the participants and by narrating participants' meaning for these situations and events" (Schumacher \& McMillan, p. 373). In short, it is a strategy that Duchnowski, Townsend, Hocutt, and McKinney (1995) recommends when one wishes to study a contemporary phenomenon when the researcher either can not or should not manipulate relevant variables.

Because this research intended to examine a theoretical proposition, it used a multiple case study design. Each school was a subject of an individual case study and each case study served a specific purpose within the overall scope of inquiry. The rationale underlying the use of multiple case studies, therefore, followed a cross-experiment rather than a within-experiment logic of design. Each case served as a unit to predict similar results (a literal replication) or to produce contrary results but for predictable reasons (a theoretical replication, Yin, 1984). In this study, each school served the purpose of testing the proposition that a combined top down (strategic plan mandate), bottom up (site based management) change strategy, coupled with a student centered goal (inclusive schooling), resulted in school restructuring. In other words, this research described whether the relationship between site based management and the development of inclusive practices served as an impetus of meaningful, comprehensive change.

Each case study analysis involved three levels: the school, the teachers; and the students. At the school level the documentary examination, observation, and composite survey scores were used to describe the school climate by detailing the decision making processes and inclusive practice from a systemic point of view. At the teacher level the survey scores, interviews, and classroom observation were used to examine how the strategic planning process and emphasis upon inclusion translated into classroom practice. At the student level, classroom observation examined how site based management's plans for inclusion impacted student outcomes.

\section{$\underline{\text { Subjects }}$}

This study conducted a census selection process to identify four case study sites. This initial sampling pool included all West Virginian schools containing grades' six, seven, and eight. This selection thereby sought to select schools that have already identified the majority of 
students eligible for special education services, given a majority of students served in special education are identified by this time in their school career (U.S. Department of Education, 1995) and excluded high schools where drop out and vocational programs decrease the number of students who actually receive special education services. Because this sample included all middle schools in the state of West Virginia, it included the distribution of the state's geographic and demographic diversity (large and small, urban and rural).

To best inform this selection process, the researcher contacted the West Virginia Department of Education in request of suggested list of schools that would best serve the study's purpose. The West Virginia Special Education Office Coordinator of Research and Data provided a list of schools determined as having a high level of integration. The researcher compared this list to all fifty-five West Virginia counties' by rank order percentage of students receiving special education (West Virginia Department of Education, 1997). The percentage ranged from $22.17 \%$ to $13.81 \%$ with $17.94 \%$ as the median. The study selected two schools from the recommended list and additional two schools from the report that matched the other to site's rank order by percentile. In sum, two selected schools by rank order have a high percentage of students receiving special education $(22.17 \%, 20.20 \%)$ and two have a low percentage $(15.97 \%$ and $14.26 \%$ ).

Each selected school served as a case study site and was treated throughout the study as a unit of analysis. Within each school, the researcher randomly selected teachers for interviews. This selection sought to identify two key stakeholders of the school's strategic inclusion planning committee and four additional teachers (two special and two regular educators). Further, seven students with disabilities were randomly selected at each case site for classroom observation.

\section{$\underline{\text { Instrumentation }}$}

This study employed both quantitative and qualitative methods that included: observation, artifact examination, teacher survey, and teacher interview. Specifically, data was gathered to examine: the systemic changes each school made for the purposes of fostering inclusion; how they made these changes; and perceived reasons for these changes. The intent 
was to probe deeply into systemic changes that, based upon the theory, a school will demonstrate (e.g., changes in faculty roles). The study's theoretical propositions, therefore, determined instrumentation and data collection strategies and, in turn, served as a conceptual framework for developing each instrument's purpose and design.

Artifacts. Artifact collection is a non interactive strategy for obtaining ethnographic data with little or no reciprocity between the researcher and the participant (Schumacher \& McMillan, 1993). According to Putt and Springer (1989) it serves as a basis for research findings. Citing directly from documents counteracts analyst bias and in turn strengthens the credibility of the study's results. It is an effective strategy for gaining insight into an organization's belief structure and behaviors by unobtrusively examining the information they generated for their own purposes.

This study obtained and analyzed each school's strategic plan for managing the inclusion of students with special needs into the general classroom setting. These plans provided a framework of reference for examining how schools promote and support inclusive practices. For example, the plans included objectives that state school's expected achievements and activities to meet these expectations. By examining these statements, the analysis was able to "interpret the ideological implications of the perspectives by making their value-laden assumptions clear" (Putt \& Springer, 1989, p. 43). To facilitate this, the process analyzed the plan's six components in relation to the requirements and suggestions described in the A Strategic Planning Guide for West Virginia Faculty Senates (1994). A protocol (Appendix B) based upon the guidelines this manual was used.

Survey. The purpose of the survey was to determine the relationship between how the participants perceived their role as a faculty senate member and the degree to which their school integrated students with disabilities in the regular classroom. Of benefit the survey served as a strategy to describe the frequency of traits held, explore relationships between different factors and delineate the reasons for particular practices (Schumacher \& McMillan, 1993). Because the survey was self-administered, it eliminated the possibility of interviewer bias. For example, it 
eliminated how an interviewer's direct physical (i.e., body language, demeanor) and verbal (i.e., tone, voice) contact can influence the participants' response.

The survey targeted the study's topic of interest: the relationship between mandated site based management activities (reform strategy) and inclusive practices (reform goal).

Specifically, the interest was in the degree to which this site-based approach coupled with a student centered focus influenced teachers' perceived roles and responsibilities. The survey's questions thereby examined these phenomena by asking questions about the teacher's perceived role of empowerment and use of inclusive practices (Appendix C).

The survey adopted the sub scale questions from the administrative school structure portion of The School Climate Educator Survey (Butera, Dempsey, Dennis, Steele, \& WebbDempsey, 1996). These items examined the teacher's perceived role of empowerment.

Items in this scale refer to the ways in which administrative decisions are made about how school activities are conducted. These administrative decisions include the extent to which teachers at the school site report that they engage in collaborative planning with other faculty members. Items reference how decisions are made about student behavior and achievement, progress reports, instructional scheduling and grouping. Teachers' attitudes about their participation in decisions about hiring, school budgets, faculty meeting agendas, and faculty evaluation are key components of this scale. Issues related to how the school faculty responds to the challenges represented by new state or federal mandates and the relationship between teachers and the principal at the school is addressed by several items on this scale. (Butera, Dempsey, \& Dennis, Steele \& WebbDempsey, 1996, p. 8)

Of strength, this instrument not only asked questions that pertained to this study's interests, it also provided this portion of the survey with established reliability and validity properties. The reliability coefficient for the Administrative School Structure scale alpha was .85. The instrument's overall reliability had an internal consistency alpha of .94. 
Questions from the Effective Practice Checklist: Building Level provided in A Strategic Planning Guide for West Virginia Faculty Senates (1994) was used to develop the survey's teacher use of inclusive practice component. By developing these questions from this resource, the survey maintained and reflected the goals and objectives of inclusive practices as defined by West Virginia Department of Education. Thus it preserved the integrity of West Virginia's Integration Initiative by examining those properties they deemed as a necessary part of this reform effort. Specifically, this survey's component contained questions about: the school mission, and philosophy, IEP development, collaborative teamwork, professional practices, student activities, and student peer interaction.

The survey in its entirety was piloted in two West Virginia schools. This instrument contained fifty question statements and was administered to sixty-eight middle school teachers. Using a Likert scale the participants responded by selecting a score that best reflects their beliefs and opinions about the statement. The response scale was as follows: one (never), two (rarely), three (sometimes), four (usually), and five (always). At the end, the survey provided five additional questions that briefly asked the respondent to provide information about their educational background and teaching responsibilities.

The pilot survey responses were factor analyzed to reduce the data. The analysis also examined each item individually and in relation to the entire survey to establish reliability, validity, and to shorten as necessary. The factor analysis and reliability procedures eliminated twenty-five questions. A component factor analysis of the remaining thirty questions created four scales. Each referenced what the study's purpose considered as four important components of reform related to site based management activities (reform strategy) and inclusive practices (reform goal).

The first scale, Professional Practice, includes eight items. The reliability alpha was .8514. Items in this scale reflected to the professional practices that support an inclusive schooling environment. Several items referenced the teachers' philosophical beliefs and attitudes toward teaching all children, including children with disabilities. Items referred to the teacher's 
perception about their school's mission and how the mission related to their own belief structure. Other items concerned the extent to which teachers adapt instructional strategies and materials to support student individual need. A high score on this scale reflects higher levels of teacher's professional practices as in congruency with West Virginia's school inclusion mission.

The second scale, School Site Based Management Climate, contained eight items and had a reliability alpha of .9155 . This scale comprised of items that referred to the way schools make administrative policy decisions. These administrative decisions included issues related to developing school budgets, designing student progress reports, and assigning teacher duties outside the classroom. They referenced the extent to which administrative decisions reflect the school's mission and the degree to which the decision making process involved teacher participation. Items also reflected how policy translates into creating a positive, supportive school climate. For example, items referred to how support services provide aide to students having difficulty and to how teachers ensure all activities involve the interaction of all students. Items also measured teacher's perception about how their school administrator provides support and how their school responded to the challenges represented by new state or federal mandates. A high score on this scale reflects a school climate where administrative decisions positively support West Virginia's school site based management mission.

The third scale, Collaborative Teaming, consisted of six items. It had a reliability alpha of 9017. This scale referenced teacher engagement in collaborative teaming in relation to achieving a common goal to support inclusive practices for students with disabilities. Items reflected teacher working relationships and referenced the extent the teachers share team ownership in planning and delivering specially designed instruction. The items also measured how collaborative planning activities related to teacher's own implementation of individualized instructional practices. A high score on this scale suggests that teachers perceive participating in a higher level of shared decision making practices to address student individual need.

The final scale, Student Involvement, contained seven items. The reliability alpha was .8387. Items in this scale referred to activities designed to facilitate positive student peer 
interactions. These items related to the extent teachers perceived school activities to involve students with disabilities. Items referenced student involvement in school programs including extra curricular activities, academic, and non academic classes. This scale also measured issues related to student behavior management and student personal management of self-advocacy. Items referred Individual Education Plan (IEP) goals and objectives in concern to student interactions and activity participation. A high score on this scale reflects teacher perceiving student with disabilities as having a high level of involvement in school activities and interaction among their peers.

Observation. The purpose of the observation and school visitation was to present the researcher with an opportunity to personally interpret events as they occur. Murphy (1980) states, "If you want to know what actually is occurring, there is not other better way to find out than to observe it yourself, rather than rely on the potentially unreliable reports of others" (p. 113). Observations through school visitation therefore provided the researcher a method to verify reported activities. For example, if a school's strategic plan for supporting inclusive practices placed an importance upon providing teachers the opportunity to discuss instructional concerns in their faculty senate meetings, the observer assessed this assertion by attending these meetings.

Observations also served to enrich the researcher's understanding of the climate and context of the setting being studied. As Putt and Springer (1989) suggest, observations enable researchers to "gain a flavor of events often important in structuring analysis" (p. 160). Using the example from above, observation allows the researcher to see how the faculty conducts their discussions (i.e., who led them, how did others participate, etc.) to, in turn draw further inference about the meanings of their plan's statements.

This study conducted a multiple of observations on a multiple of occasions to address each level of interest. At the school level, the investigator attended at least two faculty senate meetings at each site. Field notes from these meetings provided detailed descriptions and characterized the substance and nature of the interaction. Additional observations (two per site) were also included to describe events that occurred periodically throughout the school day when 
students were present. School site visits included friendly "hanging out" in the lounge, playground, and entry ways.

At the teacher level, field notes were used to record conversations and informal discussions between teachers and researcher. Classroom observational field notes detailed teacher's inclusive practices. At the student level, classroom observational field notes were used to describe how students with disabilities were faring in school practice.

Interviews. Interviews were in-person conversations from which the researcher "elicits information or expressions of opinions or beliefs from another person" (Putt \& Springer, 1989, p. 142). The purpose of the interview, therefore, was to provide a vehicle that enables the researcher to deeply probe into and further explore a respondent's explanation for events. Unlike the teacher survey, this method was more open-ended. For example, when asking questions about decisions or actions the respondent participated in, the interviewer could choose to then ask them to explain why they made them or to tell how they felt about it. The point is, is that an interview created a dialog in which the interviewer could pursue meaning about an issue in greater and richer detail.

The interviews sought committee members that oversaw the development of plans for managing the inclusion of students with disabilities into the general classroom as well as four other faculty members who are not members at each school. Specifically, it was of interest to gain detailed information about: how they conducted this plan's process; why their plans contained its contents; and what obstacles they confronted as they carried out these procedures and decisions. Furthermore, it was of interest to know their opinions about each of these topics. For example, when a respondent described why the plan includes certain objectives, the interview pursued questions about the influences that helped determine their selection, whether everyone agreed, as well as their thoughts about their outcomes.

This study devised two protocols for conducting these semi structured interviews. The first protocol (Appendix D) guided interviews that were conducted with each school's inclusion plan committee members. The questions related to three areas of interest: their involvement with 
strategy plan process, opinion and knowledge about strategic plan's components and evaluation of the plan's impact upon practice. The second protocol guided interviews conducted with four other faculty members at each site who did not serve on the planning committee (Appendix E). This protocol contained only questions that related to the participant's evaluation of the plan's impact upon practice. Each protocol was piloted by conducting several practice interviews and modified as necessary (Spradley, 1979). During the interview, responses were audio taped and recorded using the note taking procedures described by Dillman (1978) and Spradley (1979).

\section{Procedures}

Below lists the research questions followed by the instruments that were used to seek this information:

I. What systemic changes did school's faculty senates make in their restructuring efforts to foster practices for inclusion? (Instruments: Strategic Plan Protocol, Observation Protocol; Teacher Survey, School-Based Planning Team Members Interview, and Teacher Interview)

II. To what extent did these changes result in increased decision-making for teachers regarding the inclusion of students with disabilities? (Instruments: Teacher Survey; School-Based Planning Team Members Interview, and Teacher Interview)

III. What was the relationship between schools' inclusion ratios and faculty's perceived role of participatory decision making involvement? (Instruments: Observation Protocol; Teacher Survey; School-Based Planning Team Members Interview, and Teacher Interview)

IV. To what extent did the general and special education teacher's perceptions agree regarding their involvement in the special education delivery decision making process? (Instruments: Teacher Survey; School-Based Planning Team Members Interview, and Teacher Interview)

This research was conducted by completing a series of steps. The following outline lists: this sequence of events; their purpose; and the instruments used to achieve this study's goal:

Step One: Identify four case study sites

(a) Contact West Virginia State Department of Education to request a suggested list of schools they identify as having high and low levels of inclusion. 
(b) Compare suggested list to all West Virginia school systems by rank order percentage of student receiving special education.

(c) Identify two schools with a high inclusion ratio and two schools with a low inclusion ratio from suggested list and select those schools in relation to having a high and low rank order percentage of student receiving special education.

Step Two: Establish characteristic about the four case study sites.

(a) Complete Strategic Plan Protocol from each case study.

(b) Visit and Observe using filed note procedures (school environment).

Step Three: Examine teachers' perceptions by using a school-wide point of view.

(a) Disseminate Teacher Survey.

(b) Visit and Observe using filed note procedures (Faculty Senate Meeting).

Step Four: Examine teacher's perceptions from an individual's point of view.

(a) Conduct the Teacher Interviews:

1. School-Based Planning Team Members Interview.

2. Teacher Interview (non planning team members).

(b) Visit and Observe using filed note procedures (classroom environment).

\section{Data Analysis and Presentation}

Using a cross-experiment design, the data analysis procedures involved organizing the collected data into four case study site profiles. Each individual case thereby consisted of a "whole" study. Using a pattern matching process, the theoretical proposition was used to seek convergent evidence regarding the facts and conclusions for the case. Each case's conclusions were then examined in relation to the other individual cases (Campbell, 1969; Yin, 1984). Ultimately, the case study comparison determined whether their outcome patterns coincided or contradicted with emerging theoretical predictions.

As a result of the different data collection strategies used within each case study, there were lesser units of analysis embedded within the case itself (Yin, 1984). Therefore, in order to develop a case study profile, appropriate analysis of the embedded units was first analyzed 
within in each case. School, teacher and student levels of interest described below were used to organize this process.

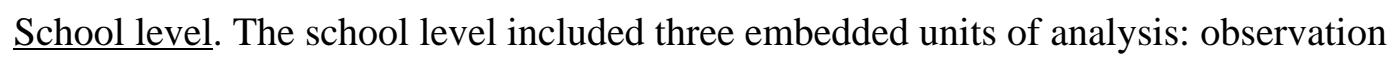
(faculty senate meetings and school site field notes), school composite survey scores, and document examination (strategic inclusion plans and artifacts). Documents and field notes collected during on-site visits were analyzed in accordance with established principles of qualitative research analysis (McMillan \& Schumacher, 1993: Spradley, 1979). A Content Analysis protocol (Appendix F) as described by Putt and Springer (1989) guided the strategic inclusion plan content data analysis. School survey composite scores were calculated after the principle component analysis of the survey was determined.

Teacher level. This level included three embedded units of analysis: observation (classroom field notes), teacher interview, and individual teacher survey scores. The data regarding classroom observations was reduced by sorting each data source into categories (Glaser \& Strauss, 1967). These descriptions were cross referenced with each other.

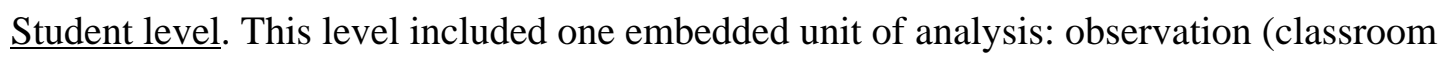
field notes). At the teacher level the data regarding classroom observations was reduced by sorting each data source into categories (Glaser \& Strauss, 1967). These descriptions were cross referenced with each other.

Case Study Profiles and Cross Case Analysis

The embedded analysis units were each treated as one of the several factors used in the pattern-matching analysis within each site. The researcher read the entire data set to identify themes informed by the theoretical proposition (Dillman, 1978; Lincoln \& Guba, 1985; Schumacher \& McMillan, 1993; Spradley, 1979). These themes (e.g., perceived decision making role) were then used to sort and organize data across embedded analysis units and to develop a case study profile. Each profile was examined to determine if a predicted pattern was produced. That is, whether the degree to which faculty senates engaged in developing strategic inclusion plans correlated with the extent to which their practices reflected a change. The four case studies 
were then compared to determine whether schools with higher perceived participatory role in decision making achieved a different level of inclusive practices then that of schools with lower perceived participatory role in decision making. Since the study involved an emerging design, the researcher examined the quality and nature of the data on an ongoing basis so as to determine effective data analysis strategies as necessary. 


\section{Chapter IV}

\section{Data Analysis and Results}

This chapter presents the study's findings. The purpose of this study was to conduct four case studies to understand the relationship between the school's level of inclusive practices and the participatory characteristics of the school's site-based management. The question was whether the fundamental principles implied by the West Virginia's effort to shift to site-based management and charging of faculty senates to develop school models to support inclusive schools presented a real catalyst for changing educational practice. From a theoretical point of view, this study established the proposition that schools with a higher perceived participatory role in decision making will achieve a different level of inclusive practices then that of schools with a lower perceived participatory role in decision making.

This chapter's format reflects the procedural design and methods used in a multiple case study. The first section presents four individual case study reports. Each case study includes an individual analysis and cross-analysis of four different data collection strategies. The four individual units of analysis are reported in order of: observation, artifact examination, teacher survey, and teacher interview. The second section presents a cross analysis of the four case studies. Ultimately, this analysis reports whether each case study served as a unit to predict similar results (literal replication) or to produce contrary results for predictable reasons (a theoretical replication). Below is a list of the research questions used to guide this process:

I. What systemic changes did school's faculty senates make in their restructuring efforts to foster practices for inclusion?

II. To what extent did these changes result in increased decision-making for teachers regarding the inclusion of students with disabilities?

III. What was the relationship between schools' inclusion ratios and faculty's perceived role of participatory decision making involvement?

IV. To what extent did the general and special education teacher's perceptions agree regarding their involvement in the special education delivery decision making process? 


\section{Gemrock School}

Gemrock School is the largest school in a county of eleven schools and serves as a primary and middle school setting with the grades Kindergarten through eighth. With a student enrollment of 1,273 , the school represents one-fourth of the county's total school population of 4,862 students (West Virginia Department of Education, 1997). In percentage of students receiving special education, this school's county ranks seventh out of West Virginia's 55 counties. This ranking places the county in the top quartile that represents the highest percentage of students with disabilities. For this reason, this study sought Gemrock School's participation.

During September through November fourteen different on-site visits were conducted. The researcher collected field notes during these times to gain a more detailed understanding about the school. These observations noted events as they occurred periodically throughout the school day. They also included reports about two faculty senate meetings. The section below reports the results of this data collection's analysis.

\section{Observation}

In 1976, the county built this school next to the Board office located in the center of the district's servicing area. Because this location is also central to the county's largest town, the school is easily accessible from a main road that connects the county's north and southbound traffic. As a result, the school is nestled behind a row of fast food restaurants, service stations, and local businesses. The school grounds, however, create a distinct and tranquil environment that sets the school apart from this commercial activity. Playgrounds and ball fields provide an open space that separates the backside of the school from the busy throughway. The school's entrance located on the opposite side, does not face the town but looks upon a quiet river. This river marks the boundary between the town and it's surrounding rural and mountainous terrain.

Upon entering the building, it is easy to misperceive the extent of open space this school provides. First, one must adjust their eyes to see down a long windowless hallway. Second, the school office is the only room located in this area. The hallway separates the school's activity from the building's main entrance. Inside the office, it too appears small with less space for four 
visitors to stand. Beyond the receptionist desk there is another room that serves as the nurse facility and behind the several closed doors there are two conference rooms, three principal offices, and one large teacher workroom. While the school's staff enter the office from these areas, others must use the main hallway to access the remaining part of the school.

In the center of the school there is a cafeteria and library that serves as a boundary between the middle and elementary schools. The elementary school is on one side of the building while the middle school is on the other. In the middle school wing, the classrooms form the shape of an octagon. This unique design creates a continual discovery of new space because one can not see all the classrooms at any one point in time. As one circulates the wide carpeted hallway, they find classroom doors on either side and walkways at the four corners that provide access to six additional classrooms. Although the school does not decorate the building with many bulletin boards or wall hangings, the clean and orderly atmosphere combined with its unusual architecture creates the perception of being new despite the building's age.

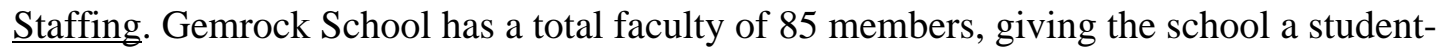
teacher ratio of 15.8 to 1 . The middle school organizes its teaching staff of 39 by content areas. These areas include: communication arts (reading, language, and social studies); science; math; related arts (family consumer science, art, technology education, and music); and physical education. Each area shares a common planning period. With the exception of the communication arts team, the other programs teach across the three grade levels. These areas thereby have planning with members who teach the same subject but do not necessarily have the same students. The three communication arts teams, on the other hand, share a planning period with members who teach different subjects to the same students and grade level.

The school assigns all the students to a communication arts team by grade level. Each of these three teams consists of six teachers, one of which is a special educator. Within each team, the teachers divide the students into two sections: morning and afternoon. While one section meets with the communication arts team in the morning the other section attends their math, science, physical education, and related arts classes. The sections then switch in the afternoon. 
Within the related arts classes, students rotate among the different class offerings each grading period of six weeks. During the last two six week rotations, the school allows students to choose the area they would like to attend.

From each of the classroom observations it was evident that the school had established several routine practices. In each class the teachers wrote the lesson's objective and assignment on the board and the students recorded it in their daily planner. The teachers also noted student attendance and stood in the hallway to monitor student behavior as they exchanged classes. Teachers conducted their lessons by using a variety of teaching techniques and styles, for example in one class students reviewed for a test by playing a game in cooperative groups. In another, the teacher presented solving problem steps to the group followed by individual student practice at the board and at their desks. In every class, teachers provided students an opportunity to participate in and demonstrate skill achievement. Each class also ended in a timely manner to allow the teacher to assign homework and to enable students to put away their materials.

Collaboration. The three special educators assigned to a communication arts team also serve as the contact person for teachers who teach the same grade level. Within their teams however, the teachers determine which reading, language, and social studies' class periods involve collaborative teaching. Under this model the special educator is in the room with the communication arts teacher on a daily basis. As one special educator reported, they are primarily responsible for how this setting addresses the student's IEP requirements. The special educator grades the student's work, makes material modifications as necessary, and provides the students with additional support during instruction. The teachers had reciprocity in presenting the content, however, the communication arts teacher more routinely served the primary instructor.

The same special educators also teach in a resource setting. Under this model the special educator provides separate instruction in the areas of math, language arts, and or reading to only students with IEPs. While these classes cover the same content as the regular education classes, they progress at a slower pace and use materials that accommodate the student's different skill 
levels. In several observations, the special educator also used this time to provide additional review of the content that the collaborative classrooms covered.

Under this dual servicing model, one special educator has three collaborative instructional periods and two resource classrooms and two have two collaborative instructional periods and three resource classrooms. Science is the only subject area in which there is no collaborative teaching nor resource setting. The interviews with these teachers did not indicate any future plans to change this. This year, however, one section of seventh grade math agreed to provide a collaborative setting. Prior to this time, the special educator only provided math instruction in a resource setting. According to the math teacher, they agreed to try one section as a collaborative in hopes that it would benefit the other students who experience trouble in class. With the exception of this one class, the math and science teachers have limited contact with the special educators because they do not share a planning period with the communication arts teams.

Gemrock School also has a special educator in the area of behavior disorders, mental impairments, and gifted education. Students assigned the teacher of mental impairments primarily receive their content area classes in a separate setting. Depending on their need, many attend the related arts classes with their peers while others attend classes at another school facility designed to develop functional skills. Students with behavior disorders and mental impairments also attend the resource and/or the collaborative classrooms. The majority of special education students in the communication arts team, however, have a learning disability.

All six special educators attend a weekly Student-Based Assistance Team (SBAT) meeting with the principal every Wednesday afternoon. This supports open communication across the different special education programs. The content areas including communication arts team also meet with a principal on a weekly basis. As a result, the communication arts team's special educators meet with the principal weekly on two different occasions. Although the different content areas do not share the same planning time, the principal's contact with each team indirectly supports a line of communication across these different teams. 


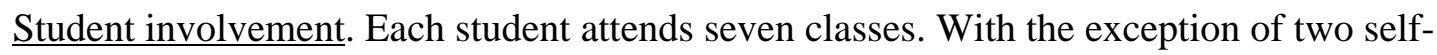
contained and eight resource classes (see Table 1), all other classrooms represent a heterogeneous group of students. These settings include the math, science, related arts, physical education, and communication art classes. All students from each grade level also eat lunch together and attend a daily guidance class the last half hour of school. The intent of this program is to provide instruction to develop student's social, emotional, and personal self-help skills in order to become productive participants in their community. One theme that the teachers are to discuss is on the proper treatment of persons with disabilities. Several teachers however commented that they more often used this time for students to begin their homework assignments and to organize their materials.

Table 1

Gemrock School Special Education Class Assignment

\begin{tabular}{|c|c|c|c|c|c|c|c|}
\hline \multirow[b]{2}{*}{ Grade } & \multicolumn{3}{|c|}{ Resource } & \multicolumn{3}{|c|}{ Collaborative } & \multirow[b]{2}{*}{$\underline{\mathrm{n}}$} \\
\hline & Language & Reading & Math & Language & Reading & Math & \\
\hline 6 & -- & 5 & 11 & 15 & 31 & -- & 38 \\
\hline 7 & 7 & 9 & -- & 19 & -- & 13 & 28 \\
\hline 8 & 9 & 10 & 9 & 11 & 7 & -- & 20 \\
\hline MI & 16 & 14 & 19 & -- & -- & -- & 16 \\
\hline
\end{tabular}

Each student also participates in a school wide 'student of the month' club. This disciplinary program rewards students with good behavior with an opportunity to receive a lunch at McDonalds. The school takes a picture of the student to display on a bulletin board positioned outside the library. During the researcher's visitations, students were observed following this programs guidelines. For example, during class changes the students walked quietly on the appropriate side of the hallway. As teachers stood outside their classrooms to monitor this orderly practice, they greeted students and acknowledged their appropriate behavior. 
Faculty Senate. The entire faculty, Kindergarten through eighth grade, met as a group for their monthly faculty senate meeting. To accommodate this large group, the school set up rows of chairs in the media center facing two large tables where the Faculty Senate Executive Board sat. Teachers were observed sitting in groups with their teams. The elementary school faculty sat on one side while the middle school sat on the other. A few teachers brought papers to grade, but the majority of the faculty left their work behind to give their undivided attention to the meeting.

Prior to the meeting the Executive Board met, prepared, and distributed an agenda to each faculty member. Using Robert's Rules, the President followed this agenda to conduct the meeting. After the minutes and budget were read and accepted, the President briefly shared the correspondence received since the last meeting. These announcements included such items as training opportunities, grant proposals, and upcoming community and school activities. The President asked different committees to give reports (e.g., the school improvement council, dress code committee). Various members stood and reported no new business.

The faculty senate spent a majority of the time discussing new business. At one meeting, a teacher delivered a fifteen minute presentation about a victim offender reconciliation program. After describing this community project with overheads, he encouraged the teachers to become volunteers. This opened the floor to questions and an additional five minute discussion. Other new business was typically presented with less formality and was more briefly stated. For example, at the various meetings teachers announced such items as the Geography Bee, new videos available for training, and state proposed changes to the teacher's retirement plans.

The school principals also spoke to provide teachers with information about new state mandates. At one meeting the Principal explained the need to adopt a Character Development Student Responsibility Program and asked for volunteers to serve on a committee. Three teachers did so. They also reviewed such items the school's application to become a Blue Ribbon School and their SAT-9 school achievement scores. At each meeting, the Principals and staff reviewed the school's security status. For example, the teachers inquired about the school's ability to buy more walkie-talkies. At the following meeting, the Principal reported how it was cost prohibitive. 
The Principal had also conducted a frequency count on whether each teacher was keeping their outdoor exits locked. Due to the high number of unlocked doors, a faculty member made a motion to require teachers to lock their doors. Another made a motion to disallow teachers' kids in the building during faculty senate. After much discussion, the President tabled these requests.

Under new business, the primary and middle school also met separately for twenty minutes to discuss issues concerning their grade. At the middle school meeting, teachers discussed such topics as the job shadowing program and school safety. At one meeting, a teacher wanted to discuss a particular student. Due to confidentiality issues, the Principal advised them not to. This raised a debate over the purpose of their meeting. Several teachers talked at once. After much deliberation, they decided that the faculty senate could only talk about program issues and not specific students. The concerned teachers decided to hold a separate meeting.

When the two groups rejoined, the President solicited additional announcements and adjourned the meeting with the Shining Star Award. According to several interviewees, the faculty senate created this award to boost teacher morale. Teachers submit a "thank-you" note to the Faculty Senate's Teacher Recognition Committee to recognize of a teacher's good deed. From a random drawing the committee read a note and awarded the recognized teacher with a donated gift and the opportunity to use the Shining Star reserved parking spot for a month.

In sum, faculty senate conducted their meetings according to an agenda that contained five items: the reading of the minutes and budget; committee reports; new business; principal announcements; and separate middle and elementary school sub-meetings. The meetings spent a majority of its time on the Principal's announcements. This was greatly due to the fact that the topics generated discussion and questions among the various faculty members. It is noteworthy that these discussions primarily dealt with administrative issues rather then with instructional or programmatic concerns. Because they rarely achieved a closure, the President often motioned to table the discussion in order to provide time to gather more information. From an observer view point, this tactic wisely served the faculty because discussion did not arrive at a clear resolution. 


\section{$\underline{\text { Strategic Integration Plan }}$}

This study examined the Gemrock school's six-page strategic plan for managing the inclusion of students with special needs into the general classroom setting to obtain a framework of reference for examining how schools promote inclusive practices. To facilitate this process, a content analysis protocol used suggestions described in the A Strategic Planning Guide for West Virginia Faculty Senates (1994) to analyze the plan's six components (Appendix B).

Table 2

$\underline{\text { Gemrock }} \underline{\text { School Mission Component Analysis }}$

\begin{tabular}{llll} 
Audience & Action & \multicolumn{1}{c}{ Aim } & Importance \\
\hline School & to provide & $\begin{array}{l}\text { an education appropriate } \\
\text { to their performance level }\end{array}$ & $\begin{array}{l}\text { within regular education } \\
\text { program. } \\
\text { to their exceptionality }\end{array}$ \\
to adapt & to fullest beneficial extent \\
School & to provide & $\begin{array}{l}\text { instruction by regular } \\
\text { and special educators }\end{array}$ & $\begin{array}{l}\text { in regular, collaborative, } \\
\text { and resource settings. }\end{array}$
\end{tabular}

The Gemrock School plan's mission stated (see Appendix F-1):

Exceptional Needs students will be provided an education appropriate to their performance level, and adapted to their exceptionally, within the regular education program to the fullest beneficial extent. The instruction of special needs students will be provided by regular education teachers and special education teachers in the regular education, collaborative, and resources settings (with appropriate support personnel).

Table 2 demonstrates how the school's two mission statements contained and relate to each of the state's recommended components. Table 3 extended this analysis by cross referencing how the contents of these components relate to the four belief statements held by the West Virginia Integrative Initiative. In this table, the school only shared three of the state's four beliefs. The school's mission gave value to creating an integrative education. Their beliefs focused, however, 
on the school rather then the on student's experience or benefit. For example, the school's mission did not address nor imply the recommended belief that integration with others fosters the life long learning process. The mission, instead, spoke to instruction in relation to the school's service configuration. It addressed how organization supports integration, not why. To this end, the mission's primary function addressed the individual appropriateness of placement and assured a continuum of regular, collaborative, and resource settings.

Table 3

Gemrock School Mission Content Analysis

Source Gemrock School Mission

State Quality education reflects our diverse society, supports, and promotes the success of all students.

Gemrock Provide education appropriate to their performance level and adapted to their exceptionality.

State Education is a shared responsibility of families, educators, and the community.

Gemrock Provide instruction by regular and special educators.

State Interaction with others fosters a life-long learning process.

Gemrock

State Each student's potential is better realized when a spectrum of educational opportunities occurs with age-appropriate peers in home school settings.

Gemrock Provide education within regular education program to the fullest beneficial extent; provide regular, collaborative, and resource settings.

Table 4 compares the school's goals to the West Virginia Integrated Initiative recommended goals. Four of the school's six goals coincided with three of the five recommendations. The two goals the school identified that differed from the state recommendation are, "The quality of educational services provided to non-special education students will not be diminished as a result of the inclusion policy" and "All special need students 
will receive instruction from the appropriate certified teachers associated with their

exceptionality." In comparison, the school and state address issues related to the plan's impact on the general student population and to the administrative accountability activities. While the school seeks to assure that the plan does not have a negative impact upon the general school population, the state recommends schools to seek funding to promote integrated education. With respect to accountability, the school specifies the goal to provide certified teachers whereas the state broadly recommends evaluation of the plan's outcomes. The school goal differences, however, out weighed the level of similarity.

Table 4

$\underline{\text { Gemrock }} \underline{\text { School Goal Analysis }}$

Recommendation Gemrock School Goal

Technical assistance -

Positive partnerships

Comprehensive training

Student-based funding Accountability system
Time allotted for joint planning of regular and special educators.

Each team and grade have special educator as full time team member or as a designated contact person for service assistance. Increase involvement of parents \& community volunteers in classroom as support personnel and resources will be utilized. All staff members receive training relative to necessary teaching adaptations required to meet needs of special needs students.

Table 5 cross references the school's eight identified need statements with the state's five recommended goals. Although the school did not contain all of the goals recommended by the state, their need component did. In comparison to the state's recommended need areas, the school did not address needs that related to student activities or interaction with peers. The school, instead, addressed internal needs that related to organizational concerns. The extent of these 
concerns primarily dealt with administrative and teacher support items such as training, planning time, and access to materials. While these items indirectly relate to student concerns, they do not specify how their programs promote student involvement and interaction.

Table 5

Gemrock School Need Analysis

Recommendation Gemrock School Need

Technical assistance

Time for regular teachers to plan with special educators.

Special educator member \& contact person for each grade level.

Positive partnership Active support groups organized for educators.

Identify, utilize community support \& qualified volunteer help.

Comprehensive training All staff general training working with inclusion of special students \& specific training to meet specific exceptionalities.

Student-based funding All support services, specialized equipment, instructional aides, specialized instructional materials available to all teachers.

Accountability system Frequent formal, informal communication between special and regular educators, special needs students, and parents.

Regular education student rights will not be adversely affected by the inclusion policy.

The Strategic Integration Plan's fourth and fifth section listed the school's objectives and activities for meeting their plan's goals. Table 6 presents the school's objectives and activities in relation to the state recommendation areas. The school addressed four of the state's six recommendations and omitted the recommended area concerning student involvement and professional practice. The professional practice recommendations were to describe how teachers adapt, modify, and support instruction to meet individual student need whereas the student involvement recommendations related to how the school promotes inclusive settings. Although none of the school's objectives and activities addressed these items, it is noteworthy, that this 
section, unlike the others, addressed the social aspects of integration. Yet, despite this addition, the majority of this plan's component continued to specify actions that are administrative in nature. They described teacher centered behaviors only in relation to the organizational aspects of an integrative school model and omit mention of practices that relate to the classroom.

Table 6

Gemrock School Objective and Activity Analysis

Recommendation Gemrock School Objective and Activity

Administrative responsibility In-service training, college courses.

Joint planning of regular \& special educators.

Emergency support team and crisis room.

IEP development

Advance notification of student's inclusion.

Appropriate transition increments to more inclusive.

Collaborative teamwork Special educator as member \& contact for each grade.

Professional practice

Student involvement

Interaction with peers

Advisory group instruction on proper treatment.

Table 7 compares the school's final section, evaluation, with the state's recommendations. The analysis identified whether the evaluation activity occurred during the course of the implementation phase (formative) or at the conclusion of the implementation phase (summative). The analysis then determined fundamental reason for the stated evaluation and included the following purpose options: (1) to identify needed changes in the plan (process evaluation); (2) to provide data (outcome evaluation); and or (3) to illustrate effectiveness (impact evaluation). The analysis also listed the resources the school would use to conduct the evaluation and identified whether this procedure used performance and or judgment data. 
Table 7

Gemrock School Evaluation Analysis

Component Analysis

School Evaluation Activity

Phase Purpose Resource Procedure

Annually evaluate special needs files to determine $\%$ of class enrollment.

Collect annual statistics to monitor increase in staff training, certification

IEP reviews: \% in regular education, performance evaluation

Staff survey of joint planning and access to special educators.

Interview educators on program effectiveness and impact on regular students.

Interview students on success and failures of inclusion.
Summative, outcome evaluation records (performance data).

Summative, outcome evaluation checklist (performance data)

Summative, outcome and impact evaluation student records (performance data)

Formative, process and outcome evaluation survey (performance data).

Summative, process and impact evaluation survey, interview (judgment data).

Formative, process and impact evaluation survey, evaluation (judgment data).

In summary, Table 8 presents a cross analysis of the themes derived from the state's recommendations with the Gemrock School Strategic Integration Plan's components. The school plan consistently targeted concerns related to staffing, collaboration, and training throughout their plan. These considerations related to the organizational structure of schooling. They promoted inclusive practices by creating and maintaining a continuum of classroom settings, by providing active interaction between the special and regular education teachers, and by offering staff developments to address teacher instructional needs. Its purpose is administrative in nature. It deals with role defining, scheduling and staff needs.

In contrast, the plan gave limited attention to student related concerns. It did not consistently address how the school programs support student socialization, participation, and extracurricular involvement. It also did not identify practices the teachers must develop and 
implement to foster inclusive classrooms. In other words, the plan did not speak to how the teacher's classrooms adapt, modify, and support instruction to meet individual student need nor how they promote student participation within these contexts.

Table 8

Gemrock School Theme Analysis

\begin{tabular}{lccccc}
\hline & \multicolumn{5}{c}{ Integration Plan Component } \\
\cline { 2 - 6 } Theme & Mission & Goal & Need & Objective/Activity & Evaluation \\
\hline Staffing & $\mathrm{X}$ & $\mathrm{X}$ & $\mathrm{X}$ & $\mathrm{X}$ & $\mathrm{X}$ \\
Collaboration & $\mathrm{X}$ & $\mathrm{X}$ & $\mathrm{X}$ & $\mathrm{X}$ & $\mathrm{X}$ \\
Training & $\mathrm{X}$ & $\mathrm{X}$ & $\mathrm{X}$ & $\mathrm{X}$ & $\mathrm{X}$ \\
Student involvement & $\mathrm{X}$ & -- & -- & $\mathrm{X}$ & -- \\
Community & -- & $\mathrm{X}$ & $\mathrm{X}$ & -- & -- \\
\hline
\end{tabular}

\section{Teacher Survey}

The study presented and disseminated a Teacher Survey at the Gemrock School Faculty Senate Meeting. With a return rate of $56 \%$, only 22 of the 39 faculty members participated. Of the 22 surveys returned, 5 were special educators, 14 were regular educators, and 3 were related arts teachers. The survey's purpose was to determine the relationship between how the participants perceived their role as a faculty senate member and the degree to which their school integrated students with disabilities in the regular classroom. To accomplish this the instrument contained 30 statements that targeted four factors.

The first factor, professional practice, contained 8 items that referred to practices that teachers used to support an inclusive schooling environment. Several items related to the teachers' philosophical beliefs and attitudes toward teaching all children, including children with disabilities, while others concerned the extent to which teachers adapted instructional strategies and materials to support student individual need. A high score of four or more on this scale 
reflects higher levels of teacher's professional practices as in congruency with West Virginia's Integrative Initiative.

Table 9

Gemrock School Professional Practice Factor Analysis

Item $\quad \underline{M}$ SD

Teachers share common view about school, teaching, and learning. $\quad \begin{array}{lll}3.82 & .393\end{array}$

$\begin{array}{lll}\text { Teachers ensure interaction of special needs students. } & 4.05 & .899\end{array}$

Teachers adapt instructional strategies in content areas to meet (IEP). $\quad 4.35 \quad .606$

$\begin{array}{llll}\text { Teachers develop age appropriate materials to address student level. } & 4.23 \quad 831\end{array}$

$\begin{array}{llll}\text { School mission reflects philosophy that all children can learn. } & 4.70 & .469\end{array}$

$\begin{array}{lll}\text { Teachers develop adaptations for students with special needs. } & 4.23 \quad 970\end{array}$

$\begin{array}{lll}\text { Teachers develop structured interaction programs. } & 3.35 & 1.11\end{array}$

Instructional staff demonstrate positive attitudes toward all students. $\quad 4.29 \quad 686$

Table 9 presents the teachers' response mean and standard deviations for each item contained within the professional practice factor. The school had a group mean of 4.1. This group score represented "usually" on the response scale. The range was 1.35 with 3.3 as the minimum and 4.7 as the maximum. This variance suggests that the teachers perceived their level of professional practices as having different levels of congruency with West Virginia's school inclusion mission. In comparison, the item "School mission reflects philosophy that all children can learn" had the highest group mean whereas the item, "Teachers develop structured interaction programs such as peer tutoring, PALS (partners at lunch), etc." was the lowest.

The second scale, Site Based Management School Climate, contained nine items. These items referenced the extent to which administrative decisions and the decision making process involved teacher participation. A high score of four or more on this scale reflects that the 
teachers perceive having a higher level of participation in the school's administrative decisions making activities as in congruency with West Virginia's school site based management mission. Table 10

Gemrock School Site Based Management School Climate Factor Analysis

Item $\quad \underline{M} \quad S D$

$\begin{array}{lll}\text { When faced with a mandate school takes proactive stance. } & 4.29 \quad 686\end{array}$

$\begin{array}{llll}\text { Faculty contributes to decision-making on how money is spent. } & 3.88 \quad & .857\end{array}$

$\begin{array}{llll}\text { Teams meet weekly to plan instructional support for all students. } & 4.58 \quad & .712\end{array}$

$\begin{array}{lllll}\text { Teachers implement positive behavior management strategies w/team. } & 4.41 & 507\end{array}$

Administrators committed to enhancing their professional knowledge. $\quad 3.76 \quad 970$

$\begin{array}{lll}\text { Teachers participate in decisions on duties outside the classroom. } & 2.47 & 1.23\end{array}$

The design of progress reports reflects school's mission. $\quad 4.05 \quad 966$

Philosophy supports need for ongoing training, technical assistance. $\quad 4.11 \quad .781$

$\begin{array}{lll}\text { Decisions about how money is spent consistent with school mission. } & 3.17 & 1.01\end{array}$

The school had a group mean of 3.8. This score that represents "sometimes" on the response scale of never, rarely, sometimes, usually, and always. This mean had a range of 2.11 with a minimum response of 2.4 (rarely) and a maximum response of 4.5 (usually). The item, "Teams meet weekly to plan instructional support for all students" had the highest group mean and the item, "Teachers participate in decisions on duties outside the classroom" as the lowest (see Table 10). These scores collectively suggest that the Gemrock School's teachers view themselves as having a moderate level of participation in the school's decision making activities.

The third scale, Collaborative Teaming, consisted of six items. This scale referenced teacher engagement in collaborative teaming in relation to achieving a common goal to support inclusive practices for students with disabilities. Items reflected teacher working relationships and referenced the extent the teachers share team ownership in planning and delivering specially 
designed instruction. The items also measured how collaborative planning activities related to teacher's own implementation of individualized instructional practices. A high score on a five point Likert scale suggests that teachers perceive participating in a higher level of shared decision making practices to address individual student need.

The school had a group mean of 3.6, that represents "sometimes" on the response scale. This mean had a range of 1.0 with a minimum response of 2.9 (rarely) and a maximum response of 4.0 (usually). This group mean of 3.6 reports that teachers perceive themselves as "sometimes" participating in a level of shared decision making practices to address individual student need. The item comparison in Table 11 reports that the item, "Teachers collaborate to make material and environmental adaptations" had the highest group mean. The item, "Educators collaborate to write joint IEP goals and objectives" had the lowest group mean.

Table 11

Gemrock School Collaborative Teaming Factor Analysis

Item

$\underline{\mathrm{M}} \mathrm{SD}$

Teachers collaborate to make material and environmental adaptations. $\quad \begin{array}{lll}4.00 & .784\end{array}$

$\begin{array}{lll}\text { Related service staff provide services in general classroom. } & 3.78 & 1.36\end{array}$

Teams collaborate to provide related services in inclusive settings. $\quad 3.64 \quad 1.08$

Teachers collaborate to adapt learning objectives within core curriculum. $3.85 \quad \begin{array}{ll}3.23\end{array}$

IEP meetings use a transdisciplinary approach. $\quad 3.50 \quad 1.45$

Educators collaborate to write joint IEP goals and objectives. $\quad 2.92 \quad 1.43$

The final scale, Student Involvement, contained seven items. The items in this scale related to the extent teachers perceived school activities to involve students with disabilities. A high score on this scale reflects that teachers perceive student with disabilities having higher levels of student involvement as in congruency with West Virginia's Integrative Initiative. The school had a group mean of 4.3 , that represents "usually" on the response scale. This mean had a 
range of .684 with a minimum response of 3.9 (sometimes) and a maximum response of 4.6 (usually). This scale's range represents the smallest variance in comparison to the other factor's ranges. According to Table 12 only one item, "Remedial programs are available for students not experiencing success" rated below 4.0. In comparison the item, "Students with disabilities are involved in extra-curricular activities" had the highest group score of 4.7. These results suggest that teacher perceives student with disabilities as having a relatively high level of involvement in school activities and interaction among their peers.

Table 12

Gemrock School Student Involvement Factor Analysis

Item

$\underline{\mathrm{M}} \quad \mathrm{SD}$

Students with disabilities are involved in extra-curricular activities.

$4.47 \quad .513$

IEP objectives reflect interaction with non disabled peers.

$4.00 \quad .942$

Remedial programs available for students not experiencing success.

$3.94 \quad .705$

All students participate in music, art and gym classes.

$4.63 \quad .597$

Student with disabilities instructional program incorporate interaction.

$4.36 \quad .597$

All students participate in general education classes.

$4.36 \quad .597$

Students with special needs participate in school activities.

$4.36 \quad .495$

Table 13

Gemrock School Teacher Survey's Teacher Mean by Factor

\begin{tabular}{lcccc}
\hline & \multicolumn{5}{c}{$\underline{\mathrm{M}}$} \\
\cline { 2 - 5 } Factor & Total & Special & Regular & Related Arts \\
\hline Professional practice & 4.1 & 3.8 & 4.1 & 4.5 \\
Site based management & 3.7 & 3.5 & 3.9 & 3.9 \\
Collaboration & 3.5 & 3.5 & 3.4 & 3.7 \\
School involvement & 4.3 & 4.1 & 4.3 & 4.4 \\
\hline
\end{tabular}


Table 13 presents a summary of the factor's group scores by individual scores for each group of teachers. On three of the four factors the related arts teachers had the highest group mean. In contrast, the special educator's had the lowest group score for the same three factors. Teacher Interview

This study conducted twelve interviews with teachers representing each of the team and grade content areas. Six interviewees initially signed up for an interview at a faculty senate meeting and an additional six participants were sought to assure each grade and content area representation. Because the purpose of these interviews was to gain a richer understanding about the school's Strategic Integration Plan's contents and teacher's faculty senate participation, this study devised two protocols (see Appendix D and E). Both served as a guide to investigate how teachers perceive their school and classroom practices. On the basis of the plan's contents, the analysis used a pattern matching process to identify related themes. The section below describes these five themes as well as two themes that were identified as unique to the interviews conducted at Gemrock School.

Integration plan effects on school practice. Each interviewee stated that the school began the practice of having a special educator in the regular classroom setting over ten years ago. This was before the state required faculty senates to develop integration plans in 1994. However, one teacher stated, "Installing the inclusion plan was an effort to assure that the Federal law was in place." As a result, the school has made several changes. Two interviewees discussed the fact that before the state mandated the plan, the school implemented a model that was strictly collaborative. Around six or seven years ago, the school changed this and began to allow for more 'pull-out' or resource classes. One interviewee commented, "The special education team is evolving: I think it is better here in the last several years."

The plans enhanced the school's practice by allowing the faculty senate to articulate additional areas in further need of development. For example, the plan stated the need to have a special educator assigned to each grade level and communication arts team. This assignment has now become practice. The plan also addressed the need to have formal and informal 
communication between the special and regular educators. In the Fall of 1998, the special educators spent an entire day meeting with each of the team and content area teachers (math, science, related arts) to discuss the students who have an IEP. Each interviewee commented on its benefit and extended hope that these meetings become a routine practice.

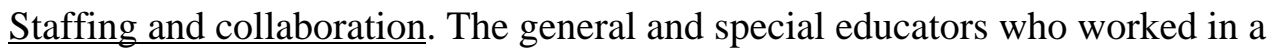
collaborative setting commented that they felt it was positive experience. One commented, "We work well together." Another stated,

I think it [collaborative class] works well because [the regular educator] is the expert and the [special educator] can go back and remediate. Just having two people in there helps because they need, even if they're not on an IEP, they need help.

Several commented that collaboration was not easy. "I think the biggest issue is just that [teachers] don't see the benefit for themselves: Some of it was purely the territory issue." Another stated, "I view special educators as having two jobs: they teach and then they've got all this other special education stuff." However, all reported positive comments in respect toward the special educators.

I think they work very hard. ... You'd even go in and say to them, okay, I'm having this problem, and you know what you can do about it, and it's never like well I don't know, that's your problem. I've never, I've never found that.

Of concern, several teachers talked about the fact that science does not work with a special educator in a collaborative model. The communication arts classes (language, reading, and social studies) and one math class only practice a collaborative model. One stated "In regular science it's a really big problem; the grades come out and they have D's and F's." As such, several teachers expressed the wish to have more special educators to teach in more classrooms. One teacher stated, "I think there needs to be a special educator in all areas so they come to physical education, related arts, everybody: not just communication arts."

Training. The Gemrock School and their county offer training throughout the year on different topics. When teachers were asked about training in the area of special education, one 
commented "I think we always need training." Another stated, "It hasn't been met in my opinion though its being done now I guess: We had an in-service this year that had to do with attention deficit and hyperactivity." Although one interviewee stressed that teachers can recommend the types of training they would like to receive, no one could specify an area they would like to have offered when directly asked. Another pointed out, "Well it is written in the inclusion plan that you can request it, but unless the man across the street, the Special Education Director, finances it he usually counts on the staff development council to provide the funds."

Student and community involvement. The teachers reported very little information in this area. In response to the integration plan's goal to increase parent involvement, three interviewees stated that parent volunteering occurs in the primary grades but rarely in the middle school. One teacher put it, "I've been teaching 22 years: all through it [parent involvement] stops about sixth grade." When asked about student involvement activities, a few talked about the guidance period that occurs at the end of each day. However, both commented on the fact that half an hour doesn't give much time to be productive. Another stated that she felt the school should offer the students the opportunity to experience more cultural events.

Heterogeneous grouping. A concern over student grouping was a unique and unsolicited theme repeated throughout several interviews. On several occasions the teachers expressed the desire to group students by homogeneous ability levels. One stated:

I worry about the educational rights of the regular education students. . . . I am not for the way we are putting all these kids together. I think this is where we are doing a disservice to the children that could move on and go beyond.

Another teacher shared:

Heterogeneous grouping is a big thing here with the teachers and I can see it coming to a head the last couple of years. We've been real unhappy with the need to mix high, low and average. The kids lose. You've got to teach these kids and it's not working as we see it. 
In response to these statements, teachers were asked why they did not change the groups. Without hesitation, each teacher stated that it was the Principal's decision and that he was adamant about maintaining a heterogeneous grouping. One interviewee further explained how the school had previously grouped students by ability level but the teams developed a stigma and children knew which group was the lowest.

Only one teacher addressed this issue with respect to students with special needs. "I think there is some unrest about having the students with IEPs in the regular classroom." He went on later to say, "It interferes with what some of the other students are getting. . . I see that as something that is more imposed on me, but on the other hand, I understand that we learn to live with differences and teachers do too." Although the many interviewees talked about their liking to have ability level classes, no one suggested that the students with special needs should all be placed in separate classes. In other words, the contention was to restructure the regular education classrooms by ability level, not to increase the number of separate settings.

Placement decisions. Decision about placement was another theme that evolved from the data as unique to this school. Despite discussion over the need for ability grouping, teachers overwhelmingly stated that they had a lot influence in determining where students with IEPs received instruction. These decisions were flexible. According to the team teachers interviewed, each team determined their schedules to include a collaborative setting. One teacher commented:

[You are] able to decide and make your own decisions instead of being dictated that you will do this, you will do that. We're given the choice of, do you want to pull children out that period or do you want to keep them in.

Each team or grade could have up to three resource classes depending upon the need. The regular education teachers did not necessarily have the same collaborative schedule from year to year, nor did the special educator always teach in the same subject areas. The teachers determined the model on an individual and yearly basis.

Faculty Senate. All teachers interviewed expressed a positive response to having faculty senate meetings. The reason overwhelming given was attributed to the fact that these meetings 
provided the only time for the entire faculty to meet. Several responses included, "I think faculty senate is a wonderful thing: It's the only time that you really have together to really iron out some of the problems." "The two buildings can mesh during that time and if we didn't have it, we wouldn't be able to do that." "I think that it [faculty senate] has made us cohesive as a school." To increase teacher morale, several teachers liked how the faculty senate recognized teachers with a Shining Star Award and sponsored a birthday club.

Throughout the years, the faculty senate has had and still has many committees to deal with areas such as the curriculum, school facility maintenance, and the budget. They created several ad hoc committees to deal with specific issues. When asked how the teachers participated in policy making activities, they gave a mixed response with respect to the amount of decisionmaking they had. All teachers brought up the fact that after spending much time in the committees and having the faculty senate approve a plan or recommendation the Principal exercised the authority to nullify it. A teacher stated, "I'm tired of committees: I used to be on many but what is the point?" "The principal can undo things after many months of work." Another suggested:

If the legislature wants the faculty senate in this state to really be effective, then they need to give us some authority. This stuff of recommending, for example, no book bags . . our principal said he would not support that in any shape or form. All we can do is recommend. We have no binding authority.

Another commented, "The administration doesn't like to share too much, you know the decision making thing."

\section{Case Study Profile Summary}

Gemrock School is located in a county that has high percentage of student receiving special education services in the state. Including the area of gifted education, this school has 140 students with IEPs and six special educators. Although the special education population represents 21 percent of the student enrollment, no students spend 60 percent or more of their 
day in a separate setting. With the exception of ten resource classes, all other classrooms have an integrated setting. To the extent, Gemrock School has a relatively high level of integration.

Gemrock School's Integration Plan contained all required components and addressed the majority of the state's recommendations. Each component consistently targeted concerns related to staffing, collaboration, and training throughout the plan. These considerations related to the organizational structure of schooling. They promoted inclusive practices by creating and maintaining a continuum of classroom settings, by providing active interaction between the special and regular education teachers, and by offering staff developments to address teacher instructional needs. Its purpose thereby is administrative in nature. It deals with role defining, scheduling and staff needs.

In contrast, the plan gave limited attention to student related concerns. It did not consistently address how the school programs support student socialization, participation, and extracurricular involvement. The plan also did not identify practices the teachers must develop and implement to foster inclusive classrooms. In other words, the plan did not speak to how the teacher's classrooms adapt, modify, and support instruction to meet individual student need nor how they promote student participation within these contexts.

On the basis of the school's Strategic Integration Plan, observation, and teacher interview data, the school made several changes that address the organizational aspects of an integrative environment. They list below presents these changes.

1. Each communication arts team has special educator as a full time team member.

2. Three of the five special educators teach in a collaborative setting on a daily basis.

3. All special educators meet as a group with the principal on a weekly basis.

4. Each student participates in an advisory group class. Teachers are to offer sensitivity toward individuals with disabilities as one instructional theme.

5. With the exception of the one self-contained and three resource classroom service options, all other classes have heterogeneous ability groupings. 
6. All students participate in physical education, lunch, and related arts classes with peers.

7. Special educators were given coverage to spend the entire day meeting with all teams in the Fall of 1998.

This school promotes several practices that are in support of the West Virginia Integrative Initiative. The school provides an informal and formal collaborative model of schooling by assigning a special educator to each communication arts team. Within these teams, the observation and interview data reveal that the teachers perceived to have a high level of participation in making decisions that concerned their classroom practice. The communication arts team reported they had a great deal of flexibility in determining the subjects each teacher would instruct, the classes that would provide a collaborative model, and whether students with IEPs would attend a separate or regular education class for reading, language, and math.

The teachers also reported they met as a team four days a week to discuss and decide the instructional approaches used in their classrooms. Once a week, the individual teams also met with the principal. Because the different content areas do not share the same planning time, the teachers reported that principal's contact with each team indirectly supported a line of communication across these different teams. The principal also hosted a weekly Student-Based Assistance Team (SBAT) meeting. In this meeting, special educators and regular teachers meet to discuss special education related issues as well as specific concerns about individual students.

It appears that the administration determines a boundary that limits the teacher's level of decision making. Several teachers expressed the desire to have students assigned to classes by ability level. This is not to say that they did not want to have students with IEPs in the regular classroom but, rather, they wished to offer different sections of the same class according to ability. In each discussion the teachers were asked why this was not done. Each response reported that it was an administrative decision. Teacher's level of decision making therefore does not include an option to group students by ability. Several also mentioned that the administration determined that each team could only offer up to three separate classes for students with IEPs. 
Interviewees also suggested that the administration's decisions also influenced the faculty senate's practices. At best, the teachers shared that they felt that the administration placed an arbitrary limit to the kinds of decision making opportunities that they could engage in. For example, three teachers raised the issue of how the faculty wanted to implement a "no book bag" policy. Although the faculty senate approved this motion, the principal overturned their decision.

The observation of their faculty senate meeting provides additional insight. During these meetings, the committee reports were brief and frequently stated no new business. The faculty senate spent a majority of their time with the principal announcements. It was at this time that other faculty members spoke with each other and to the group. The President however often tabled these discussions for the next meeting. In pursuit to understand why, two interviewees stated the opinion that these decisions fell under the responsibility of the principal. The tone and gestures of these conversations suggested that they resented how faculty got caught up in issues that they can't easily or collectively resolve. One teacher said, "I don't think its our place to tell other teachers what they can and can not do."

These mixed results suggest that while the teachers participate in making decisions within their team and classroom, their ability to influence system or school program decisions was difficult and sometimes met with resistance. On the teacher survey the group mean concerning site-based management had the second lowest score compared to other factor's group scores. This factor contained items that related to how the faculty participated as a group in making administrative decisions. The school's group mean for professional practices, on the other hand, ranked as the highest group mean factor. This scale reflected the decisions that individuals made within their classroom with respect to their instruction. This difference suggests that teachers perceive their level of classroom decision making as higher than the level they perceive in making administrative decisions. 


\section{Lucas Middle School}

Lucas Middle School is the second largest school in a county of nine schools. It is the only school in the county that serves grade five through eight. Although the school is quite old, it originally served as the county's high school. In 1992, the county adopted the middle school model and moved the students from a junior high setting to this building. In 1997, the school expanded its student enrollment to include the fifth grade. With a total county student population of 2,842 students, this school serves 659 students (West Virginia Department of Education, 1997). The study sought this school's participation based on the West Virginia Department of Education's records that report this county, in comparison to West Virginia's 55 counties, as having the highest percentage of students receiving special education services (West Virginia Department of Education, 1997).

The case study described below reports the data obtained at Lucas School. The first section, observation, describes information that was gathered by a field note data collection strategy. During September through December, observations were conducted in a multiple of settings and on eleven different occasions. Two faculty senate meetings were also attended. Field notes from these observations served to provide detailed descriptions about the school and enrich the study's understanding of the climate and context of the setting being studied.

\section{Observation}

The school is walking distance from the town's main square. Although located amid the commercial activity of this county's largest business area, the school grounds look upon a quiet residential street. On the building's one side there is grassy area and small parking lot that only accommodates a few of the teacher's cars. On the opposite side, there is a large football field and baseball diamond that spans beyond the length of the building. To the school's rear there are two additional buildings. One contains the gymnasium. This facility has a main outdoor entrance as well as an attached indoor walkway. The second facility only provides an outdoor entrance. This one-story building provides classrooms for the industrial arts, music, and choir programs and one room for special education. 
Inside the main two-story building, two wide hallways form the shape of a 'L.' On the first floor the student cafeteria is at one end while a large band room is at the other. Next to these rooms, there are exits to access the school's gymnasium and outdoor classrooms as well as stairwells to the building's second floor. The second floor has the same floor plan. The library, however, uses the space above the cafeteria and a wing containing classrooms for the fifth grade spans above the band facilities. Both floors provide large windowed classrooms by grade level and or team. Lockers, posters, bulletin boards, and samples of student's work line the hallways amidst the classroom doors posting the teacher's name and or team affiliation.

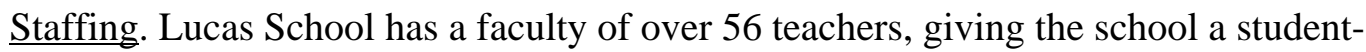
teacher ratio of 14.3 students to 1 teacher. The school organizes their teaching staff by teams and content areas. The teams contain four teachers that provide instruction in social studies, science, language arts, and mathematics. For each grade level there are two such teams. In order to distinguish these eight teams across and within the grade levels, the school named each of them by a different theme. Each grade level's two teams share an hour and twenty minutes daily planning period.

The school organizes and identifies the remaining staff by the area in which they teach. These areas include: the related arts block (health, art, music and physical education); vocational technology block (computers, technology, keyboard and careers); and special education resource programs (mental impairments, behavior disorders, learning disabilities, gifted education, and severe and profound). Unlike the other eight teams, these teachers teach across the grade levels and they do not necessarily share a common planning period with each other.

The school assigns the students in teams by heterogeneous ability groups. Each team has an equal number of students with Individual Education Plans (IEPs). With respect to each class size, the teacher has no more then six students with IEPs at one time. While students remain with their team throughout the year, they rotate between the related arts and vocational technology block classes each grading period of nine weeks. All classes meet for forty minutes with an exception: one seventh grade team follows a block schedule. The school implemented this model 
on a trial basis in 1998, at the request of the team. Under this model, students attend one content class for two periods. In practice, students have science and language arts for eighty minutes on Monday and Tuesday and social studies and mathematics on Wednesday and Thursday.

Collaboration. In 1996, Lucas School implemented a school-wide inclusive teaching model for students with learning disabilities. Under this new configuration, these students attend regular education classes instead of a resource or self-contained setting. To accommodate this restructuring, the school assigned one special educator to each grade level. This special educator thereby works with eight teachers from the two teams and shares their common planning period. The special educator's role is primarily of a consultant. With the exception of the exploratory and skill enhancement classes, the school does not assign them to teach a particular class on a daily basis. The special educator instead divides their day by morning and afternoon between the two teams. Depending on the student need, the special educator rotates among the different classes. The special educator, therefore, may work within different classrooms during the same instructional time period. One explained, "All I'd do is walk back and forth the whole morning long and help all of them, so that's worked out good."

In addition to the four consultants that work with students with learning disabilities, the school also has a consultant who works with students with behavior disorders. This teacher's role is similar to that of the others, with the exception that they work with students from all four grade levels and not just from one. As a result, they do not share a common planning period with the students' team teachers.

In total the school has 13 special education teachers. Two teach in the gifted education program. The remaining seven teach in a separate setting outside the regular education classrooms. Five of these teachers work with students identified as mentally impaired and two others work with student with behavior disorders. In these programs the same students have one special educator for up to six subjects with students from different grade levels. Because the majority of these students attend the same classroom with the same peers throughout their day, they identify this class and teacher as their 'team.' 
Unlike the learning disability consultants, the special educators that teach in the special education classrooms do not necessarily share a common planning period with the regular educators nor with each other. One teacher explained, "We do not share the same students so this limits our need to collaborate." The learning disability consultants, on the other hand, collaborate with regular education teachers on a daily basis. This is greatly due to that fact that the nature of their role is quite different from the resource and self-contained teacher's. In the latter, the teachers are responsible for planning, implementing, and evaluating the student's lesson. The consultants, however do not necessary determine and deliver the lesson's content but provide assistance within the regular classroom. They are responsible for supplementing, modifying, and or adapting the regular educator's lesson to meet an individual's specific need. According to several consultants, they spend a great deal of their time in the regular classroom reading tests aloud, assuring homework are complete, and providing one-on-one assistance to students of they have trouble with a lesson.

In several of the classroom observations, the consultants were observed providing students help after the regular teacher presented the content. In one classroom, small groups of students completed a science experiment. After completing this hands-on activity, students recorded and shared their findings at the board. The other regular classroom observations were prototypical of practice. All classes contained a large group of students traditionally seated in rows facing the teacher. Students recorded notes from the board or an overhead as the teacher presented the lesson. Several times the teachers stopped and asked questions to check student comprehension. Sometimes students raised their hands to ask questions. The majority of the time, however, students worked quietly at their desks. The special education classroom observations were similar except that the groups of students were smaller. The teachers presented the content and had the students practice the skill at their seats. In one classroom, the teacher periodically reinforced the student's success by having them make a mark by their name on the board. When later asked why students did this the teacher explained that the points contributed to 
their reward day. Each Friday the class earned free time for each point earned. This reinforcement appeared to be effective as evident by the students' smiles.

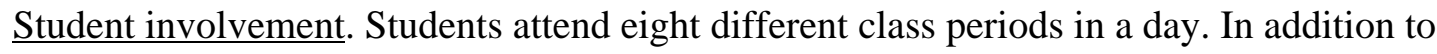
the general curriculum classes, students also participate in a daily exploratory and skill enhancement class. According to several teachers, the school omitted reading in 1997, and replaced it with a skill enhancement class to address the student's weakness identified by the county's standard test scores. The exploratory class also provides instruction at the discretion of the teacher but on such topics as photography, health issues, and study skills. Depending on the student's need, the special education consultants often use these periods to individually work with their students. Other teachers also use both these class times to provide students the opportunity to participate in the school's accelerated reader program. In this program, students have a point goal that they work toward each grading period. To achieve points, students read selected books from the library and answer comprehension test questions. As students complete each assignment or book, the teacher awards them with points based on level of difficulty.

According to the school's Fall 1998 records, 8 students with learning disabilities, 26 students with mental impairments, and 11 students with behavior disorders received their instruction in a special education setting. Apart from these programs, the remaining content and related arts classes provided an integrated instructional setting. These settings include the 61 students with learning disabilities and 1 student with mild mental impairments who received consultative services in the regular classroom (see Table 14). The school also provides the all students with the opportunity to interact during lunch time and to participate in a half hour intramural sports program. Unlike a typical recess period, students sign up to participate in such activities as football, softball, and basketball. Although all students do not have to participate, they still have this 'free' time to socialize with others outside or in the gymnasium. 
Table 14

Lucas School Special Education Delivery Model

\begin{tabular}{|c|c|c|c|c|c|c|c|c|c|}
\hline \multirow[b]{2}{*}{ Setting and Grade } & \multicolumn{3}{|c|}{ LD } & \multicolumn{3}{|c|}{$\mathrm{BD}$} & \multicolumn{3}{|c|}{ MI } \\
\hline & 6 & 7 & 8 & 6 & 7 & 8 & 6 & 7 & 8 \\
\hline Separate resource & 2 & 3 & 3 & 2 & 6 & 3 & 8 & 12 & 6 \\
\hline Regular consultative & 17 & 22 & 22 & - & - & - & - & 1 & - \\
\hline
\end{tabular}

All students also participate in the school-wide Responsible Student Program (RSP).

Under this discipline program each teacher has a sheet that lists six reminders (i.e., I will always be timely, follow rules for movement about the school, have homework completed daily).

Students who do not perform these tasks receive a reminder sheet and turn in a copy to a designated teacher for record keeping. If the student does not receive any reminders, the school rewards them with the opportunity to stay home on Faculty Senate Day. Students who experience repeated problems, however, enter what the school calls a Ladders Program. At the beginning of the school day these students meet with a designated teacher and work on their area of difficulty. One teacher described, "I basically just try to advise them if they are having problems; for example they have to have a daily planner filled out so I make sure the daily planner is filled out." As students improve they may exit the program and re-enter the program as necessary.

Faculty Senate. Lucas School has both full and half day faculty senate schedules. On the full day, teachers attend a training session prior to the meeting; for example, in the fall teachers attended a workshop on violence in schools and had the opportunity to meet with their teams. On the half-day, the faculty senate meets after the students leave the school. Because the students rewarded by the RSP program do not have to attend school, one teacher commented that they have only $40 \%$ of the student population on that day. 
Prior to each faculty senate, every teacher attended at least one committee meeting located at different places throughout the building. These committees included such areas as school beautification, teacher recognition, student recognition, public relations, and finance. The entire faculty then met as a group in the cafeteria and sat with their teams around cafe style tables. They enjoyed food and refreshments provided by different teams before the meeting officially started. Because very few teachers brought school related work with them, the meetings achieved a very focused and professional atmosphere.

Each meeting began with an approval of the minutes. The Faculty Senate President then called upon each of the nine different committees to report new business. The importance of and opportunity for teacher decision-making was evident by amount of time and the seriousness that teachers gave each report. In addition to teachers asking questions and commenting on given information, the committees submitted proposals for teacher approval. For example, at one meeting the student recognition committee proposed that the school reward students with a grade point average of 3.8 or better with free passes to the dances and games. The faculty discussed this proposal and passed a motion of approval. At another meeting, the finance committee led a discussion about whether an individual or a team should request for money to buy new materials. After much debate, the faculty senate voted to allow either to make such requests. They then discussed specific requests and voted support for each proposed item.

The two Vice Principals also briefly spoke at each meeting. One Vice Principal gave the discipline report while the other discussed upcoming staff development opportunities. In the discipline report, the Vice Principal informed the faculty about the number of infractions that students committed for the month and compared the month's numbers with the previous year's and month reports. Each comparison reported a decline. Under the staff development report, the Vice Principal at one meeting requested for the teachers to elect a faculty member to sit on the county wide staff development council and at another announced up-coming events. In comparison to the faculty senate committee reports, these announcements used little time. This was largely due to the fact that there was no discussion from the faculty. After the Vice 
Principals spoke, the Faculty Senate President called for announcements from the floor. Several different teachers stood and shared miscellaneous information. For example, one teacher encouraged staff to have their students sign up for the talent show while another announced the opportunity to participate in a PBS survey.

Each meeting concluded with a time for the Principal to speak. The focus of their announcements was in the form of praising the staff in their efforts since the last gathering. At one meeting, the Principal formally recognized the individual teachers who wrote grants for the school. After presenting the criteria for the award, the Principal gave a brief description of each recipient's merit and individually presented them with a plaque. The seriousness of this occasion was evident by the faculty's silence followed by the loud applauding to their colleagues. The Faculty Senate President then thanked the faculty for their committee efforts and motioned for approval to adjourn. Because the faculty held these meetings for the entire designated period of time, the faculty were free to go home when they finished.

In sum, Lucas School conducted faculty senate meetings according to an agenda that contained four items: the reading of the minutes and budget; committee reports; new business; and principal announcements. The meetings spent a majority of its time on the committee's reports. This was greatly due to the fact that these reports required teacher response of approval. The reports generated discussion and questions among the various faculty members. It is noteworthy that these reports dealt with instructional, programmatic, and student concerns rather then with decisions more administrative in nature. The teachers thereby addressed a variety of activities to shape school and classroom practice. From an observer point of view, the faculty held a high regard toward these activities as evident by the level of seriousness and sincerity they gave each report.

\section{Strategic Integration Plan}

This study obtained the Lucas school's Integration Strategic Plan to further examine how the school manages the inclusion of students with special needs into the general classroom setting. Specifically this analysis investigated the extent to which the school's plans reflect the 
ideas advocated by the Integrative School Initiative by using a content analysis procedure. This protocol compared the contents of the school's seven-page plan with the recommended components described in the West Virginia Department of Education's Strategic Planning Guide for West Virginia Faculty Senates (1994). The section below presents these results.

Table 15

Lucas School Mission Statement Components

\begin{tabular}{|c|c|c|c|}
\hline Audience & Action & Aim & Importance \\
\hline School & committed & to the belief & all children can learn. \\
\hline Students & provided & opportunity & to actively engage in learning. \\
\hline School & recognize & $\begin{array}{l}\text { students entitled to } \\
\text { quality education }\end{array}$ & $\begin{array}{l}\text { for future endeavors, social, } \\
\text { emotional maturity, and positive } \\
\text { attitudes toward life. }\end{array}$ \\
\hline School & provide & $\begin{array}{l}\text { opportunity to be } \\
\text { academically successful }\end{array}$ & education is a shared on-going process. \\
\hline
\end{tabular}

Table 15 presents the school's mission statement in relation to the state's recommended components. The school's statements contained each recommendation. The Lucas School's mission stated (see Appendix F-2),

The personnel of the school are committed to the belief that all students can learn and shall be provided the opportunity to actively engage in the learning process in a secure, orderly environment. We recognize that all students are entitled to a quality education that prepares them appropriately for future endeavors, social and emotional maturity, and positive attitudes toward life. With community and family support we will provide students the opportunity to be academically successful, emphasizing that education is a shared on-going process.

In comparison to the Integrative Initiative's themes, the school's mission statement excludes the mention of staffing, collaboration, and training concerns, but it speaks to the areas of student and 
community involvement. To this extent, school's mission has a philosophical rather than a pragmatic focus. The mission does not address how the school's organizational structure supports an integrative setting but it rather describes their beliefs in terms that underpin the organization's general perceptions of what is important in schooling. For example, the statement "all students are entitled to a quality education," states what the school values but it does not identify the particular activities that the school will use to achieve it.

Table 16

Lucas School Mission Content Analysis

Source Lucas School Mission

State Quality education reflects our diverse society, supports and promotes the success of all students.

Lucas Committed to belief all children can learn, recognize all students are entitled to a quality education.

State Education is a shared responsibility of families, educators, and the community.

Lucas Through Community and family support we will provide students the opportunity.

State Interaction with others fosters a life-long learning process.

Lucas Quality education prepares students for future endeavors, social, and emotional maturity and positive attitudes toward life.

State $\quad$ Each student's potential is better realized when a spectrum of educational opportunities occurs with age-appropriate peers in home school settings.

Lucas Committed to belief all students can learn and students shall be provided the opportunity to actively engage in the learning process.

Table 16 cross references the school's mission statement with the belief statements held by the West Virginia Integrated Initiative. The school's mission clearly reflected three of the four recommended belief statements. Although the school did not specifically address the state recommendation, "Recognize that each student's potential is better realized when a spectrum of educational opportunities occurs with age-appropriate peers in home school settings" their 
statement, "All students can learn and shall be provided the opportunity to actively engage in the learning process in a secure, orderly environment" may imply similar meaning. This correlation however assumes that the school recognizes that in order to promote all students' potential, the school must provide a spectrum of educational opportunities.

Table 17 compares the school's four goals to the state's five recommendations. Lucas School does not include the recommended goal "to use student-based funding that encourages integrated education." Each of the other goals however coincides with the remaining recommended goals. Three of these shared goals contain the same or alike wording. The school's fourth goal, "to provide the opportunity for all students to learn," implied similar meaning to the state's recommendation "to provide technical assistance to promote a unified system that fosters integration." In comparison, both statements seek the same outcome. While the state recommends a specific activity to provide technical assistance, the school generically states the goal to provide opportunity. The difference is that the school's focus is on the student whereas the state's is on the environment. In sum, each of the school's goals is general a statement that seeks broadly defined outcomes. Together they address systemic practices of the organization that involve such activities as: community partnership; student opportunity to learn; staff training; and accountability measures.

Table 17

Lucas School Goals Analysis

Recommendation Lucas School Goal

Technical assistance $\quad$ Provide opportunity for all students to learn in an atmosphere conducive to educational development.

Positive partnerships Maintain positive partnerships that support and enhance quality integration.

Comprehensive training Provide comprehensive, on-going staff training.

Student-based funding

Accountability system Develop \& implement accountability system to measure progress. 
The school's integration plan did not include a need section and therefore was omitted from the analysis. Table 18 however displays how each of the school's objectives correlated with four of the six recommended need areas. In this comparison the school's objectives did not address the student activity nor the professional practice recommended area. As a result, the school's objectives did not describe how teachers adapt, modify, and support instruction to meet individual student need, nor did they relate how the school supports inclusive settings to promote student involvement. The majority of this plan's component instead dealt with items that were administrative in nature. They described organizational level aspects that related to teacher communication, training, and planning time.

Table 18

Lucas School Objective and Activity Analysis

Recommendation Lucas School Objective

Administrative responsibility Create evaluation system and procedure in conjunction with students, staff and community.

Secure funding to enhance mission, goals, action plans.

Participate in school, county, state staff development.

Collaborative teamwork Provide time to interact, communicate, work together to implement and evaluate progress.

IEP development Maintain open and unrestrictive communication system between school, community, and parents.

Professional practice

Student involvement

Interaction with peers

Provide orderly, safe, positive environment where students will feel safe and wanted.

From a pragmatic perspective, the school's objectives also do not clearly serve as intermediate steps to accomplish the school's goals. Stated differently the objectives do not 
provide a more concise, measurable statement of what the school expects to achieve. As like the goals, the objectives used broadly defined terms to describe generic outcomes. For example, the school wrote, "Maintain an open and unrestrictive communication system between the school, community, and parents" as an objective to achieve the goal, "Maintain positive partnerships that support and enhance quality education." Because both statements seek 'to maintain,' the objective only narrows our understanding that the school seeks communication to achieve the positive partnerships. Of strength, however, the school increases their level of specificity by listing activities that identify specific tasks used to accomplish the objectives and goals.

Table 19

Lucas School Evaluation Analysis

Component Analysis

School Evaluation Activity Phase Purpose Resource Procedure

Team journal

Formative: outcome evaluation records (performance data)

Student, staff, community survey Summative: outcome and impact evaluation survey (judgment data)

Needs assessment.

Formative: process evaluation survey, record, observation (judgment data)

Student achievement analysis

Summative: process and outcome evaluation records (performance data)

Policy analysis

Formative: process, outcome \& impact evaluation survey, records, observation (performance \& judgment)

Team \& faculty senate meetings Formative: process evaluation observation (judgment data)

Table 19 compares the school's final section, evaluation, with the state's recommendations. The analysis identified whether the evaluation activity occurred during the course of the implementation phase (formative) or at the conclusion of the implementation phase 
(summative). The analysis then determined fundamental reason for the stated evaluation and included the following purpose options: (1) to identify needed changes in the plan (process evaluation); (2) to provide data (outcome evaluation); and or (3) to illustrate effectiveness (impact evaluation). The analysis also listed the resources the school would use to conduct the evaluation and identified whether this procedure used performance and or judgment data.

To summarize this analysis, Table 20 compares themes derived from the state's recommendations with the school's Strategic Integration Plan components. With the exclusion of the need component not addressed in their plan, the school's plan addressed student involvement and community in each of the other sections. The plan's components unfortunately did not provide direct measurable statements to detail what student and community involvement looks like. For example, the areas concerning student involvement did not state how students have access to and integration in the instructional environments nor how they participate in other school related and extra curricular activities. The plan instead stated, "Provide opportunity for all students to learn in an atmosphere conducive to educational development" (goal statement) and "Provide orderly, safe positive environment where students will feel safe, secure and wanted" (objective). While these statements may in imply a quality of their student involvement, they do not demonstrate to our knowledge how the programs incorporate student interaction.

This lack of clarification may relate to the fact that the school's plan primarily addressed the components from a philosophical rather then a pragmatic point of view. Their approach was generic in nature to describe practices that encompassed the needs of all students. While this may ultimately be the goal of the West Virginia Integrative Initiative, it is nonetheless unclear that the school's intends their practices to facilitate individual need. The plan's lack of detail given to such management issues as role defining, scheduling, and staff needs further compounds this lack of clarification. Without these items the plan does not demonstrate how their commitment is an effort that effects or relates to their organizational structure of schooling. More what is more important, the plan did not mention such words as collaboration, co-teaching, or team 
instructional planning: each of which are practices that transcend the issue of whether the plan is from philosophical or pragmatic perspective.

In sum, the plan describes qualities that one does not necessarily or commonly associate with concerns directed toward students with special needs. This is further evident by their lack of emphasis given to the organizational qualities of schooling areas of staffing and collaboration. As a result, the school gives limited reference to the support fact that the plan's purpose was to manage the appropriate placement of students with exceptional needs in the regular classroom. It however provides a global understanding about what is important to their school by emphasizing positive partnerships, student opportunity, training, and evaluation.

Table 20

Lucas School Theme Analysis

\begin{tabular}{lccccc}
\hline Theme & Mission & Goal & Need & Objective/Activity & Evaluation \\
\hline Staffing & -- & -- & -- & -- & -- \\
Collaboration & -- & -- & -- & $\mathrm{X}$ & $\mathrm{X}$ \\
Training & -- & $\mathrm{X}$ & -- & $\mathrm{X}$ & -- \\
Student involvement & $\mathrm{X}$ & $\mathrm{X}$ & -- & $\mathrm{X}$ & $\mathrm{X}$ \\
Community & $\mathrm{X}$ & $\mathrm{X}$ & -- & $\mathrm{X}$ & $\mathrm{X}$ \\
\hline
\end{tabular}

Teacher Survey

The Teacher Survey data targeted the study's topic of interest: the relationship between mandated site based management activities (reform strategy) and inclusive practices (reform goal). Specifically, it was of interest to determine the degree to which this site-based approach coupled with a student centered focus influenced teachers' perceived roles and responsibilities. The survey's 30 statements examined these phenomena by posing items that concerned the teacher's perceived role of empowerment and use of inclusive practices (Appendix C). 
During the faculty senate Meeting, 50 of the 56 teachers completed a survey. This gave the study a return rate of 89 percent. Only 35 teachers provided information regarding their teaching assignment. Of these 35 teachers, 21 were regular education teachers, 4 were special educators, and 10 were related art teachers. The section below presents the results.

Table 21

$\underline{\text { Lucas School Professional Practice Factor Analysis }}$

Item

$\underline{\mathrm{M}} \mathrm{SD}$

Teachers share common view about school, teaching, \& learning.

$3.47 \quad .547$

Teachers ensure interaction of special needs students.

$3.71 \quad .655$

Teachers adapt instructional strategies in content areas to meet (IEP). $4.13 \quad .618$

Teachers develop age appropriate materials to address student level. $\quad \begin{array}{lll}3.73 & .953\end{array}$

School mission reflects philosophy that all children can learn. $\quad 4.67 \quad \begin{array}{ll}.598\end{array}$

$\begin{array}{llll}\text { Teachers develop adaptations for students with special needs. } & 3.93 & .827\end{array}$

$\begin{array}{lll}\text { Teachers develop structured interaction programs. } & 3.32 & .990\end{array}$

$\begin{array}{lll}\text { Instructional staff demonstrate positive attitudes toward all students. } & 3.89 & .737\end{array}$

Table 21 presents the professional practice factor's results. Items in this scale related to the professional practices that teachers provide in their classroom to support an inclusive schooling environment. For example, several items concerned the teacher's perception about their school's mission and how the mission related to their own belief structure, while others referenced the extent to which teachers adapt instructional strategies and materials to support student individual need. A high score reflects higher levels of teacher's professional practices as in congruency with West Virginia's Integrative Initiative.

On this factor's five-point scale, the teachers had a group mean of 3.8 that had a range of 3.3 to 4.6. In comparison to scale's terms, this group mean had a response of "sometimes" and an upper range response of "usually." The item with the highest score stated, "School mission 
reflects philosophy that all children can learn" and the item with the lowest score stated,

"Teachers develop structured interaction programs."

Table 22

Lucas School Site Based Management School Climate Factor Analysis

Item $\quad \underline{M}$ SD

$\begin{array}{lll}\text { When faced with a mandate school takes proactive stance. } & 3.78 \quad .703\end{array}$

Faculty contributes to decision-making on how money is spent. $\quad 3.39 \quad 1.00$

$\begin{array}{llll}\text { Teams meet weekly to plan instructional support for all students. } & 3.81 & .865\end{array}$

$\begin{array}{llll}\text { Teachers implement behavior management strategies with team. } & 4.34 & .708\end{array}$

Administrators committed to enhancing professional knowledge. $\quad 2.68 \quad 1.33$

Teachers participate in decisions on duties outside the classroom. $\quad 3.68 \quad 1.06$

The design of progress reports reflects school's mission. $\quad 4.15 \quad 966$

$\begin{array}{llll}\text { Philosophy supports need for ongoing training, technical assistance. } & 4.11 & .717\end{array}$

Decisions about how money is spent consistent with school mission. $\quad 3.10 \quad 1.00$

The second scale, Site Based Management School Climate, contained nine items that referenced the extent to which administrative decisions and the decision making process involved teacher participation. A high score on this scale reflects that teachers perceive as having a higher level of participation in administrative decision making activities. Such scores have congruency with the West Virginia's school site based management mission. The school had a group score of 3.6, or a response of "sometimes." This mean had a range of 1.65 with a minimum response of 2.6 (rarely) and a maximum response of 4.3 (usually). The item with the lowest score and largest standard deviation stated, "Administrators are committed to enhancing their professional knowledge." The item, "Teachers implement positive behavior management strategies with team" had the highest group mean (see Table 22). 
Table 23

Lucas School Collaborative Teaming Factor Analysis

Item $\quad \underline{M} \quad$ SD

Teachers collaborate to make material \& environmental adaptations. $\quad 3.61 \quad .784$

$\begin{array}{lll}\text { Related service staff provide services in general classroom. } & 3.59 & .947\end{array}$

Teams collaborate to provide related services in inclusive settings. $\quad \begin{array}{lll}3.59 & 1.04\end{array}$

$\begin{array}{lll}\text { Teachers collaborate to adapt learning objectives in core curriculum. } & 3.70 & .701\end{array}$

$\begin{array}{lll}\text { IEP meetings use a transdisciplinary approach. } & 4.00 & .777\end{array}$

Educators collaborate to write joint IEP goals and objectives. $\quad 3.68 \quad 1.27$

The third scale, Collaborative Teaming, consisted of six items. This scale's items referenced items concerning the teacher engagement in collaborative and teaming activities that support inclusive practices for students with disabilities. One a five-point scale, a high score suggests that teachers perceive to participate in higher level of shared decision making practices to address individual student need. The school had a group mean of 3.6, or a response of "sometimes." This mean had a range of .409 with a minimum response of 3.5 and a maximum response of 4.0 (usually). According to Table 23, the item, "IEP meetings use a transdisciplinary approach" was the only statement to have a score of 4.0.

The final scale, Student Involvement, contained seven items. The items in this scale related to the extent teachers perceived school activities to involve students with disabilities. A high score on this scale suggests that teachers perceive student with disabilities as having a relatively high level of involvement in school activities and interaction among their peers. The school had a group mean of 4.2, that represents "usually" on the response scale. This mean had a range of .6136 with a minimum response of 4.0 and a maximum response of 4.6 (usually). It is noteworthy that no items rated below 4.0 (see Table 24). The item "All students participate in music, art, and gym classes," had the highest score and smallest standard deviation. 
Table 24

$\underline{\text { Lucas School Student Involvement Factor Analysis }}$

Item

$\underline{\mathrm{M}} \mathrm{SD}$

$\begin{array}{lll}\text { Students with disabilities are involved in extra-curricular activities. } & 4.15 & .805\end{array}$

$\begin{array}{lll}\text { IEP objectives reflect interaction with non disabled peers. } & 4.13 & .632\end{array}$

$\begin{array}{lll}\text { Remedial programs available for students not experiencing success. } & 4.06 & .846\end{array}$

$\begin{array}{lll}\text { All students participate in music, art and gym classes. } & 4.68 & .561\end{array}$

$\begin{array}{lll}\text { Students with disability instruction incorporates interaction. } & 4.15 & .680\end{array}$

$\begin{array}{lll}\text { All students participate in general education classes. } & 4.18 \quad 691\end{array}$

$\begin{array}{lll}\text { Students with special needs participate in school activities. } & 4.31 & .601\end{array}$

Table 25 reports the teacher's group scores for each factor. This table also demonstrates the special, regular, and related arts teachers' group scores. In comparison the related arts teachers had the highest group score for each factor. The special educators, on the other hand, had the lowest group score for all four factors.

Table 25

Lucas School Teacher Survey's Teacher Mean by Factor

$\underline{\mathrm{M}}$

Factor

Total Special Regular Related Arts

$\begin{array}{lllll}\text { Professional practice } & 3.8 & 3.4 & 3.8 & 4.1 \\ \text { Site based management } & 3.6 & 3.5 & 3.9 & 3.9 \\ \text { Collaboration } & 3.7 & 3.0 & 3.7 & 4.0 \\ \text { Student involvement } & 4.2 & 4.1 & 4.2 & 4.5\end{array}$




\section{$\underline{\text { Teacher Interview }}$}

This study conducted nine interviews with teachers by grade, content area and special education affiliation. Eight interviewees initially signed up for an interview at a faculty senate meeting and the researcher then sought the participation of an additional participant to provide equal representation. The theoretical propositions established in this study were used to guide the analysis of the interview data. To this end, a qualitative analysis involving a pattern matching strategy was used to identify the themes derived from the recommendations described in the $\underline{A}$ Strategic Planning Guide for West Virginia Faculty Senates (1994) and the Lucas School Strategic Integration Plan. This analysis also identified two additional themes unique to the interviews conducted with Lucas School. The section below describes these themes.

Integration plan effects on practice. The organizational structure of Lucas School is relatively new. In 1992, the county changed their junior high model of schooling to a middle school. As a result, the school reorganized the teachers once grouped across the grade levels by content areas into teams grouped across the content areas by grade level. In other words, the school no longer identifies all science teachers as one team. The school instead now groups a science, social studies, language arts, and mathematics teacher as a team. In response to these changes one teacher commented, "The middle school concept allows us to talk about students and to meet as a team in parent conference, whereas, before we each had to do it on our own."

In 1996, the county again restructured the school. The school added the fifth grade to their six, seventh, and eighth grade model. Also at this time, the school replaced the special education resource classes with an inclusive regular education delivery model. As a result, the majority of students with learning disabilities that once attended a resource class for language arts, math, and reading, now receive their services in a regular classroom. The special educator, therefore, no longer serves as the primary teacher, but provides consultative support to and in the regular classroom. One interviewer explained, "We went from always having our kids in that basically the only classes we had to worry about outside our classes was science and social 
studies classes." In response to how this changed their role, they stated, "I no longer have a classroom and last year I did not teach any classes."

Staffing and collaboration. Each team, including the special education consultant meet on a daily basis. From several observations, the teachers were seen grading papers, writing lesson plans, and informally talking as a group during these times. From the regular educator's point of view, in addition to their math and language arts classes now including students that once attended a resource setting, they also have another teacher coming in the room to work with students. The interviewees reported, however that they have not necessarily altered their teaching styles as a result of these changes. They did say that the special educator was primarily responsible for making such changes as reading tests aloud, reducing response choice options, and providing prompts to assist student to locate information.

Interviewees also discussed how their teams sought school improvements by making recommendations to the Principal. For example, one team talked about how they requested to adopted a block schedule to increase student time in class. A special educator shared how last year she did not have a time to work individually with her students. Her team requested to change this and as a result the teacher reported, "This year I do have kids from one team in the morning for an exploratory and then I have the other team for third period which is called skill enhancement class." In addition to providing the special educator direct instructional time with their students, the teams also changed how they assigned students to a class.

They put a lot of slow kids in there together because they thought well I could help them too: so it was like having a whole class of LD kids. It was terrible. . . This year they're split up into two different classes instead of one.

Because these changes resulted at the request of teacher's suggestions they imply that the school gives value to teacher decision-making.

Training. The interviewees gave conflicting opinions toward the issue of whether the school provided training. The statements ranged from the comment that there has not been any training to the response that there had. This teacher's response may clarify the confusion. They 
stated, "There has been discussions during different meetings, but I haven't really been trained on how to deal with inclusion students." Another reported, "We had some inclusion training, but the problem that I think, specifically, is that you have old teachers who are not receptive to special education students and I don't know if there is anything that will change attitudes toward that." A third teacher talked about their training experience that included the opportunity to visit other schools. Unfortunately they did not perceive this training as beneficial. They said,

I knew it was ridiculous for them to send us there because we don't even compare. They had a total of 28 special education kids and that includes all exceptionalities. It was everything. Here we were with that many in every grade level so there wasn't really another school that would even compare to ours because our numbers are so high. Student and community involvement. The teachers interviewed did not make a distinction between students unless they were directly asked to. Stated differently, when the interviewees talked about their students, they did not single out a particular group as having a different set of concerns. They instead approached issues in a collective manner to imply that student involvement included everyone. To this extent, teachers shared how their school offers several school-wide programs that all students participate in. For example they mentioned the exploratory class, the after lunch intramural sport activity, and the Responsible Student Program. One teacher talked about how school also cultivates teacher-student mentor relationships through their Ladders program. According to their description, students not doing well in school because of behavioral and or academic reasons have a teacher mentor that they meet with on a daily basis.

In reference to community involvement, the interviewees mentioned how parent teacher conferences, grade reports, newspaper announcements, and after school activities, such as the talent show, involved parents with their student's education.

With respect to how the school restructured their special education delivery model, the interviewees overall gave a positive regard toward having the students with IEPs in the regular classroom. Several shared this teacher's outlook: 
In my opinion, it's extremely rewarding for the LD student to go into a regular classroom and have some success. So in that sense yeah it's working. It's building their selfconfidence, self-esteem, that they can fit in with every body else.

Others commented as this teacher did, "There may be some teachers who don't like that [inclusion], but that's not a real issue here, that I know of." Regular and special educators expressed the opinion that the inclusion model met the needs of most students, but not all. Several commented that some would benefit more from a resource model. This teacher's comment best captures the opinions given, "I've been on both sides and I think inclusion does work, but I think that sometimes there needs to be more support for certain students."

Faculty Senate. Each interviewee described their faculty senate by talking about their different committees. This may be a reflection of the fact that as one teacher explained, "Everybody is on a committee whether you want to be on one or not, you're assigned." The general opinion that these committees helped shape and determine the school's practices was evident by the fact that almost all interviewees at one point or another listed the areas in which the faculty senate made decisions. These references included the areas of: student and teacher recognition, school beautification, grant writing, and finances. Very few, however, cited specific activities to exemplify what their decisions accomplished. The discussions, instead, included broad general statements as typified by this curriculum committee member's comment, "We can make decisions [and] its hard to over-ride it: they have a lot of power as far as curriculum." When asked to give examples, their response was, "Well we do a lot of things."

Several teachers also talked about how the faculty senate was of benefit because it brought the faculty together, while others mentioned that the faculty senate moneys as benefit because they provided teachers with computers and classroom materials. From discussions about their school's programs, two teachers praised how the faculty senate provided a day to reward students for good behavior. Students that do not have any 'reminders' from the Responsible Student Program may opt to stay home. 
Faculty Senate impact on teacher morale. In almost half of the interviews, teachers provided unsolicited comments about how the faculty senate also created negative outcomes. For example one stated,

Personally I don't like the time it takes away from the classroom. I know it's a positive step toward you know the teachers being more involved in the decision-making in the school, but I do resent the time that it requires.

While another also supported the notion that "faculty Senates give teachers more authority in making decisions," they contended that, "it has started controversies too." They explained, "Anytime you have teachers making decisions, then it pits teachers against teacher: I personally feel the administrations hide behind that sometimes." Others also supported this concern. "Yeah we make decisions, but at the same time I wonder if it wasn't better when the principal just made the decisions." They later explained,

I don't enjoy Faculty Senate Day. I'd rather deal with the students all day then deal with the adults. I think the money thing has kind of divided our faculty because there are some who get upset when things don't go their way and sort of thing.

Another interviewee suggested that the faculty senate created cliques within the faculty. Because the faculty senate announces the agenda in advance, the teacher explained that teachers try to influence one's vote. "There is no longer a surprise like we had in faculty meetings."

From these opinions the role of faculty senate and their decision-making clearly has an impact on teacher morale. This relationship suggests that the faculty perceives the administrator's role as one that should regulate and strike a balance between the faculty senate's authority and their level of cohesion. One may speculate that these comments reflect past negative experiences. The fact that a great number of the teachers spoke favorably about having a new principal this year supports this assumption. Their tone and comments that they were so far pleased with this administrator's work suggested that they saw hope for improvement.

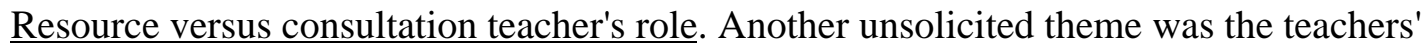
need to distinguish between the different special educator's roles. The consultants talked about 
their role in relation to their team and school. The special educators from the resource delivery model focused upon how they were different and often detached from the rest of the school. One supported this notion with the comment, "They have no idea what we do down here, I am in a different world." It is also noteworthy that the consultants referenced other teacher's names with respect to whom they work with, while the resource interviewees did not. When they were asked if they as special educators met formally or informally as a group, the consultants stated that they primarily worked with their team. One resource teacher's comment, on the other hand, suggested that there was some tension between the different resource teachers. "We talk occasionally, but [the other teacher] doesn't want to deal with the lower functioning kids." "I don't care what they do: I am here for my kids."

\section{Case Study Profile Summary}

Lucas School's integration plan primarily addressed the organization's components from a philosophical rather then a pragmatic point of view. Although they included several goals that addressed the systemic practices that involve such activities as: community partnership; student opportunity to learn; staff training; and accountability measures, the statements did not clearly indicate that the school's intends their practices to facilitate individual need. In other words, the plan described qualities that one does not necessarily or commonly associate with concerns directed toward students with special needs. The plan also lacked detail to such management issues as role defining, scheduling, and staff needs. As a result, it did not demonstrate how their commitment is an effort that effects or relates to their organizational structure of schooling and how they manage the appropriate placement of students with exceptional needs in the regular classroom.

It is noteworthy that the special education delivery model at Lucas School has undergone several changes in the past few years. Several of these changes occurred after the state mandated these plans and therefore one can not say that the plans served as the impetus. Specifically, the school redefined the role of the learning disability teachers two years ago. The following is a list 
of the changes the school has made as noted by the school's integration plan, teacher interview and observation data.

1. The school restructured the students with learning disabilities' classroom assignment from a resource setting to a regular education classroom.

2. The school assigned one special educator to each grade level to provide consultation.

3. The school added a skills enhancement class in replacement of reading.

4. The school implemented the Responsible Reminder Program as an incentive disciplinary program.

5. The school equally divides the students with learning disabilities among the teams.

The restructuring of the school's special education delivery model redefined the learning disability teachers' role. As consultants, these teachers no longer plan and implement the student's instruction but provide supports to the regular education classroom. Each team content teacher also now instructs students, who previously had reading, language arts, and math in a separate setting. This change in placement has had an impact on these teachers by directly involving them in the student's program of study and IEP goals. The consultants, on the other hand, continue to work with these students but under a different model. This model changes the orientation of decision-making from what to teach to how to support. Their instructional decisions are in direct relationship with and relative to the context of the general classroom. In sum this consultative model directly increased the number of teachers involved in the decisionmaking process and accountable for the instruction concerning students with IEPs.

The interviews also reveal the special educator's role influenced how they perceived their involvement with student decision making. Stated differently, within the data concerning special educators they reported different levels of decision making involvement. Both maintained a responsibility toward their student's program of study but the consultant discussed how they shared this role with their other team members. The resource teacher, on the other hand, did not report that their involvement included decision making with others. Because the majority of their 
students spend most of the day in their classroom, the persons involved with decisions concerning these students primarily remain with that individual teacher.

The regular educators reported that the special educator's consultative role increased their interaction to include them. Because this model increased the number of special education students in their classrooms, it simultaneously increased the number of teachers involved in the decisions concerning those students. These teachers however did not report that their decisions changed necessarily as a result of having students with IEPs. The person for whom they interacted did. This is to suggest that the model did not introduce decisions to modify their instruction but rather it increased the number of decisions by the number of students they make these accommodations for. With respect to the related arts teachers, they reported that they forever had students with IEPs in their classrooms. This may be indicative of their having the highest group score on the teacher survey's student involvement and professional practice factors.

Interviewees noted how their school has increased the students with learning disabilities' level of integration. The resource teachers, on the other hand, reported otherwise and shared the opinion of feeling isolated from the school. The observation data may explain this contrast. According to the school's Fall 1998 student records, Lucas School had a student enrollment of 500 students in the grade six, seven, and eight. Of these students 21 percent or 107 students had an IEP. In comparison, 55.5 percent or 62 students received their services under the consultative model while the remaining 44.5 percent or 47 students received their services in a special education classroom. Nine percent of the student body and seven of the school's fourteen special educators therefore spend the majority of their school day in a separate setting. In comparison 91 percent of the student enrollment have class in an integrative setting where four special educators serve as consultants and share a planning period with two teams per grade level.

With respect the teacher's decision making involvement, the observation, teacher survey, and interview data each report that the majority of teachers perceive themselves as having a relatively high level of involvement in collaboration and school level decision making activities. 
For example in the teacher interviews, several teachers talked how their suggestions influenced school practice. The consultants talked about how they have changed student class assignment and created times to work one on one with their students. Two resource teachers talked about how their school added a new teacher this year as a result of their report of having too many students in their program. In short the teachers shared how the school valued their recommendations. On the teacher survey, the teachers had a group score of 3.6 and 3.7 for the site based management climate and collaboration respectively. The comparison of these two figures also suggests that the teacher perceive their levels of involvement in school's administrative decisions closely match how the teachers perceive their level of engagement in collaborative and teaming activities.

The observations conducted at the Lucas School's Faculty Senate meetings also noted how teachers influenced school level decisions. All teachers are a member of a committee and every committee met before the faculty senate meeting. During these meetings, the committees gave reports. Teachers asked questions and provided response. It was of the general opinion that these committees helped shape and determine the school's practices as evident by the fact that almost all interviewees at one point or another listed the areas in which the faculty senate made decisions. Several shared how different groups wrote grants to support new programs and teacher training opportunities and at one faculty senate meeting the principal acknowledged these teachers' contributions by presenting them with a plaque. 


\section{$\underline{\text { Bucknell Middle School }}$}

Bucknell Middle School is the only middle school in a county of eleven schools. It is the second largest and serves grade sixth, seventh, and eighth. Their student enrollment of 1,031 represents one-forth of the county's student population of 4,265 (West Virginia Department of Education, 1997). In comparison to other counties, this school district's percentage by rank order of students receiving special education services was 49 out of 55. In other words only 6 other counties had a lower percentage of students who received special education services whereas 48 counties by rank order had a higher percentage.

During the months of September through December, 11 on-site visitations were conducted. The study collected field notes during these times were to gain a more detailed understanding about the school. These notes included the observation of events as they occurred throughout the school day and at two faculty senate meetings. The section below reports the results of this data collection's analysis.

\section{$\underline{\text { Observation }}$}

The county built the school over fifty years ago on the outskirts of their districts largest town. The building sits right off the main road near a traffic light that enables cars to enter and exit a busy shopping plaza located across the street. Although the light is not intended for the school, it nonetheless allows one to enter the school parking lot at a reasonable speed so to maneuver over its many pot holes. Visitors may also access the school from the circular drive that spans the front of the building. Yet, depending on the time of day, this is where buses often park. For this reason, visitors may not leave their car there for any length of time.

It is apparent by this school's series of additions that the building has undergone a history of changes. The original building's faded masonry and worn entrance steps echoes that there was once a time when one probably considered this three-story building to be a grand and stately facility. Yet, it is not the years of wear and tear that diminishes this building's character. It is rather due to how the additions pronounce a contrast. These one and two-story flat roof additions typify architecture of the 1970s. They lack windows and the windows that they do have are much 
smaller in comparison. Their construction is also of brick, not stone and their ceiling height fall several feet shorter then that of the original building's. Notwithstanding these different proportions, the settings' overall depreciation suggests that this school once experienced a more prosperous time. In other words, while the additions provide evidence that there once was a for need of expansion, its premature aging also suggests that this time of good fortune has passed.

Indicative of a school building this age, the main hallway's wide polished wooden floors and lofty ceilings create a quiet austerity. The sixth grade students at one end of the hall are the only one to interrupt this atmosphere when they change classes. On the opposite end, there are two large administrative offices. Often one finds parents and students sitting on church-like pews positioned outside the office doors. Above their heads a peg board reads, "Every child, every young person, every adult was designed for accomplishment engineered for success and endowed with the seeds of greatness."

Other assortments of school paraphernalia fill this hallway. Several wooden trophy cases and school banners that announce "Just be yourself" and "Recognized school of excellence," adorn the walls. A large bulletin board posted upcoming school and community events and newspaper clippings that recognized the school's honor role students. The hallway also contains several glass cases. They exhibit student made posters about the school's Tobacco Use Free club, artwork by Georgia O'Keefe, and information about the school's Weekly Incentive Plan that displays prizes the students may earn for good behavior.

The main building's third and first floor mimic the second structurally. The only difference is that rows of blue lockers and classroom doorways line the entire hallway. The classrooms for one sixth grade section and a severe and multiple special education classroom occupy the third floor. Because no other students have a reason to up there, the hall is quiet. Various items such as kick balls and other sport equipment fill the corners of the hall while storage boxes sit on top of the lockers. Student work and inspirational posters, "It's normal to be yourself" fill the empty wall spaces. The first floor, in contrast, has fewer decorations and is traveled more by others. In addition to having classrooms designated for special education and a 
section of seventh grade, this floor also provides the only access to the remaining sections of the school. Students and faculty must use this hallway to reach the gymnasium, library, and cafeteria.

The several plaques adorning the entrance of one wing indicate that the school added a four-room addition off the first floor in 1994. The purpose of this addition primarily serves as the school's computer lab and the learning disabilities' resource program. On the opposite end there are several additions that the school added at different times. The oldest addition provides space for a large cafeteria and gymnasium. In 1971, the school added another wing that adjoins these areas in the shape of a "T." This area provides space for a large library and over twenty classrooms that serve two eighth grade sections and one seventh. In 1977 the school lengthened this hallway to provide room for choral and band facility. In 1994, the school again expanded its space to provide for their technology education programs by building a separate facility behind the main building next to this "T" shaped wing. Students access these rooms from the outside from either facility.

In sum the design of the school's additions creates a maze of hallways that singularly lead to separate areas representing each grade level or section. As a result, it is easy for a visitor to become disoriented. Often one has to stop and think how to access one area from another. Yet despite this confusion, the posters and student work adorning the walls help identify each area by team. The office also provides visitors with a guide to lead them to where they want to go.

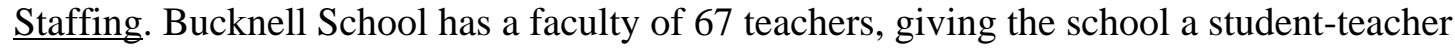
ratio of 15.6 students to 1 teacher. The middle school organizes the majority of its staff by teams. Each team, identified by a letter, consists of five teachers that provide instruction to the same students from one grade level. Their area of instruction includes: English; mathematics; reading; science; and social studies. Three of these eight teams have a special educator as an additional member. The remaining faculty referred to as 'out-of team' teachers, represent the related arts block and the remaining nine special education teachers who work in self-contained setting. The related arts block represents different classes (band; French; health and wellness; physical 
education; home economics; and music) whereas special education block represents different programs (learning disabilities, behavior disorders, severe and multiple and gifted education). Unlike the other teams, these teachers teach across the different grade levels and do not share a common planning period.

The school assigns each student to a team by ability level. Those three teams that have a special education member primarily serve the lower achieving and learning disabled students whereas the other teams serve the higher achieving and gifted education students. The school assigns all students that do not have a majority of their classes in a regular education setting to a special education program. Two teachers each teach students mental impairments, learning disabilities, and behavior disorders and three teachers teach in the severe and multiple disabilities, moderate mental impairments, and gifted education program. Unlike the other teams, these eleven teachers do not necessarily instruct the same students and they teach across the grade levels. As a result, students with behavior disorders for example have one or two teachers, not five, for all of their subjects and their classrooms also have not one level but a mix of sixth, seventh, and eighth graders.

The classroom observations noted that the self-contained classrooms differed in many respects to the regular education's setting. In addition to having fewer students, the special education settings were physically smaller and crowded. Students had little space between their desks and their seats were practically on top of the teacher's desk. This limit of space may attribute to the observed opinion that the teachers continually dealt with behavior management concerns. In one class two to three students worked one-on-one with a teacher while the others worked independently at carrels. When the teacher was asked why some students worked alone, they responded that the students were not ready to join the group. In several classes the teachers also had a point system to monitor student compliance. During several observations students received points and as a result lost their recess privilege.

Collaboration. The delivery of service model at Bucknell School has undergone many changes. As one teacher explained until 1983 all students with IEPs took classes in a self- 
contained classroom. Today, one section from each grade level now has a special educator as a team member they referred to as the strategy teacher. In this model, these three teachers spend their time both in a resource classroom and a regular education setting. For example, one teacher has two sections of special education English and a strategy class that only include students with IEPs. They also teach remedial math and social studies in an inclusive setting. These classes contain regular and special education students and the regular educator primarily leads the instruction. As a team member they share a planning period to meet regularly with the student's other teachers. According to one teacher, they have discussions about individual students and plan instructional modifications to better meet the student's level of performance.

The teachers from the special education program, on the other hand, collaborate by area of disability rather than with the other teams. For example, the two teachers of mental impairments were observed meeting together during lunch where they discussed their students' progress. According to one teacher however, they rarely meet with the other special educators even though one or two of their students may take classes across the programs. In other words, the behavior disorder and mental impairment teachers do not plan instruction together. According to several interviews, they also do not meet with the special educators assigned to a regular education team.

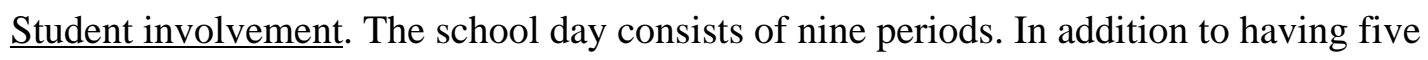
core classes, the students rotate among the different related arts' classes on a nine week cycle. They also have a daily recess and an advisory period once a week. During advisory, all students meet with a teacher to discuss different theme topics. For example, the school devotes each month to such topics as study skills, test taking strategies, and career development. Because the school does not group this class by teams, the students gain an opportunity to work with classmates and teachers that differ from their routine schedule. It also provides the students in the special education programs with at least one class in an inclusive setting.

According to the school's 1998 records, two teachers of behavior disorders and learning disabilities, and four teachers of mental impairment respectively taught 17, 21, and 38 students in 
a separate class setting. As defined by the West Virginia's Regulations for the Education of Exceptional Students (Policy 2419), the setting represents a separate class where the teacher delivers specially designed instruction for more then $60 \%$ of their day. Table 26 reports that 73 students had such a placement at Bucknell Middle School. Within the regular education teams 90 student received services from their team's special educator.

Table 26

Bucknell Middle School Special Education Delivery Model.

\begin{tabular}{|c|c|c|c|c|}
\hline \multirow[b]{2}{*}{ Class $^{\mathrm{a}}$} & \multicolumn{3}{|c|}{ Special Education Team } & \multirow{2}{*}{$\frac{\text { Regular Education Team }}{\text { LD }}$} \\
\hline & $\mathrm{BD}$ & LD & MI & \\
\hline $0-1$ & 1 & 2 & 3 & 52 \\
\hline $2-3$ & 1 & -- & 6 & 30 \\
\hline $4-9$ & 17 & 20 & 38 & 8 \\
\hline
\end{tabular}

aClass $=$ Number of times the student attends a separate setting outside the regular classroom.

The school also offers several integrated school programs. Students may choose to participate in such sport activities as, football, baseball, basketball, track, and wrestling or a student math club after school. This year the school added an Early Bird Homework Program. Each morning, instead of playing outside, students may choose to report to the library and work on homework with a volunteer teacher. Four years ago the school also developed the BUCS program (Building Up Conscientious Students). This program intention is to encourage the student's sense of belonging by rewarding them for complying with eight basic school rules (e.g., entering appropriate doors at the beginning of school). Its purpose established a set of expectations that all students must follow and all teachers must reinforce by providing incentives. The school weekly rewards the teams that have the fewest violations by providing them with the opportunity to go to lunch first. At mid term the teams with four or fewer 
violations get to "hang out" for a class. The school also enters individual students with less then one violation in a monthly prize drawing and reports their achievements in the local newspaper.

Faculty Senate. Each meeting informally began with the opportunity for teacher to socialize over the refreshments and food that different teams provided on a rotating basis. On one occasion the school used the library and on another the cafeteria to provide enough seating for this large group. After 20 to 30 minutes of informal interaction, the President called the meeting to order. During this time several graded papers while others sat with their focus on the speaker.

Each meeting used a similar format. After the reading of the minutes, the President called upon the different committees to give a report. At their first meeting the President spent this time encouraging others to join the various committees. She stressed the importance of their participation and raised the fact that few of the men were members. The faculty then passed a sheet around to list the different team membership and to elicit new participants. After this time a member of the Xerox Committee gave an elaborate report of how they did not have enough funds to support their use of materials. Several teachers responded in attempts to rectify this situation. One fervently mentioned that it should not be the faculty senate's responsibility to fund their basics needs. Others stated that the minimum weekly paper allowance was insufficient. Because they could not reach a resolution, the President tabled the issue and brought up again at each meeting there after.

The other committees gave reports in a far less time. Several reported no new business while other made brief announcements. For example the student assistance team announced that they had started their Early Morning Program and solicited teachers to volunteer. The Nicaragua relief ad hoc committee stated that they were still collecting ten dollar donations. Others, like the Health Wellness Committee stated that they did not have any new business to report. At one meeting, the faculty formed a three-person ad hoc committee to investigate and report on the PEIA teacher benefit changes. They announced that they would meet and present a response letter for the Legislature at the next faculty senate. 
The meetings then ended with a time for the Principal to speak. At the first meeting he discussed the fact that this was his first year as Principal and praised the faculty for their help. Each meeting there after the Principal discussed the disciplinary committee's progress. He stated that the committee intends to submit their policy proposal to each faculty member for their review. In this document he asked for teachers to examine several modifications. For example, the committee will propose to provide students with a behavior contract instead of having them attend an in-school or out-of-school detention. He also stated that they will consider new incentives, such as a school store, to reward students. During this description the faculty sat and listened. No one asked questions nor gave comments to this report.

Each meeting ended prior to the end of the teacher's work day. After a faculty member motioned to adjourn, different committees announced that they planned to use this spare time to meet. The President reiterated these requests and stated the rooms where the different committees would meet. Everyone exited the room to finish their day as they saw fit.

\section{$\underline{\text { Strategic Integration Plan }}$}

Bucknell Middle School prepared a two-page inclusion plan that serves as an addendum to its school wide mission and goal statement policy. This section presents an analysis of their plan for the purpose to provide a framework of reference to how the school promotes inclusive practices. To accomplish this, the analysis used a pattern matching strategy to compare the school's plans with the state's recommendations in A Strategic Planning Guide for West Virginia Faculty Senates (1994). This examination however omits the need component analysis because the school's plan only included four of the five required components.

Table 27 presents how school's mission statements related to the state's recommended components. The Bucknell Middle School's mission stated (see Appendix F-3),

The mission of the school community is to create a safe school where all children will learn essential skills, experience the feelings of being valued, learn to respect responsibility, and contribute to the quality of our school. Through the shared 
responsibility of staff, students, and the community, we are committed to excellence be teaching for all learning.

In comparison to the Integrative Initiative's themes, the school's mission statement speaks to the areas of student and community involvement in terms of their responsibility and contribution toward the quality of the school. From a contextual orientation, the school's mission specifically lists the experiences the school will provide each student. Their purpose thereby serves to exemplify how the school supports their commitment to "teaching for learning for all." Because these experiences broadly apply to all children, it is not clear whether their focus supports an inclusive setting. The mission instead describes the school's purpose toward students without articulating a model by which they will achieve them.

Table 27

Bucknell School Mission Component Analysis

\begin{tabular}{llcc} 
Audience & Action & Aim & Importance \\
\hline Community & create a school & learn essential skills & committed to teaching \\
& & learn to accept responsibility & for learning for all \\
& contribute to quality of school & \\
& experience feeling of being valued \\
\hline
\end{tabular}

Table 28 cross references the school's mission statements with the belief statements held by the West Virginia Integrated Initiative. The school's mission statements state two of the four recommended beliefs. One statement contains the same wording while the other implied similar meaning. In contrast the school's mission does not address nor imply the recommended beliefs that refer specifically to the topic of integration. This may be due to the fact that the school did not write a mission for the plan's purposes. The school only made the plan as an addendum to their existing mission and goal statement policy. Notwithstanding, the mission does not contain statements that correlate a need with an outcome. For example, the school omitted the two 
recommended areas that stipulate the relationship that integration fosters life-long learning and student's potential is better realized when of spectrum of opportunities occurs with peers. The school, instead, included only those beliefs that describe what the education is (education promotes success and education is a shared responsibility), but not why it is so.

Table 28

Bucknell School Mission Statement Analysis

Source Bucknell Mission

State Quality education reflects our diverse society, supports \& promotes the success of all students.

Bucknell Teaching for learning for all.

State Shared responsibility of staff, students, and community.

Bucknell

State Interaction with others fosters a life-long learning process.

Bucknell

State Each student's potential is better realized when a spectrum of educational opportunities occur with age-appropriate peers in home school settings.

School

Table 29 pairs the school's goals with the corresponding West Virginia Integrated Initiative recommended goals. Two of the school's seven goals related to only one of the five recommendations. Notwithstanding of how each of these recommended goals specifically speaks to activities that support, encourage, promote, and evaluate an integrated education, the school's remaining six goals did not address items that remotely relate to these types of activities. For example, the school stated the goal to: maximize individual student achievement; to develop and encourage programs which will promote technological literacy; and to create a safe and orderly environment through the implementation of policies and programs. As a result of these differences, it is of question to the extent the school followed the guidelines provided by the 
state. It is also noteworthy that the two shared goals are common to the extent that they target similar areas of concern (e.g., parent involvement and collaboration) but do not necessarily imply that they serve the same purposes (to promote an integrative education).

Table 29

Bucknell School Goal Analysis

Recommendation School Goal

Technical assistance

Positive partnerships Increase parent involvement in achievement of the goals and objectives of our school.

Encourage the spirit of collaboration among all teachers, students, administrator, parents and citizens in our community.

Comprehensive training

Student-based funding

Accountability system

Table 30 presents the school's objectives and activity analysis. Unlike the school's mission statement and goals, their objectives and activities directly relate to the organizational dynamics of an integrative model of schooling. This focus concerns such items as teacher role defining, assignment, and training. The activities also state specific measurable outcomes. For example, the school wrote the objective, "to provide for the individual student needs" followed by the activity "to provide one more BD teacher to work as a transition person in the regular classroom." These statements together further one's knowledge about how the school intends specific tasks to accomplish their goals. Furthermore, the contents of the objective and activities, unlike the previous sections, support the meaning of the goals in manner that describes an integrative school model. The school's objective and activity component however omit four recommendations. These omissions specifically relate to how the teacher designed and 
implemented their instruction to accommodate individual student need and how the school supports an integrative model as experienced by the students.

Table 30

Bucknell School Objective and Activity Analysis

State Recommendation Bucknell School Objective

Administrative responsibility Add BD, MMI teacher for transition in regular class.

Regular educators for 6 and 7 grade self-contained classes.

One grade team assigned a special educator with same planning.

BD teachers contact regular ed. during planning as needed.

Need assessment for staff to plan training sessions.

Staff development recommended by need assessment.

IEP development

Collaborative teamwork Senate time for teachers to communicate with special educators.

Individual student needs discussed with regular teachers.

Professional practice

Student involvement

Interaction with peers

Table 31 compares the school's final section, evaluation, with the state's

recommendations. The analysis identified whether the evaluation activity occurred during the course of the implementation phase (formative) or at the conclusion of the implementation phase (summative). The analysis then determined fundamental reason for the stated evaluation and included the following purpose options: (1) to identify needed changes in the plan (process evaluation); (2) to provide data (outcome evaluation); and or (3) to illustrate effectiveness (impact evaluation). The analysis also listed the resources the school would use to conduct the evaluation and identified whether this procedure used performance and or judgment data. 
Table 31

$\underline{\text { Bucknell School Evaluation Component Analysis }}$

Component Analysis

School Evaluation Activity

Phase Purpose Resource Procedure

Team minutes

Summative, process evaluation team records (judgment $\&$ performance data).

Documentation (teacher assignments) Summative, outcome evaluation checklist (performance data)

Faculty Senate feedback (training)

Formative, process evaluation need assessment (judgment data)

Training feedback

Summative (impact evaluation) training evaluations (judgment \& performance data).

Special educator's meeting notes

Summative, process and impact evaluation team \& individual meeting log (judgment data).

Student success

Summative, impact evaluation test scores, grades (performance data).

Table 32 summarizes the themes derived from the state's recommendations by comparing them with the school's Strategic Integration Plan components. The school's plan does not consistently address the same areas across each of the plan's components. For example, the plan begins with a mission that promotes student and community involvement but it does not address these areas under the objective, activity, and evaluation components. In a similar fashion, the latter components dealt with staffing, collaboration, and training, that the school did not address in the mission and goal component. In short, the plan's mission focus is on community and student involvement while the remaining components focus on administrative functions.

The Bucknell School's plan targeted concerns related to collaboration in three of the five components and training and evaluation in two. These considerations relate to the organizational structure of the schooling. They promote inclusive practices by providing active interaction 
between, support for, and appraisal of the special and regular education teachers' associations. Their purpose is not teacher or student oriented but rather administrative in nature. For example, the components do not address specific classroom activities or teacher practices. They also do not include student concerns related to socialization, participation, and extracurricular involvement. The component's purpose deals rather with how the administration provides teacher planning and training time. In sum, it is in these areas that the school directly reflects the plan's purpose to promote integrative education, whereas the mission and goals only broadly support this purpose (see Table 32).

Table 32

Bucknell School Theme Analysis

Integration Plan Component

Theme Mission Goal Need Objective/Activity Evaluation

\begin{tabular}{lccccc}
\hline Staffing & -- & -- & -- & $X$ & $X$ \\
Collaboration & -- & $X$ & -- & $X$ & $X$ \\
Training & -- & -- & -- & $X$ & X \\
Student involvement & X & -- & -- & -- & -- \\
Community & X & X & -- & -- & -- \\
\hline
\end{tabular}

\section{Teacher Survey}

The survey's purpose was to determine the relationship between how the participants perceived their role as a faculty senate member and the degree to which their school integrated students with disabilities in the regular classroom. The survey's 30 items sought to determine the degree to which the school's site-based approach coupled with a student centered focus influenced teachers' perceived roles and responsibilities. At the Bucknell Middle School 56 teacher surveys were disseminated at a faculty senate meeting. A total of 54 teachers or $96 \%$ returned them. Only 51 teachers provided information regarding their subject and grade level 
teaching assignment. From this reported data, the participant's group affiliation was as follows: 7 special educators, 31 regular educator, and 13 related art teachers.

Table 33 presents the teacher survey data analysis of the professional practice factor variable. Items in this scale related to the professional practices that teachers provide in their classroom to support an inclusive schooling environment. While several items concerned the teacher's perception about their school's mission and how the mission related to their own belief structure, others referenced the extent to which teachers adapt instruction to support student individual need. A high score reflects higher levels of teacher's professional practices as in congruency with West Virginia's school inclusion mission.

Table 33

Bucknell School Professional Practice Factor Analysis

Item

$\underline{M} \quad \mathrm{SD}$

Teachers share common view about school, teaching, and learning. $\quad 3.59 \quad 680$

Teachers ensure interaction of special needs students.

$3.65 \quad .635$

Teachers adapt instructional strategies in content areas to meet (IEP). $4.04 \quad .721$

$\begin{array}{llll}\text { Teachers develop age appropriate materials to address student level. } & 3.93 & .818\end{array}$

School mission reflects philosophy that all children can learn. $\quad 4.57 \quad \begin{array}{ll}650\end{array}$

$\begin{array}{llll}\text { Teachers develop adaptations for students with special needs. } & 4.00 & .589\end{array}$

$\begin{array}{lll}\text { Teachers develop structured interaction programs. } & 3.59 & .741\end{array}$

Instructional staff demonstrate positive attitudes toward all students. $\quad 4.34 \quad .730$

On a five-point scale, the teachers had a group mean of 3.9. The range was .9787 with 3.5 as the minimum and 4.5 as the maximum. In comparison to the response scale, this group score had a response of "sometimes" and an upper range response of "usually." Two items had the lowest group score. They were, "Teachers share common view about school, teaching, and learning" and "Teachers develop structured interaction programs." The item with the highest 
group score stated, "School mission reflects philosophy that all children can learn." In comparison the teachers rated the item concerning school-wide levels of professional practice a score higher to items concerning individual teacher's level of professional practice.

The second scale, Site Based Management School Climate, contained nine items that referenced the extent to which administrative decisions and the decision making process involved teacher participation. A high score on this scale reflects that the school's administrative decisions positively support West Virginia's school site based management mission. The school had a group mean of 3.8, or the term "sometimes" on the response scale. This score had a range of 2.1 with a minimum response of 2.4 (rarely) and a maximum response of 4.5 (usually). Table 34 reports that the item, "Teachers participate in decisions on duties outside the classroom" was the only item with a score below 3.0. It also had the highest standard deviation. The item, "Teams meet weekly to plan instructional support for all students" had the highest score.

Table 34

\section{Bucknell School Site Based Management School Climate Factor Analysis}

Item $\quad \underline{M} \quad S D$

When faced with a mandate school takes proactive stance. $\quad 4.29 \quad 686$

$\begin{array}{llll}\text { Faculty contributes to decision-making on how money is spent. } & 3.88 & .857\end{array}$

Teams meet weekly to plan instructional support for all students. $\quad \begin{array}{lll}4.58 & .712\end{array}$

$\begin{array}{llll}\text { Teachers implement behavior management strategies with team. } & 4.41 \quad & .507\end{array}$

Administrators committed to enhancing their professional knowledge. $3.67 \quad .970$

$\begin{array}{lll}\text { Teachers participate in decisions on duties outside the classroom. } & 2.47 & 1.23\end{array}$

The design of progress reports reflects school's mission. $\quad 4.05 \quad 966$

$\begin{array}{lll}\text { Philosophy supports need for ongoing training, technical assistance. } & 4.11 & .781\end{array}$

$\begin{array}{lll}\text { Decisions about how money is spent consistent with school mission. } & 3.17 & 1.01\end{array}$ 
The third scale, Collaborative Teaming, consisted of six items. This scale referenced items concerning the teacher engagement in collaborative and teaming activities that support inclusive practices for students with disabilities. A high score on this scale suggests that teachers perceive to participate in higher levels of shared decision making practices to address individual student need. The school had a group mean of 3.6 or "sometimes" on the response scale. This score had a range of .547 with a minimum response of 3.3 and a maximum response of 3.8 . This small variance suggests that the teachers had a relatively high level of agreement on this factors items. The item with the lowest score, "Related service staff provides services in the general classroom" also had the largest standard deviation. "IEP meetings use a transdisciplinary approach" had the highest score (see Table 35).

Table 35

Bucknell School Collaborative Teaming Factor Analysis

Item

$\underline{M} \quad$ SD

Teachers collaborate to make material and environment adaptations. $3.60 \quad .706$

Related service staff provide services in general classroom. $\quad 3.35 \quad 1.04$

Teams collaborate to provide related services in inclusive settings. $\quad 3.70 \quad 898$

$\begin{array}{lll}\text { Teachers collaborate to adapt objectives within core curriculum. } & 3.70 \quad .701\end{array}$

$\begin{array}{lll}\text { IEP meetings use a transdisciplinary approach. } & 3.89 & .856\end{array}$

Educators collaborate to write joint IEP goals and objectives. $\quad 3.45 \quad 1.14$

The final scale, Student Involvement, contained seven items that related to the extent teachers perceived school activities to involve students with disabilities. The school had a group mean of 4.2 or a scale response of usually. This mean had a range of 1.16 with a minimum response of 3.7 (sometimes) and a maximum response of 4.8 (usually). A high score suggests 
that teachers perceive student with disabilities as having a relatively high level of involvement in school activities and interaction among their peers. According to Table 36, the item, "Remedial programs available for students not experiencing success" had the highest score. The item, "IEP objectives reflect interaction with non disabled peers" had the lowest score and it was the only item in this scale that had a score below 4.0.

Table 36

$\underline{\text { Bucknell School Student Involvement Factor Analysis }}$

\begin{tabular}{lll}
\hline Item & $\underline{M}$ SD \\
\hline Students with disabilities are involved in extra-curricular activities. & 4.14 & .880 \\
IEP objectives reflect interaction with non disabled peers. & 3.70 & .735 \\
Remedial programs available for students not experiencing success. & 4.86 & .298 \\
All students participate in music, art and gym classes. & 4.40 & .638 \\
Student with disability instruction program incorporates interaction. & 4.04 & .668 \\
All students participate in general education classes. & 4.60 & .764 \\
Students with special needs participate in school activities. & 4.14 & .670 \\
\hline
\end{tabular}

Table 37

Bucknell School Teacher Survey's Teacher Mean by Factor

\begin{tabular}{lllll}
\hline & \multicolumn{4}{c}{$\underline{\mathrm{M}}$} \\
\cline { 2 - 5 } Factor & Total & Special & Regular Related Arts \\
\hline Professional practice & 3.9 & 4.0 & 4.1 & 3.8 \\
Site-based management & 3.6 & 3.5 & 3.9 & 3.9 \\
Collaboration & 3.7 & 3.9 & 3.7 & 3.5 \\
Student involvement & 4.2 & 4.1 & 4.2 & 4.3 \\
\hline
\end{tabular}


Table 37 presents the scores for each group of teachers. In comparison, the related arts teachers had the lowest group score for professional practice and collaboration. They also had the highest group score for the school site based management climate and student involvement factor whereas the special educators had the lowest score for these factors.

\section{Teacher Interview}

This study conducted thirteen interviews. Six teachers represented each grade level and seven represented the special education and related arts block. Nine interviewees initially signed up for an interview at a faculty senate meeting and the researcher sought the participation of the additional four in order to assure equal representation. It was of interest for these interviews to gain detailed information about how they conducted their Strategic Integration Plan's process; why their plans contained its contents; and what obstacles they confronted as they carried out these procedures and decisions. Furthermore, it was of interest to know their opinions about each of these topics. The analysis used the recommendations described in the A Strategic Planning Guide for West Virginia Faculty Senates (1994) and the school's Strategic Integration Plan to reduce the data into themes. This analysis also identified two additional themes unique to the interviews conducted at Bucknell Middle School. The descriptions below describe these themes.

Staffing and collaboration. Across the interviews, teachers emphasized several distinctions when defining the staff's roles. A majority of interviewees pointed out how different teams worked with students representing different ability levels. Due to this distinction, half of the content teachers interviewed from each grade level instructed students with disabilities, while the other half did not. The teacher's level of collaboration with a special educator had a direct correlation with their team's configuration. Those teachers in a team without a strategy teacher consistently responded as this teacher did: "My team is not one of the LD grade teams, so all the students are served in another team that has an extra certified person." When they were asked if they work with any of the special educators, they mentioned the person by name and went on to explain how that teacher worked with the other team, not with them. Although two interviewees 
talked about a pervious year when a special educator approached them to take a student, none of these teachers reported that they currently interacted with a special educator.

The teams with a strategy teacher, on the other hand, explained how their team met as a group in team meetings. The level of interaction, however, differed across the interviews. Their level of collaboration had a direct relationship whether the teachers worked together in the same classroom. Although no one defined the nature of their collaborative interaction per se, one teacher commented,

Our previous principal talked about moving [the special educators] out of teams and I'm just like you don't know what you're asking. What benefits my kids reap by having those same people. Well I know how they teach and their methods.

In reference to how their teams met, one teacher stated, "We meet when there is a need: some teams meet everyday." They went on to explain,

Our team leader will call, well anyone can, and say I really need to get together and talk about the problems with Johnny or Susie or how we are going to handle the next basketball game. You know, just what ever as a team kind of thing.

It is noteworthy that in the discussions with the team teachers no one made reference to the other eight special educators who work solely in a separate setting. Special educators, on the other hand, talked about each other in order to make a distinction. They pointed out the fact that they did not all share the same role: there was instead two kinds of special educators. One special educator suggested, "I think I have a different situation [and] you should talk to one of the selfcontained people." In talking with special educators from both settings, it was clear that their level of collaboration depended on their role or classroom setting. The self-contained or resource teachers reported as this teacher did, "No we don't have any team meetings because we don't have anything actually in common: like the LD teacher's there's nothing in common with them [that we] can work with." In contrast, the other special educators all stated that their teams met and that they each interacted on a daily basis with at least one other team member. 
Training. Two teachers mentioned that their school had a training session on inclusion a couple of years ago. "A guy was here only for an hour, an hour and a half, but you know it was a checklist thing: All we did was go over it." Two teachers from the related arts also talked about a summer IEP training session that they just attended at Fairmont State. When they were asked how they got involved, one commented, "We actually volunteered: they just opened it up at faculty senate and said we have this." As a result, a total of four related arts and a reading teacher went to represent the school. This person also later mentioned that they also attended a county staff development in the Fall on writing IEPs. Their evaluation was less favorable: "I didn't really feel that it addressed what I needed to do in a classroom."

The remaining interviewees did not talk about a particular training experience. Their responses were instead, much like this teacher's:

It is quite possible that there were members of this faculty who have, who did, who will attend different things depending on their availability, but I specifically did not and I don't know that anyone ever really did.

In sum, this teacher's comment emulates the school's overall sentiment, "We've had training sessions on inclusion ... Its just a problem that we're having is finding time to coordinate this whole program."

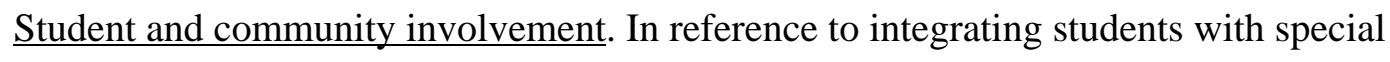
needs, interviewees referred to several changes that they are working on to increase student involvement. For example, one teacher stated:

Basically the kids are to be with as much as possible their ages throughout the day whether it be a class or a lunch or whatever. But I think the arts block which is art, music, and physical education will have all of these kids and try not to have them as a specific class but have them integrated with other students. ... In the past all the kids came to one class, it was a special ed. class at a special ed. time so now they have to split those kids up so that they aren't a special ed. class with three grades. 
While another teacher stated, "We also tried to make it so that they [special education students] were all out for arts block" they also added, "That was a real focus for us, the art, music, phys. ed., if they were capable."

The interviews with the related arts teachers confirmed that the school has made several changes with respect to their classes. In the area of home economics and industrial arts however there are still some classes that only had students with IEPs. "We felt that [we're] trying to get more kids into regular classes and out of the self-contained type environment: some will move this year into regular classes, but my ninth period is still sixth, seventh, and eighth graders all together." The teacher also positively added that these 'self-contained' classes were now smaller then a few years ago when the industrial arts classes had 22 students with IEPs.

Several teachers talked about how the school lunch period and advisory group also served as a time to integrate students. In reference lunch a teacher pointed out,

At least for a year we tried very hard to get every student eating with his or her grade appropriate lunch time because some of the special ed. classes where there my be 6th, 7th, and 8th graders all together to make it easier for the teacher. Another teacher however stated, "I know from doing lunch duty, I know some kids aren't in regular teams." During the weekly advisory period students also attend a class with a teacher from another team. One teacher explained, "We are still fighting this battle and I hope we win eventually because it is an opportunity for kids to get out of their team." They went on to say, "I have two self-contained EMI kids in my advisory group [and] I would like to see it be across the school." In contrast, another teacher stated,

[Advisory] is the real place where they try inclusion which doesn't work very well because I have some students in my advisory group that I only see for those thirty minutes a week who are from special education. They don't know who I am. They don't know any of the other kids and then we wonder why they don't participate in discussions. In sum these statements reveal that the teachers have an awareness that integration is an area that the school is trying to improve. From the discussions, it is relatively clear that teachers 
perceive it as an issue that relates to the general context of schooling and not necessarily to their classroom. In other words, the teachers talked about administrative type decisions that concern student scheduling rather then sharing about activities that they used or had control over to increase student involvement. It is noteworthy to share this teacher's comment, "The seventh grade team, up until two years ago never had LD kids." The teachers perceive that the school's accomplished level of integration is problematic. In the examples given to demonstrate how the school has attempted to increase student involvement they suggest that the school has not fully achieved their goals. This teacher's comment best captures the overall feeling about these efforts, "I think that integration isn't something that we do easily."

Faculty Senate. The discussions about the faculty senate were generally positive and supported with comments about how they had a good faculty. Many of the interviewees began their conversations by giving a synopsis of their meetings. For example one teacher began, "They go through business of like what's going on, do we vote for something or whatever, and then we eat and the Principal talks if needed." Another explained it this way, "We have eight to ten standing committees: They give their reports and then of course our principal is always given a little bit of time." Regardless of how they started, all the interviewees mentioned at least one of these three topics: the copier, committee involvement, and their discipline policy.

Although the copier was by far the most frequently mentioned topic, it also represented the least positive component of their conversations. While one teacher commented, "The copier has been the most divisible issue that we have dealt with and we are trying to come to terms with it" another pointed out, "Every month we talk about the copy machine and they always table that and keep putting off and putting off about using to much paper." Although their discussions were brief, they nonetheless captured the teacher's attitude toward the subject. This teacher's comment best exemplifies their predilection, "I think unfortunately, for us, we have the most dreaded word for anyone to mention as the faculty senate though is copier." Another explained, "The copier seems to be constantly eating up more and more of the money that we were going to have the 
discretionary funds to do some newer and more innovative things at our school." Several talked about this issue in relation to how their county levy failed and thus created a budgetary strain.

Almost all interviewees talked about their committees and their accomplishments. For example one stated, "We also applied for several grants which really helped out: one of which was to train a student assistance team that tries to address issues with at risk students." Another mentioned, "We were successful in getting a field trip policy in place." A member of the school beautification committee described how they started a Spring work day where students, faculty and members of the community spend a school day improving the grounds. One teacher also gave the example of how this committee rearranged the parking lot to prevent teachers from having to park on the street. In addition to these examples the majority discussed how their faculty senate dealt with their school advisory class, their BUCS student incentive program, and their newly formed discipline committee.

According to one teacher's statement, "Behavior is a big thing with the whole school: everyone is talking about how to control behavior and being consistent." Since the beginning of the year the discipline committee has been meeting twice a week. Interviewees explained that there were concerns about the in-school suspension program. Several teachers said that the committee wanted to revamp this program because did not appear to be effective. One gave this example, "Out of a thousand, maybe ten, but I'm sure there are students that have spent as many as 35 to 40 days in in-school, which is almost a quarter." In addition to having repeated offenders, several teachers commented that assigning teachers with a class period to monitor the in-school suspension was a problem. Others talked about an issue of consistency. Five interviewees expressed a feeling of relief that the school was looking into this matter. One teacher responded, "[We need] to discipline students on how they are not who they were." They later shared how the school did not discipline one student because his father was an administrator's friend. The over use of suspension with students with special needs was also a raised concern with respect to meeting compliance with state policy. 


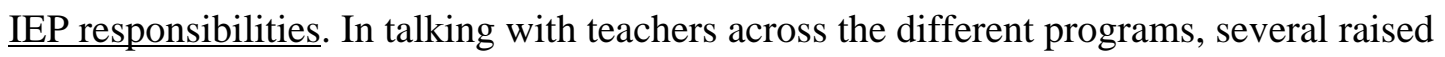
an issue about IEPs. It was of question who was responsible to monitor those students who attended classes across the programs. In other words, if the school assigns a student to the special education team, was the special educator or the strategy teacher the one who modified a student's regular education setting assignment? One teacher exclaimed, "We don't have time to modify all these tests for these regular teachers." Another teacher said, "We seem to have to do both at the same time, a job that maybe two teachers would be doing they are expecting us to do." Further discussion revealed that the school brought this issue to the county office's attention. With much grief in their voice a teacher said that county's response was, "I know, but you are going to have to [because] that's your job."

A different interviewee shared how she felt, "I kind of feel more responsible for these students that are out that I'm not helping them as much as I should." A regular educator added, "Unusually we try to put them somewhere where their might be a strategies teacher but that's not always possible because they are short on teachers too." When the strategy teachers discussed this issue, they too expressed a feeling of being short handed. "I know some of those kids: I do work with them but only in that limited time."

Teachers were asked how one determined whether a student attends the special education team or the regular education team's resource classes. One teacher commented, "That's an issue that's coming up." According to this teacher, the student's strategy teacher is the one responsible for their IEP. In practice this role has caused some confusion because some students with IEPs in the regular education teams have a different special educator for other classes. To exemplify this problem the teacher explained that they had a student in a resource class that she felt ought to attend a regular class setting. She pointed out,

If I go to change the IEP, is that my responsibility? Or do I ask the regular education teacher, or the strategy teacher to redo that? Because that's never been delineated, I don't think he belongs to me. 
In reference to who attends IEP meetings, several teachers shared this observation, "It is atypical for what we call out-of-team teachers: They have a valid complaint and quite often I think they also are failed to be notified when they have these students."

Special education team stigma. The second theme unique to this school was in form of comments concerning the effect of having two different special education delivery models. This teacher's comment typifies the concern shared, "Any student with a special need is placed on their own team xyz: which is an issue, the stigma associated with being a member of this team." Another teacher added, "I don't like to ask the kids what team they are in when they get here because I don't want anybody to have to say I am in team xyz." A related arts teacher shared this,

I really think that there really needs to be a little bit more communication so that I know exactly who these children are so they go through no embarrassment, I mean I have periods where I don't have any body's team in here.

In sum, these comments reveal that the teachers share a level of discomfort that the school identifies some students with IEPs as their own team. This feeling of uneasiness suggests that they don't want to bring undue attention to the fact the school singles out these students. This teacher best typifies this sentiment, "I think that I have somebody in here in team xyz and I would never let on that they were."

\section{Case Study Profile Summary}

The Bucknell Middle School's Integration plan served as an addendum to their existing mission and goal statement policy. As a result their mission and goals did not directly relate to nor include the several state recommendations that clearly promoted an integrated model of schooling. These components did however address student and community involvement. For example they stated, "Through the shared responsibility of staff, students, parents and the community, we are committed to teaching for all." The remaining components supported their stated values by addressing elements that related to the organizational structure and administrative responsibilities of schooling. For example, in their efforts to 'share responsibility,' the plan stated the objectives, "to provide training" and "collaborative planning and or 
communication between special and regular education staff." The plans however did not address concerns that related to student socialization, participation, and extracurricular involvement nor did they address teacher practices that related to individual student needs within their classroom.

In sum, the following provides a list to clarify the activities that the school has implemented to support an integrative education setting based on the observation, interview and integration plan analysis.

1. The school and integration plan assigned a learning disability teacher to one team per grade level to provide support through a resource and consultative delivery model.

2. The interviews suggested that number of self-contained related arts classes have decreased. As a result more students with IEPs attend these classes with their peers from the other teams.

3. The interviews suggested that the number of students who eat with students their grade appropriate peers has increased. As a result more students with IEPs eat with their grade level peers.

4. The integration plan and observation support that all students with IEPs attend at least one integrative classroom setting once a week during their advisory period. This class takes place with students from other teams and with a teacher who is not their special education instructor.

5. The interview and observation revealed that the school offers an Early Bird Home work program to help students with their studies.

The observation and interview analysis clearly report that the teachers have an awareness that the school imparts an effort to increase the level of inclusion. The extent to which these changes increased the teacher's level of decision-making did not directly associate with the inclusion of student with disabilities but to the general functions of schooling. For example, in this reference to a teacher's reflection about the Integration Plan he stated, 
I don't know that it had anything to do with the special education laws that was just our goal of making sure that everyone would have the opportunity to do the best that they could do without we could get rid of any barriers and try.

In another teacher discussion they suggested, "We have a basic goal with several parts: the child achieves what they can, positive atmosphere, safe atmosphere, you know that sort of thing." These statements coupled with the teacher's list of committee accomplishments characterize their perspective toward decision-making as being utilitarian in nature. Stated differently, the teacher's decisions did not strive to solely increase one interest. As a result the practices or decisions to a great extent, upheld the school's model of practice and did not solely seek to increase the student's level of inclusion.

Although the teacher's survey results concerning student involvement rated this factor as relatively high, the interview analysis suggests that this level of integration warrants further understanding. The level's quality is of suspect as evident by the fact that several students with do not eat with grade appropriate peers, some related arts classes maintained mixed grade levels of students with IEPs, and teachers expressed a feeling that there is a stigma associated with the fact that one team consists of only students with IEPs.

The school's integration ratios further support this notion that the school's level of integration is problematic. The school's enrollment of 1,031 has over 178 students with IEPs. Within this population 95 students attend up to three separate classes a day, whereas 83 other students attend up to nine outside regular education setting. Out of the school' enrollment, 8 percent of the population spend more than 60 percent of their day in a separate setting.

In sum, the interview and observation analysis suggest that the level of student involvement is relatively low due to the fact that close to 50 percent of the students with IEPs spend the majority of their day in a special education setting. The interview data also pointed out this fact, "I do know that certain teams get most of the LD students because the LD teacher was with that team." In other words, the regular education classes do not each represent a heterogeneous group of ability levels. Furthermore, in a school with 12 special educators, 2 teach 
in the gifted education program, 8 teach solely in a separate classroom, and 3 teach in a separate and regular setting and are a member of one of the teams per grade.

The special educators continue to serve as a key person in determining student service configuration. The distinction between in-team and special education program teacher responsibilities, however, was an area of concern. Through observation and interviews the teachers noted how students belonged to different teams and or teachers. As a result it appeared that the teacher's decision making role depended on whether they were the person who had primary responsibility to the student. Student classroom membership did not imply that the teacher played an active role in determining the student's service configuration. The student's primary teacher as defined by their team affiliation rather dealt with these decisions. This teacher's comment in essence summarizes the problem, "Pretty much most teachers are accepting of the idea [inclusion]: It's just a problem that we're having is finding the time to coordinate this whole program."

The interview and observation analysis also suggest that although one team has a special educator as a member, the team's involvement with the decision making process did not necessarily decrease the special educator's autonomy. One shared, "For the LD kids it's not been if anything a step back." They explained,

A couple of years ago, I had to start an English [resource] class and now I have two that are both over the limit. I have twelve in both classes, plus our group of however many in the self-contained classes: So it seems somewhat backwards.

It appears, that although the efforts to assign a special educator to a grade level team was to increase and enable teacher opportunity to collaborate, these changes did not proportionately increase the team's number of integrated settings.

The school restructuring efforts had the greatest impact upon the related art teachers. Although these teachers do not work with students in the severe and profound program, the integration initiative increased the number of student of IEPs attending their classes. In the interviews, one teacher talked about how they now collaborate and in one case team-teaches with 
a special educator. Each expressed a desire to attend IEP meetings, however, only two interviewees stated that they had. It is noteworthy that four of the five teachers who volunteered to attend a summer work shop on IEPs represented the related arts block. In short, the restructuring of the school has enabled or promoted the related arts teacher to become more actively involved in concerns regarding students with IEPs.

In terms of the teacher's level participation in making administrative decisions, the teachers expressed several examples to support how they actively engage in this process. Teachers talked about a variety of committees. They suggested that these committees were instrumental in designing their school-wide programs such as the advisory class, the BUCS student-behavior incentive project, and Early Morning Homework program. Members of the disciplinary committee shared that they met twice a week before school. The faculty senate meeting's observations also found evidence of how the committees had a high level of decision making involvement. Several committees gave reports that included proposed a new practice or recommendation for improvement. The faculty discussed these proposals and asked questions in a manner that suggested that they gave these ideas a serious and respectful consideration. The faculty senate devoted the greatest amount of their meeting time on the agenda items led by teachers. Although the administration had the opportunity to speak, their announcements related to committee activity and to the recognition of teachers for their efforts. 


\section{Arnold School}

Arnold School is a middle school for grade sixth through eighth. It is the fifth largest school and is one of three middle schools in a county of 21 schools. The student enrollment of Arnold is 740 students of the county's student population of 11,977 (West Virginia Department of Education, 1997). In comparison to other counties, this school district's rank order by percentage of students receiving special education services was the second lowest in the state.

In the months of September, October, and November, 12 separate on-site visitations were conducted. During these visits the study's field-based data collection strategy collected detailed descriptions of the school's operations. These observations occurred while time the students were present and when the faculty senate met on three different occasions. The section below reports the observation analysis.

\section{Observation}

The county originally built this school thirteen years ago to serve as a high school. Yet, due to the increase in younger student population, the school became the middle school instead. The school's location is near a major highway, but it's setting is quite rural. The only other building in view is a school currently under construction across the street. The building is positioned several yards away from the main road on a large plot of land. One may not see the school because a small rolling hill creates a natural boundary between the road and the open grassy fields that surrounds the school. The school's large paved parking lot is located to the one side and is very visible. As one drives in, it becomes evident that you enter the school from the archway that extends from the side of the building. On a warm sunny day, one often can see students at play in the building's front side field.

Upon entering this one-story building, one is greeted by sunlight pouring through the library's floor to ceiling windows located to one side. Because the entire length of this large spacious room opens entirely into the hallway, the library creates a warm welcoming atmosphere. Windows and a doorway open into the main office. This is where all visitors must report before preceding into the remaining portion of the building. Apart from the library and 
office, there are no other classrooms in proximity. The main hallway instead continues as long quiet walkway where one wall is only windows. It is not until one is half way down this airy walkway they find double doors that open into a large gymnasium and a cluster of five classrooms that outline the end of the hallway.

It is easier to get around after one realizes that the school has four hallways that form the shape of a large square. This design creates a circular traffic pattern. In order to reach the cafeteria from the main entrance one must walk to the opposite corner of the building using the one of two hallways. In either selection, one walks down one hallway, turns, and continues down another. Because the hallways are equal in length, one option is not necessarily shorter then the other. The school attempts to lessen student travel by clustering each grade's classrooms together. The related arts classes, gymnasium, and cafeteria are on three opposite corners of the building. As a result, students in point of time must travel from end of the building to another. This is often problematic because the four corners where the hall turns become bottlenecked by the students trying to get through.

The architectural design allows classrooms on both sides of each hallway to have exterior windows. The floor plan accomplishes by placing the building's four hallways around an outdoor courtyard. Each room thereby has natural lighting that creates an open airy atmosphere. In various sections of the hallway, teachers increase the school's positive appearance by displaying student work on the bulletin boards located outside their classrooms. In the hallway outside the gymnasium, large student-made banners that advertise different story books also hang from the lofty two-story ceiling.

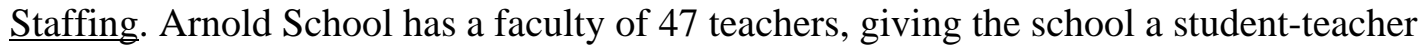
ratio of 16.1 to 1 teacher. The school organizes their content teaching staff into six teams. Each team includes five members that teach: reading, language, science, mathematics, and social studies. The school identifies the remaining teachers by the department that they teach in. These programs include: related arts (art, technology education, computer, keyboarding, home economics, music, and health), physical education, and special education (learning disabilities, 
mental impairments, and gifted education). Unlike the other teams, these teachers have students from three grade levels, not just from one. All faculty members have a group and an individual planning period.

The school has a total of seven special educators that all teach in a separate setting outside the regular classroom. In the area of learning disabilities and mental impairments there are three teachers who teach the same students in five content subjects in a separate class. The remaining four special educators teach in a resource model. One teacher provides a reading enrichment class to students in the gifted education program. The other three teachers provide math, language arts, and or reading instruction to students with learning disabilities. Unlike selfcontained settings, these students have science and social studies in a regular education setting and they each belong to a regular education team rather than a special education team.

In the resource classroom observations no more then twelve students attended the class. In this setting the teacher provided group instruction and called individual student to respond. During independent practice, the teacher rotated among each of the students to check their performance levels. In the regular education setting the teacher also presented the content in a group format. The students, however, raised their hands to participate. In a few cases the teacher called upon individuals who did not volunteer to respond but every student did not participate. Also like the resource class, the teacher provided students with assistance. In one class, the teacher sat with a group of students and went to others when they raised their hand. In every class the students were responsible for completing a written assignment either in-class or as homework. Each student also recorded their assignment in a notebook. In several classes the teachers checked to see that students were up to date and rewarded them with a piece of candy.

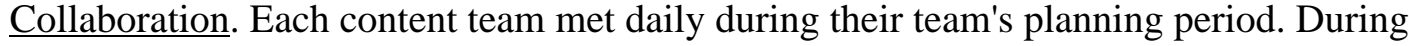
these times the teachers were observed grading papers, discussing student behavior and or academic performance, and on several occasions, meeting with a student's parents. In visiting each team, it was quite apparent that the teachers valued the opportunity to work together. Although their interaction was informal, each member gathered at their routine time and sat in a 
manner to give each other their attention. Several teams used a team-log appointment book to document their team's contact with the student's home and to record the gist of their discussions.

The special education and related arts teacher's team meetings contrasted. The related arts and special education teachers did not formally meet as a team on a routine basis. These teachers, instead were observed individually gathering materials for their next class, preparing lesson plans, and doing other such instructionally related activities. The self-contained teachers performed activities in collaboration with their classroom aide. Because the resource teachers shared an office they were observed informally talking to each other as they each prepared the carts that they used to carry their materials to classrooms located throughout the building. Apart from this interaction, these teachers reported that they did not collaborate to design instructional materials. They reported that they worked independently and met with their student's team members only on a spontaneous basis.

Student involvement. According to the school's 1998-99 records, 61 of the school's 740 students received instruction in a resource setting and 26 students were in a self-contained classroom (see Table 38). In sum, 12\% of the student population received at least one class in setting outside the regular classroom. With the exception of the self-contained program's 26 students, the school randomly assigned students, including those in resource classes, to one of the two grade level teams. These classrooms consequently contain a heterogeneous ability group. Each student's schedule contains seven periods of instruction. Their first period begins by serving as a 'home-room' session where students watch their peers on a televised morning announcement program. They then attend four to five classes followed by a lunch and recess period. During this time the students from each grade level have the opportunity to socialize. Students also attend a physical education and a related arts class in an integrated setting. Each nine-week grading period the students rotate among the different related art classes. The school also offers an organized after-school sports program to all students. Depending on the season, two teachers supervise such sports as football, baseball, soccer, and basketball. In the Fall 1998, 18 students participated in this program. 
Table 38

Arnold School Special Education Class Assignment

\begin{tabular}{|c|c|c|c|c|c|}
\hline \multirow[b]{2}{*}{ Grade } & \multicolumn{3}{|c|}{ Resource } & \multicolumn{2}{|c|}{ Self-contained } \\
\hline & Language & Reading & Math & MI & $\mathrm{LD}$ \\
\hline 6 & 7 & 25 & 18 & 4 & 11 \\
\hline 7 & 8 & 27 & 17 & 3 & 5 \\
\hline 8 & 4 & 9 & 6 & 1 & 2 \\
\hline Total & 19 & 61 & 31 & 8 & 18 \\
\hline
\end{tabular}

Faculty Senate. The Arnold School faculty gathered in the library for their monthly faculty senate Meetings. Teachers primarily sat with their teams around large tables facing the Faculty Senate President's table positioned in the center of the room. While several teachers graded papers, most were observed sitting quietly in attention to the meeting's activities.

Each meeting followed a standard agenda that began with a reading and approval of the minutes. Without much discussion the meeting then turned its attention to the treasurer's reading of the budget. At one meeting the treasurer passed out checks in the amount of fifty dollars to each teacher and reviewed the procedures that they were to use to report their purchased items. Under old business, teachers stood and updated the faculty about a certain topic. For example in one meeting, the art teacher talked about an upcoming event and asked for faculty to serve as a cultural art judge. Two persons volunteered. At another, a teacher spoke about their PEIA benefits. They explained proposed changes and requested the faculty to submit a letter of opinion. The President also shared correspondence that he had received since the last meeting. He held up different bulletins concerning grant award and training opportunities and briefly reviewed their information. 
The meeting spent a majority of its time on the agenda of new business. At one meeting the treasurer read an individual request to buy a new camcorder to video tape the morning announcements. Several teachers raised the issue of whether the faculty senate should buy this type of item. One pointed out that they were not to fund items that the school could pay from their capital. This prompted more discussion. It was of concern whether teachers would need to buy items for their classrooms next year because they would be moving to a new building. The Principal then spoke and said that he would request for the county to buy all new supplies for their future setting. Another teacher questioned if this would include computer software. The Principal again assured the staff that the office would set aside funds. With this in mind, a teacher motioned for the faculty senate to provide $\$ 600$ toward the purchase of the camcorder and the school fund the remaining balance. After discussion, another amended this motion to state $\$ 350$ instead of $\$ 600$. The Principal agreed and the faculty unanimously passed the motion.

Other items under new business took the form of an announcement rather then a discussion. The Faculty Senate's Policy Committee's announced that the school's interpretation of the Safe School's Act was correct. The school could suspend students with disabilities as long they conducted a manifestation determination meeting. One teacher announced that they had made a request book for teacher to describe the type of computer assistance that they needed. A third member reported about a scholarship to support student travel to visit Ashland College.

Each meeting ended with the opportunity for the school principals to speak. At the various meetings the Principal reported about the county's truancy concerns, field trip policy, and accreditation requirements. He also explained how the plans for the new school were coming. At one meeting he announced the possibility of changing their schedule of eight periods to nine in order to add a remedial skill class. This sparked a lively response from the faculty. At one time several teachers voiced their opinions. One asked how this plan would meet the higher achieving student needs and other asked how they were going to make the time. For several minutes following, teachers began informal discussions among the different tables. These discussions quieted down when a teacher asked whether the school had a choice. The Principal responded 
that it may be a county decision, not a school's. As the Principal moved on to other announcements, one member interrupted him to reiterate their concern and requested that he shared this opinion with the county.

Because the meeting's remaining announcements did not spark a lively debate, they used less time. The Vice Principal spoke about the school's discipline status that he called the Frontline Report. He reported how many infractions occurred during the month. For example there were four referrals in September and 127 in October concerning assaults. In October 55 students were tardy. Teachers asked to if their tardiness was to school or to class. The Principal responded that they were throughout the day. He ended his report by thanking the faculty for covering classes when teachers were absent and commented, "It was a total team effort."

The meetings formally ended with a motion from the floor. Because each meeting only lasted a little over an hour, the teachers had a half hour to forty-five minutes to spend as they wished. At this time the teachers returned to their classrooms. Several were observed chatting the hallways, running off papers in the teacher's workroom, and using the office phone to record their team's homework assignments.

\section{$\underline{\text { Strategic Integration Plan }}$}

Arnold School prepared an eight page inclusion policy that included all of the components required by the, Strategic Planning Guide for West Virginia Faculty Senates (1994). On the basis of upon these guidelines, this study analyzed the plan's six components using a content analysis protocol. This purpose of this strategy was to provide a framework of reference to examine how the school promotes and supports inclusive practices. The section below presents this protocol's content analysis.

Arnold School's mission was, "Through collaborative efforts among students, faculty, parents, and community, all students will participate in the learning process." Table 39 presents the school's mission statement in relation to the state's recommended components. The school's mission contained each recommendation. The school's plan speaks to the areas of collaboration, student and community involvement, and excludes the mention of staffing and training concerns. 
It is important to note that this mission statement has a pragmatic rather than a philosophical focus. It defines collaborative efforts and student participation as the plan's primary function. To this extent, the mission uses a community based perspective. This orientation does not refer to a specific group nor does it limit to an administrative and or teacher's level of ownership.

Table 39

Arnold School Mission Component Analysis

\begin{tabular}{|c|c|c|c|}
\hline Audience & Action & Aim & Importance \\
\hline Students & collaborative & all students & participate in learning \\
\hline Faculty & efforts & & process \\
\hline \multicolumn{4}{|l|}{ Parents } \\
\hline Communi & & & \\
\hline
\end{tabular}

Table 40 cross references the school's mission statements with the belief statements held by the West Virginia Integrated Initiative. The school's mission statements included two of the four recommended beliefs. Within these common beliefs, the mission does not specifically address how student participation relates to the school's service configuration. The plan instead described what they value (all student participation) in terms of how they will achieve it (collaborative efforts) but they do not clarify the extent to which the students experience an integrative model of schooling.

Table 41 compares the school's five goals to the West Virginia Integrated Initiative recommendation. Four of these goals coincided with each of the state's five recommendations. One goal contained two statements that individually addressed two different state goals. The school's fifth goal, "Follow state guidelines for the administration of medication" did not correlate with a state recommendation. In sum, the school addressed each recommendation that included a broad array of concerns. To this end, the school viewed the organization from an external (community) and an internal (administration) point of view. 
Table 40

Arnold School Mission Statement Analysis

Source Arnold School Mission

State Quality education reflects our diverse society, supports \& promotes the success of all students.

Arnold All students will participate in learning process.

State Education is a shared responsibility of families, educators, and the community.

Arnold Collaborative efforts: students, faculty, parents, and community

State Interaction with others fosters a life-long learning process.

Arnold

State Each student's potential is better realized when a spectrum of educational opportunities occur with age-appropriate peers in home school settings.

Arnold

Table 41

Arnold School Goal Analysis

Recommendation Arnold School Goal

Technical assistance $\quad$ Establish and maintain effective communication among staff members.

Positive partnerships Engage in shared decision making to achieve a common goal.

Comprehensive training Appropriate training will provide the necessary skills and strategies for functioning as effective educators.

Accountability system IEP development and evaluation conducted in accordance with state Federal guidelines.

Student-based funding Maximize resource services while maintaining quality instruction. 
Table 42 cross references the school's three identified need statements with the state's five recommended goals. Even though the school's goals contained each state recommendation, the need component of the plan did not. Arnold school's plan did not address needs that related to external considerations such as community involvement or funding supports. The plan instead, targeted needs that associate with the school's internal organization. These considerations identified teacher training and planning time as well as safeguard levels to assign students to classrooms. The school's needs included organizational considerations that related to teacher supports and their ability to meet individual student needs but did not involve community support.

Table 42

Arnold School Need Analysis

Recommendation Arnold School Need

Technical assistance $\quad$ Set up and schedule meetings for regular \& special educators affected by inclusion to develop and evaluate IEPs.

Positive partnerships

Comprehensive training

Provide staff training and adequate professional personnel to accomplish IEP goals and objectives.

Accountability system

Safeguard $20 \%$ or less proportion of special need students to the number of other students in a regular education classroom.

Student-based funding

The Strategic Integration Plan's fourth and fifth section listed the objectives and activities for meeting the plan's goals. Table 43 presents the school's objectives and implied activity in relation to the state's six recommendations. In comparison, the school addressed only five of the checklist's six areas and omitted items related to the state's student involvement and interaction with peers. The school did not describe how or the extent to which the students have access to all school environments for instruction and interactions nor how the school or teachers promote 
student participation within these contexts. Of strength, the remaining areas identified describe administrative outcomes that intend to support the organizational aspects of integrative education. In several areas the school listed more then one objective and each objective clearly defines outcomes that one easily associates with students with disabilities.

Table 43

Arnold School Objective and Activity Analysis

Recommendation Arnold School Objective and Activity

Administrative responsibility Training of strategies and implementing IEP goals.

Administer medications to students as prescribed.

Provide staff when special needs population exceeds $20 \%$.

Provide additional staff on case by case basis.

Provide flexible scheduling to meet individual student need.

Provide common time to staff within school contract to determine, facilitate, and review IEP goals and objectives.

IEP development IEP committee determine appropriate placement and services.

IEP committee develop goals to meet needs of student.

IEP evaluation by those implementing and reviewing IEP.

Appropriate placements for special education students.

Collaborative teamwork Students, parents, faculty responsible for IEP implementation.

Professional practice

Student involvement

Interaction with peers

Table 44 compares the school's final section, evaluation, with the state's recommendations. The analysis identified whether the evaluation activity occurred during the course of the implementation phase (formative) or at the conclusion of the implementation phase 
(summative). The analysis then determined fundamental reason for the stated evaluation and included the following purpose options: (1) to identify needed changes in the plan (process evaluation); (2) to provide data (outcome evaluation); and or (3) to illustrate effectiveness (impact evaluation). The analysis also listed the resources the school would use to conduct the evaluation and identified whether this procedure used performance and or judgment data.

Table 44

Arnold School Evaluation Component Analysis

Component Analysis

School Evaluation Activity

Phase Purpose Resource Procedure

IEP Review

Annual Review

Training feedback

SBAT and IEP committee
Summative, outcome and impact evaluation teacher evaluation \& records (judgment \& performance).

Summative, outcome and impact evaluation IEP (performance data)

Formative, process evaluation survey (judgment data)

Formative, process evaluation observation (judgment data).

Table 45 compares themes derived from the state's recommendations with the school's Strategic Integration Plan components. Of strength, the school's plan targeted concerns related to staffing, collaboration, and training in at least three of the five components. From a contextual point of view, these considerations relate to the organizational structure of the schooling and deal with activities commonly associated with administrative level decisions. The administration promotes inclusive practices by providing training opportunities and scheduled time for teacher collaboration. It is noteworthy that these supports specifically reference that their purpose is to serve IEP development and implementation. These qualities strengthen the plan's general purpose to support an integrative model of schooling. 
It is of concern that the plan's components do not further our understanding of how the administrative decisions that regard role defining, scheduling, and training translate to the classroom level of practice. For example, the plan does not address specific classroom activities or teachers instructional qualities nor do they include concerns related to student socialization, participation, and extracurricular involvement. Thus, the summation of the plan's purpose clarifies how their organizational and administrative aspects support an integrative model but they do not qualify the extent to which these supports achieve their purpose.

Table 45

Arnold School Theme Analysis

Integration Plan Component

Theme Mission Goal Need Objective/ActivityEvaluation

\begin{tabular}{lccccc}
\hline Staffing & -- & $\mathrm{X}$ & $\mathrm{X}$ & $\mathrm{X}$ & -- \\
Collaboration & $\mathrm{X}$ & $\mathrm{X}$ & $\mathrm{X}$ & $\mathrm{X}$ & -- \\
Training & -- & $\mathrm{X}$ & $\mathrm{X}$ & $\mathrm{X}$ & $\mathrm{X}$ \\
Student involvement & $\mathrm{X}$ & -- & -- & $\mathrm{X}$ & $\mathrm{X}$ \\
Community & $\mathrm{X}$ & -- & -- & -- & -- \\
\hline
\end{tabular}

\section{Teacher Survey}

The survey's purpose was to determine the relationship between how the participants perceived their role as a faculty senate member and the degree to which their school integrated students with disabilities in the regular classroom. Specifically this data source could serve to determine the degree to which the school's site-based approach coupled with a student centered focus influenced teachers' perceived roles and responsibilities. To accomplish this, the study disseminated 47 teacher survey at a faculty senate meeting. A total of 43 teachers or $91 \%$ returned their surveys. Only 38 teachers provided information regarding their subject and grade 
level teaching assignment. From this reported data, the participant's group affiliation was as follows: 3 special educators, 24 regular educator, and 11 related art teachers.

Table 46 presents items concerning professional practice. Items in this scale referred to the teacher's professional practices that they used to support inclusive environment. Several items related to the teachers' beliefs and attitudes toward teaching all children, including children with disabilities, while others concerned the extent to which teachers adapted instructional strategies and materials to support student individual need. A high score reflects higher levels of teacher's professional practices as in congruency with West Virginia's Integrative Initiative.

The Arnold school had a group mean of 4.0 and a range of 1.1 with 3.5 as the minimum and 4.6 as the maximum. The item, "Teachers develop structured interaction programs" had the highest group score, whereas the item, "Teachers develop adaptations for students with special needs," was the lowest (see Table 46). On a five-point scale this group mean suggests that the teachers perceive their practices as having a relatively high level of agreement with the West Virginia Integration Initiative's practice recommendations.

Table 46

Arnold School Professional Practice Factor Analysis

\begin{tabular}{lcc}
\hline Item & $\underline{\mathrm{M}}$ & $\mathrm{SD}$ \\
\hline Teachers share common view about school, teaching, and learning. & 3.75 & .537 \\
Teachers ensure interaction of special needs students. & 3.68 & .649 \\
Teachers adapt instructional strategies in content areas to meet (IEP). & 4.21 & .689 \\
Teachers develop age appropriate materials to address student level. & 4.09 & .735 \\
School mission reflects philosophy that all children can learn. & 4.65 & .616 \\
Teachers develop adaptations for students with special needs. & 4.92 & .679 \\
Teachers develop structured interaction programs. & 3.51 & .810 \\
Instructional staff demonstrate positive attitudes toward all students. & 4.21 & .689 \\
\hline
\end{tabular}


The second scale, Site Based Management School Climate, referenced the extent to which administrative decisions and the decision making process involved teacher participation. On a five-point scale a high score reflects that the school's administrative decisions positively support West Virginia's site based management mission. The school had a mean of 3.6 or "sometimes" on the response scale. This mean had a range of 1.84 with a minimum response of 2.4 (rarely) and a maximum response of 4.2 (usually). Table 47 reports that the item with the highest group score was, "Philosophy supports need for ongoing training, technical assistance." "Teachers participate in decisions on duties outside the classroom" had the lowest group score. Table 47

Arnold School Site Based Management School Climate Factor Analysis

Item $\quad \underline{M} \quad S D$

When faced with a mandate school takes proactive stance.

$3.68 \quad .808$

Faculty contributes to decision-making on how money is spent. $\quad 3.39 \quad 789$

Teams meet weekly to plan instructional support for all students. $\quad 3.92 \quad .996$

Teachers implement behavior management strategies with team. $\quad 4.18 \quad .691$

Administrators committed to enhancing their professional knowledge. $4.00 \quad .805$

Teachers participate in decisions on duties outside the classroom. $\quad \begin{array}{lll}2.42 & 1.13\end{array}$

$\begin{array}{lll}\text { The design of progress reports reflects school's mission. } & 3.97 & .788\end{array}$

Philosophy supports need for ongoing training, technical assistance. $\quad \begin{array}{lll}4.26 & .685\end{array}$

$\begin{array}{lll}\text { Decisions about how money is spent consistent with school mission. } & 3.44 & .921\end{array}$

The third scale, Collaborative Teaming, consisted of eight items concerning the teacher's engagement in collaborative and team activities that supported inclusive practices for students with disabilities. The school had a group mean of 3.5 or "sometimes" on the response scale. This mean had a range of .973 with a minimum response of 3.1 and a maximum response of 4.1 (usually). One a five-point scale, higher scores suggest that teachers perceive to participate in 
higher levels of shared decision making practices that address individual student need.

According to Table 48 the item with the score of 4.1 stated, "Teachers collaborate to adapt objectives within core curriculum." The item with the lowest score stated, "Educators collaborate to write joint IEP goals and objectives."

Table 48

Arnold School Collaborative Teaming Factor Analysis

Item

$\underline{M}$ SD

Teachers collaborate to make material \& environmental adaptations. $\quad 3.67 \quad 626$

$\begin{array}{lll}\text { Related service staff provide services in general classroom. } & 3.48 \quad 989\end{array}$

Teams collaborate to provide related services in inclusive settings. $\quad \begin{array}{lll}3.29 & 1.05\end{array}$

$\begin{array}{lll}\text { Teachers collaborate to adapt objectives within core curriculum. } \quad 4.10 & 698\end{array}$

$\begin{array}{ll}\text { IEP meetings use a transdisciplinary approach. } & 3.72 \quad 902\end{array}$

$\begin{array}{lll}\text { Educators collaborate to write joint IEP goals and objectives. } & 3.13 & 1.31\end{array}$

The final scale, Student Involvement, contained seven items. The items in this scale related to the extent teachers perceived school activities to involve students with disabilities. The school had a group mean of 4.3, that represents "usually" on the response scale. This mean had a range of 1.0 with a minimum response of 3.9 (sometimes) and a maximum response of 4.9. A high score on this scale suggests that teachers perceive student with disabilities as having a relatively high level of involvement in school activities and interaction among peers. Only one item, "IEP objectives reflect interaction with non disabled peers," rated below 4.0 and that this scale. The item, "All students participate in music, art, and gym classes," on the other hand had the highest score (see Table 49). 
Table 49

Arnold School Student Involvement Factor Analysis

Item

$\underline{M} \quad \mathrm{SD}$

$\begin{array}{lll}\text { Students with disabilities are involved in extra-curricular activities. } & 4.45 & 677\end{array}$

$\begin{array}{lll}\text { IEP objectives reflect interaction with non disabled peers. } & 3.95 & .875\end{array}$

Remedial programs available for students not experiencing success. $\quad \begin{array}{lll}4.20 & .853\end{array}$

$\begin{array}{lll}\text { All students participate in music, art and gym classes. } & 4.95 & .220\end{array}$

$\begin{array}{lll}\text { Student with disability instruction incorporate interaction. } & 4.25 & .707\end{array}$

$\begin{array}{lll}\text { All students participate in general education classes. } & 4.27 & 1.10\end{array}$

$\begin{array}{lll}\text { Students with special needs participate in school activities. } & 4.40 & .590\end{array}$

Table 50 presents a summary of Arnold School's group scores for each factor. This table also reports the group scores for each factor by teacher assignment. On the three factors, sitebased management school climate, Student involvement, and collaboration, the related arts teachers had the highest group score and the lowest group score for professional practice. On three of the factors the special educators and regular educators also shared the same mean.

Table 50

Arnold School Teacher Survey's Teacher Mean by Factor

\section{$\underline{\mathrm{M}}$}

Factor Total Special Regular Related Arts

\begin{tabular}{lllll} 
Professional Practice & 4.0 & 4.0 & 4.0 & 3.9 \\
Site Based Management & 3.7 & 3.5 & 3.5 & 4.0 \\
Collaboration & 3.4 & 3.0 & 3.4 & 3.6 \\
School Involvement & 4.3 & 4.3 & 4.3 & 4.4 \\
\hline
\end{tabular}




\section{$\underline{\text { Teacher Interview }}$}

The purpose of the interview was to provide a vehicle to enable the researcher to deeply probe into and further explore a respondent's explanation for events. Unlike the teacher survey, this method was more open-ended by allowing the interviewer to pursue meaning about an issue in greater and richer detail. This study devised two protocols for conducting these semistructured interviews. The first protocol (Appendix D) guided interviews with the school's inclusion plan committee members while the other (Appendix E) guided interviews with noncommittee members. Both interviews used the contents of their school inclusion plans as a guide in asking teachers to describe their school and teacher practices.

During three months, thirteen interviews were conducted at Arnold School. Eight interviewees initially volunteered participation at a faculty senate meeting and the researcher sought five additional participants to assure equal representation for each grade and content area. A pattern matching analysis identified four interview themes based on the Inclusion Plan components and two additional themes that were unique to the interviews conducted with Arnold School. The following section describes these themes.

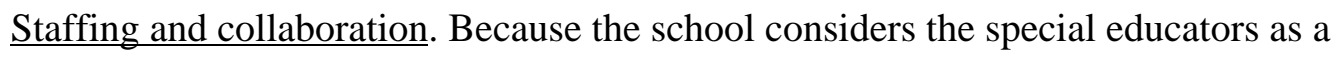
department, they are not members of the teams. As a result the school's organizational pattern of staffing and planning of schedules does not support a high level of collaboration. Three teachers stated that they would like to have a special educator a team member. One commented, "So then you could team plan: And really plan whatever works for our kids." The fact that the special educators are not team members may explain why the team's conversations about collaboration did not refer to how they met with their student's special education teacher. One teacher flatly stated, "I don't see them during the day."

The resource teachers' conversations also supported the notion that there was a lack of collaboration. One commented, "We're written down as resource, that is a lie." They explained that they teach subjects in isolation and do not serve as a resource to another class as their title implies. As a result, any "resource" or supports that they provide is only accomplished in their 
classroom if their subject's activity allows for spare time. A second teacher commented, "I try to help students with their science and social studies by going over their test, but I don't always know about it before the day it's scheduled." When asked if they modified student's regular education assignments, they stated "The student's teachers are good about doing that: No, I don't change their work." In short, these teacher's references to the teams indirectly related how they supported them but they did not suggest that the individuals directly worked together to determine the nature of support.

Members from the school's six teams however each reported that they routinely met on a daily basis. This comment captures the general opinion, "I prefer the team because I think it meets the needs of our kids cause we sit down." Others reported, "We focus a lot of time on talking about our students." "We can be all together and when we do call parents in we all meet as a team even: If they're doing well [we still meet]."

When asked about problems they dealt with one teacher raised the issue about homework. They said, "The biggest problem is getting homework assignments in from special education students and it's grown: I'd say the problem is snowballing." It is not of interest that this discussion involved homework but rather that it dealt with their involvement with special educators. They later commented, "If we had the LD teacher on our team things could be brought up week in and week out and we need to teach these children responsibility." Another stated,

A common problem among almost every social study and science teacher that has students mainstreamed in their classroom is that there seems to be a difference of what the regular education classroom teacher demands from the special education student and what the special education teacher demands.

Through further discussion the teacher explained, "There is a common thread: They'll fail science an social studies, and pass reading, language arts and math." In response to their comment they later said, "I'll go to those [resource] teachers and I'll say how do you get them to work?" These comments suggest that the teams feel that their level of expectation differs from the student's other classes. It also reveals that the level of collaboration among the teams and 
special educators did not routinely occur and that this lack of communication has had a negative impact on how the programs achieved cohesion. In one interview the teacher stated, "Somewhere along the line this child has gotten the idea that I don't have to do work at all."

Training. The interviewees shared a positive regard toward the training opportunities offered by their county. One teacher commented, "I think the opportunities are here: I think our county is very good in that area." Several mentioned that the Principal asked what the school would like the county to offer in terms of staff development and, as this person stated, "He's taken our suggestions and we have had in-services on that." Another made reference to how teachers can attend a Tri-County Institute and that they too solicited suggestions for topic by giving an inventory to assess their needs.

When teachers were asked to describe the training sessions they had attended, the science teachers reported about a safety seminar, while others talked about a computer software session. Most opinions referred to how the training addressed their knowledge and skill needs. One teacher however gave this evaluation, "

The training I've had I know has benefited the resource kids that I have had in the classroom. Like the APL training where you restate the objective at the beginning and end and where you get a lot of active participation: I know those things benefit those kids.

Another teacher also mentioned the term "APL" and explained that this was a two-day workshop that all teachers had to attend. They reported that this training developed a standard of activities all teachers were to implement such as the stating of objectives exemplified in the other teacher's discussion.

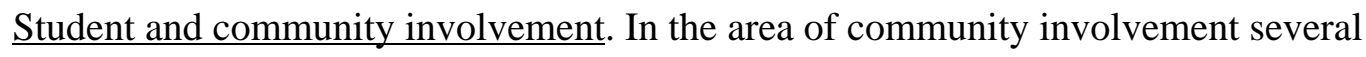
teachers talked about how it was common for the teams to individually meet with student's parents in addition to scheduled parent conferences. Another shared how their faculty senate also formed a committee to address the concerns that parents had regarding curriculum. In terms of student involvement, all teachers reported that every student attends physical education, related 
arts, and lunch in an integrated setting. With the exception of three self-contained classes, all other students with IEPs had regular classes in science and social studies. Several teachers also positively mentioned that a computer generated their team list in heterogeneous groups.

In short, the teachers perceived their school as having a high level of inclusion. It is noteworthy however, that three teachers raised a concern about special education and suggested what they would like to see changed. One commented, "I think they should assign a special education teacher per grade." The reason for this was not necessarily for their benefit but the students. They went on to say, "Their should be a special education room for kids and their teacher right in that pod instead of just going down: You know cause once you pass the double doors, here its got a label on it." Another shared the same opinion and added, "I don't think it's good to single them out and disperse them throughout the building making it even more evident to them that they are in special needs areas."

Faculty Senate. The teachers at Arnold school spent much on their interview time on the topic of faculty senate. A great deal of the comments characterized the positive attributes that these meetings promoted. For example different people gave the following opinions, "I think it is good because people think they got more voice." "I feel that people are, have more confidence in speaking out and in voicing their opinions because they are in a group that's made up mainly of teachers like themselves." A third stated, "If we did without faculty senates there would probably be a morale problem."

In terms of their level of decision-making, a couple of teachers stated the county and state dictated much of their curriculum and therefore it was not a topic for them. The majority however, reported that they made decisions to how the school operated. For example, almost every teacher mentioned that they were in the midst of discussing the possibility of having an eight rather then seven periods in a day. Others talked about how the faculty senate enabled teachers to set a standard and gave reference to their gum and tardy policy.

In reference to committees, the interviewees reported that they have had several but on a need-to-have basis. One teacher talked about how one year the faculty senate assigned everyone 
to a committee. Because all the committees did not meet, they did away with this idea. Although most of the interviewee did not currently belong to a committee almost everyone mentioned the benefit of how the faculty senate reviewed state and county policy proposals. The interviewees in fact portrayed this activity as being the Senate's single most important function as evident by the frequency by which they discussed it. The majority each shared how the Faculty discussed this information and wrote letters to voice their opinions.

Heterogeneous grouping. Shared opinion about student grouping was a unique theme identified in Arnold School interviews. With the exception of one dissenting opinion five other members talked the importance of heterogeneous grouping. Two persons stated that one intention of their school's inclusion plan was to assure equal grouping across the teams.

One of the big changes that the plan did is teachers didn't want all their LD kids dumped in one room: They wanted them sprinkled out instead of having for some body's convenience six, seven, eight or nine which is sometimes is even a lot more then the special education teachers have.

The other stated, "One of our goals I do remember was that we set a number . . in a class of LD kids mainstreamed." It is noteworthy that two other regular education teachers made such comments as this,

I personally feel that resource kids should be in a regular classroom . . . . I feel that those students can benefit from being in the classroom and ideally what I think we had put down was that resource teacher come in and work with those students in the classroom. Another said, "You know pulling these kids out for reading and math and language, I personally don't think that's the way to go: I really don't."

Inclusion plan effects. Every member recalled the time when the faculty senate implemented their Inclusion Plan. Of strength several of the interviewees also stated items that they wrote on the plan. For example, several mentioned how they limited the number of students with IEPs in a regular education class, two suggested that a special educator or aide would attend a class that was over this limit, others also mentioned that their mission addressed all students of 
all abilities. The four planning committee interviewees noted that they had a substitute teacher to allow them to work during school time. They each remembered was on the committee in manner that suggested that they were proud of their multidisciplinary approach.

In discussing the actual plan, two made these such comments: "If I remember correctly what we did was we basically left everything the way that it was"; "I don't see that we've done anything differently." It is noteworthy that three persons shared that they felt inclusion was good in theory but that it would warrant the need for additional training and staff before the school could make such changes.

Case Study Profile Summary

This county has the second lowest percentage of students receiving special education services in the state. The school has seven special educators and 137 students with IEPs. According to the school's records 12 percent of the student population attend at least one class (reading, language and or math) in a special education setting and less than four percent spend 60 percent or more of their day in a separate setting. At minimum all students attend a related arts and a physical education class in addition to lunch in a fully integrated setting. To this end, the school involves each student to some level in the conventions of their school's practices.

The teacher survey results for the student involvement factor support this appraisal. It reported that teachers had a group mean of 4.3. With the exception of one item (IEP objectives reflect interaction with non disabled peers), the teachers gave an average scale response of "usually" to the remaining items that referenced program integration. Consequently, these scores suggest that teachers perceive student with disabilities as having a relatively high level of involvement in school activities and interaction among peers. Furthermore, this factor also had the highest group score to that of the other factors.

The Arnold School Inclusion plans contained all of the required components and addressed the majority of state's recommendations. Their mission statement, "Through the collaborative efforts of students, faculty, parents, and community all students will participate in the learning process," defines collaborative efforts and student participation as the plan's primary 
function. To this extent, mission does not specifically address how student participation relates to the school's service configuration. The plan instead described what they value (all student participation) in terms of how they will achieve it (collaborative efforts) but they do not clarify the extent to which the students experience an integrative model of schooling.

The plan's remaining components targeted needs that associate with the school's internal organization. These considerations identified teacher training and planning time as well as safeguard levels to assign students to classrooms. The plan's components however, do not detail how role defining, scheduling, and training translates to the classroom level of practice and or how they relate to the extent to which the students have access to integrative settings. The plan therefore does not address specific classroom activities or teachers instructional qualities nor do they include concerns related to student socialization, participation, and extracurricular involvement. Thus, the summation of the plan's purpose clarifies how their organizational and administrative aspects support an integrative model but they do not qualify the extent to which these supports achieve their purpose.

The teacher's interviews suggested that the inclusion plan did not restructure their existing mode of operation. The teacher's level of decision making in this regard did not increase nor decrease. One teacher commented, "We basically decided to leave it up to individual teams of teachers how they were going to include kids." Another stated, "On our inclusion plan decided that placement decisions would be on a case-by-case basis instead of painting it with a broad paintbrush and saying what we were going to do for every child in the building."

When they were asked if the faculty considered changing their existing practices, one teacher made this point: "I think probably it's nothing that we're aware of that we could bring up in faculty senate because I never thought about that before." This opinion is notable in light of the fact that several interviewees suggested that they felt that the students in resource classes ought to be in the regular education setting. Apparently the teachers view such decisions as a departure from practice and therefore, beyond their immediate control in terms of achieving systemic change. This teacher's evaluation best summarizes this appraisal, "I think for it [special 
education] to be effective it needs a radical change: You don't have to prove to me that it's being effective now because I don't think it is."

Several teachers reported that this school has had the same special education delivery model since it opened 13 years ago. There has always been two options of placement: resource and self-contained. In the resource program the students are members of the regular education team and only attend at most three classes in a separate setting. In the self-contained setting the students do not belong to a regular education team and have all academic classes with one teacher in a separate classroom. None of the special educators are team members and therefore they do not share a team planning period with the regular educators. In short, the school has not change its staffing patterns.

The school's integration plan included several items to promote teacher interaction. For example, they included two goals that stated, "Establish and maintain effective communication among staff members" and "Engage in shared decision making to achieve a common goal." Their needs component also stated to "Set up and schedule meetings for regular and special educators affected by inclusion to develop and evaluate IEPs." The plan restated this request in the objective and activity section as well.

On the surface each of these statements gives value to collaboration. Yet the extent to which this collaboration is to support students with special needs is problematic. First, the goal statements do not specify communication and decision making as practice to be achieved by special and regular educators. To this end, the school's teaming achieves this outcome. Second, the needs, objective, and activity statements only refer to teacher interaction in terms of IEP meetings. They do not imply frequent routine interaction. In sum the school's integration plan does not restructure the special and regular educator's role to include collaborative decision making that extends beyond IEP meetings.

The teacher interviews provide evidence that the general and special educator's perceptions did not agree regarding their involvement in the special education delivery decision making process. Several regular educators shared the opinion that resource students ought to 
attend the regular education setting. Their discussions regarding collaboration were also team specific. Interviewees reported that they collaborate within their teams but the teams and special educators do not routinely meet to design instruction for students with IEPs. The special educator's interviews concurred with this evaluation. The teacher survey also reported that the collaboration factor had the lowest group score of 3.4. In short, there was limited interaction between the special and regular educators.

Despite the lack of collaboration across programs, the teacher survey scores suggest that the teachers perceived their practices as having a relatively high level of agreement with the professional practices described by the West Virginia Integrative Initiative. On a five-point scale, the regular and special educators had a group score of 4.0 and the related art teachers had group score of 3.9. On five of this factor's eight items the score was above 4.0. To this extent, the teachers gave an average response of "usually" to items that concerned whether they adapted instructional strategies, developed age appropriate materials, and provided adaptations for students with special needs. This rating supports the notion that teachers make classroom level decisions regarding how they address the need of individual students.

At the school level, the teacher survey revealed that the site-based management climate factor had a group score of 3.7. The item, "Teachers participate in decisions concerning duties outside the classroom" had the lowest group score of 2.4, whereas the item, "Philosophy supports need for ongoing training and technical assistance," had the highest. The teacher interviews supported the notion that the administrative decision making process did not directly involve teacher participation. In other words, the teacher's role in decision-making was reactionary rather than proactive. Teachers did not develop policy: they voiced opinion about how to improve the policy's practice. Several interviewees attributed the benefit of faculty senate to their ability to discuss state and local policy. The faculty senate has also discontinued having a variety of committees. Interviewees pointed out that because the committees often did not meet they became inactive. At the faculty senate meetings attended, the policy and technology committees 
were the only two groups that spoke. They made announcements to update the members about new materials but they did not propose recommendations.

These findings suggest that the Arnold School Faculty Senate value teacher decision making. The role of this process however is not necessarily to develop new school-wide practice but rather to monitor existing practice. It is noteworthy that the school's integration plan contained 13 of the state's 20 recommendations and addressed each required component according to the state guidelines. The planning committee also had classroom substitutes to allow them to meet as a group during school hours. Interviewees could recall how and when the faculty senate reviewed this plan. The contents, however, did not seek to change the mode of practice but offered suggestions for improvement. Several mentioned a disappointment that the county nor state reported back to them about their efforts. 


\section{Cross Case Analysis}

This section's purpose is to ultimately present a cross analysis of the individual case to determine whether schools with higher perceived participatory role in decision making achieved a different level of inclusive practices then that of schools with lower participatory role in decision making. The analysis therefore considered each case study as a unit embedded within a larger case, whereby the larger case is the major interest of the study.

This section treats each case as an individual unit of analysis and examines each case study's conclusion in relation to the other individual cases. In order to compare results, the cross analysis conducted a two-step process. In the first phase, the analysis individually examined each data collection strategy across the four case studies. The report below presents these comparisons in the following order: observation, integration plan, teacher survey, and teacher interview. In the second phase, the analysis reexamines the four strategies in relationship to each other by conducting a multiple strategy comparison. The report presents these comparisons as units embedded with a larger case and reports these findings in relation to the research questions. Observation

The study initially selected each case study based on demographic information concerning special education services. Through a census selection process, the study selected four case studies that differed and compared by rank order percentage of students receiving special education. According to the West Virginia Department of Education's report, Exceptional Student's in West Virginia's County School Districts (1997) the state's 55 county percentage of students with disabilities was 22.17 (highest), 13.81 (lowest), and 17.94 (median). The study selected two counties with the high and low percentages (see Table 51). Two schools from each quartile also represents a site that the West Virginia Department of Education identified as having a high level of integration (S. McQuain, personal communication, April 15, 1998).

Table 51 presents the case site's county and school population information. This analysis reveals that the Gemrock and Bucknell Schools have student enrollments that are relatively the same and similarly differ in comparison to Lucas and Arnold Schools. The size of these schools 
was considered important because these schools represent a prototypical sampling of West Virginia's school populations. The ratio of students to teachers was also considered important. Despite having different enrollments, all four schools had the relatively same student-teacher ratio. The proportion of students and teachers within each school counteracts how the populations differ between the schools.

Table 51

$\underline{\text { Case Site Student and Teacher Populations }}$

\begin{tabular}{lllllll}
\hline & \multicolumn{2}{c}{ Student } & & \multicolumn{3}{c}{ School } \\
\cline { 2 - 3 } \cline { 5 - 6 } Site & County & School & & Grade & Teacher & Ratio \\
\hline Gemrock & 4,862 & 1,273 & & K-8 & 85 & 15.8 \\
Lucas & 2,842 & 659 & & $5-8$ & 56 & 14.3 \\
Bucknell & 4,265 & 1,031 & $6-8$ & 67 & 15.6 \\
Arnold & 11,977 & 740 & $6-8$ & 47 & 16.3 \\
\hline
\end{tabular}

Table 52 presents population information that specifically relates to special education. The analysis of these demographics demonstrates that the Gemrock and Lucas Schools' counties have a higher percentage of students receiving special education services in comparison to the other two school's. These percentages by rank order are counties that have the highest and lowest percentages with respect to the entire state's county comparisons. In other words, the Gemrock and Lucas Schools special education population by county represents having the highest or near highest percentage of special education students. In contrast, the Bucknell and Arnold School's counties have the lower or the lowest percentages.

A school's number of special educators who teach in the mild and moderate area of special education did not replicate this pattern. Lucas (high) and Bucknell (low) have ten special educators, whereas Gemrock (high) and Arnold (low) have five and six respectively. As a result, 
Lucas has twice as many special educators in relation to Gemrock School even though both counties have a high percentage of students receiving special education services.

Table 52

Case Site Student and Teacher Special Education Population

\begin{tabular}{lcccccc}
\hline & \multicolumn{2}{c}{ County } & & \multicolumn{3}{c}{ Schoola } \\
\cline { 2 - 4 } \cline { 5 - 7 } Site & Percentage & Rank Order & & Student & Teacher & Ratio \\
\hline Gemrock & 20.20 & 7 & 102 & 5 & 20.4 \\
Lucas & 23.17 & 1 & & 109 & 10 & 10.9 \\
Bucknell & 15.97 & 49 & & 178 & 10 & 17.8 \\
Arnold & 14.26 & 54 & & 86 & 6 & 14.3 \\
\hline
\end{tabular}

aSchool = mild special education populations (LD, BD, MI) for grade six, seven, and eight only. Data omits gifted, moderate, severe and profound programs.

Each school has a different model for delivering special education services (see Table 53). The study used the West Virginia Department of Education's Regulations for the Education of Exceptional Students (Policy 2419) to define each setting. The self-contained (SC) classroom represents a separate class where the school delivers specially designed instruction outside the regular setting for $60 \%$ or more of the student's day. The resource $(\mathrm{R})$ classroom represents a separate classroom that students attend outside the regular setting in at least $21 \%$ but no more than $60 \%$ of their day.

The term resource-collaborative (R-Collaborative) relates to how the special educator provides instruction in the resource and regular education setting. The students have instruction outside the regular classroom for less then $21 \%$ of their day. The special educator provides daily support in the regular setting. The consultants also represent this placement option. The consultants do not teach in a resource setting on a daily basis but periodically "pull" students from the regular education class to work individually with them. Unlike the collaborative model, 
the students do not routinely attend a separate setting but instead receive their services primarily within regular education setting.

On the basis of the data presented in Table 53, Arnold is the only site that does not offer a collaborative or consultative service model. Unlike the other schools, Arnold School's special educators do not work within a regular setting. Lucas School's special educators worked in a separate setting or in the regular classroom, but not in both. This is in contrasts to the Gemrock and Bucknell Schools where the special educators offer services in both placements. In other words, Bucknell School offers the greatest variety of placement options and the Arnold School offers the least. In comparison across all schools more than half of the special educators teach in a separate setting outside the regular classroom.

Table 53

Case Site Special Education Delivery Model by Teacher Placement

\begin{tabular}{lcccccc}
\hline Site & SC & Resource & R-Collaborative & Consultant & Gifted & Total \\
\hline Gemrock & 1 & 1 & 3 & -- & 1 & 6 \\
Bucknell & 8 & -- & 3 & -- & 1 & 12 \\
Lucas & 5 & 2 & -- & 5 & 2 & 14 \\
Arnold & 3 & 3 & -- & -- & 1 & 7 \\
\hline
\end{tabular}

Note. $\mathrm{SC}=$ self-contained setting; $\mathrm{R}$-Collaborative $=$ combined resource and collaborative.

Table 54

$\underline{\text { Case Site Student Percentage in Separate Settings }}$

\begin{tabular}{lcccc}
\hline \multirow{2}{*}{ Site } & \multicolumn{5}{c}{ Setting Percentage Outside Regular Classroom } \\
& above $60 \%$ of day & $21-60 \%$ & below 21\% of day & \multicolumn{1}{c}{$\underline{.}$} \\
\hline Gemrock & --- & .08 & .12 & .21 \\
Bucknell & .08 & .04 & .05 & .17 \\
Lucas & .07 & .02 & .12 & .21 \\
Arnold & .04 & .08 & --- & .12 \\
\hline
\end{tabular}


Table 55 presents the school's team affiliation by subject area. According to this table, two of the four school's teams contained the five basic subject areas. The Bucknell School team is similar in that they offer a skill enhancement class in place of reading. The Gemrock School is most different because they group the math and science teachers each as a department and not as members of the team. Gemrock is the only school that has special educator on every team. These teams however represent each grade level. The Bucknell School only differs to the extent that two teams per grade share a special educator. The special educator thereby is a member of both teams. The Lucas School, however, assigns a special educator to only one team per grade level. Thus only half of the teams have a special educator. Arnold is the only school that does not assign a special educator to a team.

Table 55

Case Site Teacher Team Membership

\begin{tabular}{lllll}
\hline & Gemrock & Bucknell & Lucas & Arnold \\
\hline Team & Language Arts & Language Arts & English & Language Arts \\
& Reading & Skill Enhancement & Reading & Reading \\
& Social Studies & Social Studies & Social Studies & Social Studies \\
& -------- & Science & Science & Science \\
& -------- & Math & Math & Math \\
& Special Ed & Special Eda & Special Edb & --------- \\
Other & Related Arts & Related Arts & Related Arts & Related Arts \\
& Gym & Gym & Gym & Gym \\
& Math & Exploratory & Strategies & --------- \\
& Science & & --------- & --------- \\
& Special Ed & Special Ed & Special Ed & Special Ed \\
\hline
\end{tabular}

aSpecial Ed $=$ Teacher membership to one team per grade

bSpecial Ed = Teacher membership per grade 
Table 56

Case Site Demographic Summary

\begin{tabular}{lllll}
\hline Source & Gemrock & Lucas & Bucknell & Arnold \\
\hline County \% special ed. students & High & Highest & Low & Lowest \\
School \% student with IEPs & .21 & .21 & .17 & .18 \\
$\%$ in 5 or more separate classes & --- & .07 & .08 & .03 \\
$\%$ in 5 or less separate classes & .21 & .14 & .09 & .15 \\
Number of special educators & 6 & 14 & 12 & 7 \\
Teams with special educators & $3 / 3$ & $4 / 8$ & $3 / 8$ & $0 / 6$ \\
\hline
\end{tabular}

Table 56 summarizes the school's demographic information concerning special education. The schools with the highest county percentage of students with disabilities had the highest school enrollment percentage of student with IEPs. Gemrock and Arnold had the lowest percentage of students that attended a separate setting for 60 percent or more of their day. In Gemrock School's enrollment 21 percent attended less than 60 percent of their day in a separate class of whereas at Bucknell they had only nine percent. The different settings had an impact on how many teachers were at each school. In the Gemrock and Lucas Schools, 21 percent of the student population have IEPs. Gemrock has only six special educators and Lucas had 14. This may suggest that schools that have more separate classes require to have more special educators. Strategic Integration Plan

Each school's strategic plan for managing the inclusion of students with special needs into the regular classroom setting was analyzed. To facilitate this process, a content analysis protocol used suggestions described in the A Strategic Planning Guide for West Virginia Faculty Senates (1994) to analyze the plan's six components (Appendix B). The purpose of this section is to report the plan's analysis as a framework of reference for examining how schools promote and support inclusive practices. 
According to the strategic plan, each school's plan was to include: (1) a mission statement; (2) goals; (3) needs; (4) objectives and activities to implement the strategic plan; and (5) evaluation (West Virginia Code, §18-20-3, 1995). Two of the four school's plans contained all required components, however Bucknell and Lucas omitted the section concerning needs. The state also recommended schools to consider five areas of interest: staffing; collaboration; training; student; and community involvement.

Table 57

Case Study Mission Content Analysis

School Mission

Recommendation Gemrock Lucas Bucknell Arnold

Quality education reflects our diverse society, supports \& promotes the success of all students.

$\begin{array}{llll}X & X & X\end{array}$

Education is a shared responsibility of families, educators, and the community.

X $\quad \mathrm{X} \quad \mathrm{X}$

Interaction with others fosters a life-long learning process.

Each student's potential is better realized when a spectrum of educational opportunities occurs. $\mathrm{X} \quad \mathrm{X}$

The mission statement provides teachers and community members with a rationale for and the methods of developing and maintaining an inclusive environment. It establishes a standard by which one can evaluate a school's educational practices. Each of the school's plans contained a mission statement according to the state recommended component guidelines. Table 57 however illustrates the extent to which the school's statements reflect the West Virginia Integrative Initiative's mission. All four schools contained statements that related the state's first two mission recommendations. Only Lucas School addressed all four of the recommendations. 
Bucknell and Arnold Schools' missions did not reference how they arrange their organizational structure to support integrative model of schooling. In contrast the Lucas and Gemrock Schools' mission clearly defined outcomes for inclusive education.

The plan's goals detail how the school intends to achieve their mission. According to the state's recommendation, goals are to embrace all components of the educational process. They suggest these statements include how the school will: obtain technical assistance; establish positive partnerships; provide training; and develop an accountability system (West Virginia Department of Education, 1994, p. B-2). Table 58 reports the extent to which the individual schools addressed these goals. In this analysis, only Arnold addressed all five recommendations, whereas Bucknell School addressed one. All four schools considered the organization's internal and external needs to establish community and school partnerships. The state intended that goals targeted communication and interaction as an important ingredient to promoting inclusive schooling. Each of the school's mission statements mentioned such partnerships.

Table 58

Case Study Goal Content Analysis

School Goal

\begin{tabular}{lcccc}
\cline { 2 - 4 } Recommendation & Gemrock & Lucas & Bucknell & Arnold \\
\hline Technical assistance & $\mathrm{X}$ & $\mathrm{X}$ & -- & $\mathrm{X}$ \\
Positive partnerships & $\mathrm{X}$ & $\mathrm{X}$ & $\mathrm{X}$ & $\mathrm{X}$ \\
Comprehensive training & $\mathrm{X}$ & $\mathrm{X}$ & -- & $\mathrm{X}$ \\
Accountability system & -- & $\mathrm{X}$ & -- & $\mathrm{X}$ \\
Student-based funding & -- & -- & -- & $\mathrm{X}$ \\
\hline
\end{tabular}

In order for schools to identify goals that are specific to their needs, the strategic plan process required each faculty senate to conduct a comprehensive, multifaceted need assessment. Specifically the state recommended schools consider the same internal and external 
organizational factors suggested in the goal component. Internal organizational analysis was to examine the "human and organizational strengths and weaknesses of the school that will contribute to or restrict the realization of the mission statement" whereas the external analysis was to "identify the barriers and opportunities that may affect the ability of the school to achieve their mission" (West Virginia Department of Education, 1994, p. C-2).

Table 59 reports that Gemrock and Arnold completed the needs section. Because the Lucas and Bucknell plans omitted this section, the analysis could not use them in the study of comparison. Only Gemrock addressed all five recommendations. Their goals however did not include two areas that the need's section addressed. In contrast, the Arnold School's plan contained goals for each recommendation but did not state a need for two. Both plans did not include sections related to student based funding.

Table 59

Case Study Need Content Analysis

School Need

\begin{tabular}{lcccc}
\cline { 2 - 4 } Recommendation & Gemrock & Lucas & Bucknell & Arnold \\
\hline Technical assistance & $\mathrm{X}$ & -- & -- & $\mathrm{X}$ \\
Positive partnerships & $\mathrm{X}$ & -- & -- & -- \\
Comprehensive training & $\mathrm{X}$ & -- & -- & $\mathrm{X}$ \\
Accountability system & $\mathrm{X}$ & -- & -- & $\mathrm{X}$ \\
Student-based funding & $\mathrm{X}$ & -- & -- & -- \\
\hline
\end{tabular}

The West Virginia Integration Initiative required each plan to contain an objective and activity section. The state recommended six areas to consider. The administrative responsibility factors related to items that concerned staffing and teacher training. Collaborative teaming identified items with respect to staff planning and interaction. The IEP development and professional practice recommendations described the practices that teachers use to support an 
inclusive model on the school and classroom levels. For example, the professional practice items speak to how teachers adapt, modify, and support instruction to meet individual student need. The remaining areas deal with considerations that are student centered. These sections describe how the school provides inclusive settings and promotes student participation.

As demonstrated in Table 60, not one school addressed the student involvement recommendation while just two included items that related to integration with peers.

Consequently these plans collectively focus on system and teacher levels of consideration but not the student's. Each school's objective and activity referenced items that concerned teacher staffing, training, and collaborative associations. Furthermore, three schools gave attention to IEP development and more clearly associated the plan's intent to support student with disabilities in their school's practices. None of the schools addressed the area of professional practice. This recommendation detailed such methods of adaptation and supports necessary for student success in the classroom. None of the strategic plans specifically identified practices the teachers must develop and implement to foster inclusive classrooms.

Table 60

Case Study Objective and Activity Content Analysis

\begin{tabular}{lcccc}
\hline & \multicolumn{4}{c}{ School Objective and Activity } \\
\cline { 2 - 5 } Recommendation & Gemrock & Lucas & Bucknell & Arnold \\
\hline Administrative responsibility & $\mathrm{X}$ & $\mathrm{X}$ & $\mathrm{X}$ & $\mathrm{X}$ \\
IEP development & $\mathrm{X}$ & $\mathrm{X}$ & -- & $\mathrm{X}$ \\
Collaborative teamwork & $\mathrm{X}$ & $\mathrm{X}$ & $\mathrm{X}$ & $\mathrm{X}$ \\
Professional practice & -- & -- & -- & -- \\
Student involvement & -- & -- & -- & -- \\
Interaction with peers & $\mathrm{X}$ & $\mathrm{X}$ & -- & - \\
\hline
\end{tabular}


Table 61 presents a cross analysis of the themes derived from the state's recommendations with the four school's Strategic Integration Plan components. Each of the four schools collectively targeted collaboration and training objectives and activities. With respect to collaboration, these items relate to the organizational structure of schooling. The objectives and activities addressed the scheduling of common collaborative planning to establish and maintain effective communication among staff members. The training component addressed measures to provide teachers with opportunities to advance their skills and knowledge necessary for appropriately serving students with special needs in integrated classrooms.

Each school also wrote a mission statement that addressed student involvement. Lucas School had the only plan that provided a goal to support student involvement and yet three schools stated an objective and activity for this area. It is noteworthy that not one school wrote student involvement as a need. The school's plans also did not consistently address how the school programs support student socialization, participation, and extracurricular involvement. Table 61

Case Study Theme Analysis

Case Study Integration Plan Component ${ }^{\mathrm{a}}$

\begin{tabular}{lllll} 
Theme & Mission & Goal & Need & Objective /Activity \\
\hline Staffing & G -- -- & G -- -- A & G -- -- A & G -- B A \\
Collaboration & G -- -- A & G -- B A & G -- -- A & G L B A \\
Training & G -- -- & G L -- A & G -- -- A & G L B A \\
Student involvement & G L B A & -- L -- -- & -- -- -- & G L -- A \\
Community & -- L B A & G L B -- & G -- -- & -- L -- --
\end{tabular}

aCase Study Integration Plan Component = each cell reports whether the individual schools contained the given items. $\mathrm{G}=$ Gemrock, $\mathrm{L}=$ Lucas, $\mathrm{B}=$ Bucknell, $\mathrm{A}=$ Arnold School. 
The state regards each of the plan's components as interdependent. Together they are to function to promote a successful, dynamic learning environment intended for all students. As Table 61 displays, only two of the school's included a need component. Within each plan's components the state identified five areas for schools to address. Each plan could contain up to 20 items that related to the state's recommendations. Gemrock and Arnold schools addressed 16 and 13 items respectively. The Lucas and Bucknell plans addressed 9 and 6 of the 20 recommendations. The analysis of the Gemrock and Arnold integration plans suggest that they are more comprehensive and multifaceted as the state intended.

\section{Teacher Survey.}

The Teacher Survey targeted the relationship between mandated site based management activities (reform strategy) and inclusive practices (reform goal). Specifically, this instrument examined the degree to which this site-based approach coupled with a student centered focus influence teachers' perceived roles and responsibilities. The survey's 30 statements concerned: school mission; IEP development; collaborative teamwork; professional practices; student activities; student interaction; and teacher decision making (Appendix C). The study conducted a principal component analysis and reduced the data to four factors (see Appendix C-1).

In order to ascertain if the four case study schools differed in relationship to the teacher survey's four factors, a factorial ANOVA was conducted. Using factor scores as the dependent variable, the professional practice and student involvement factors each achieved a difference at the significance level of .05 (see Table 62). Post hoc comparison tests were conducted and determined that the professional practice factor did produce a statistical difference. The comparison between Gemrock and Lucas schools were different at level of .069. The Arnold and Gemrock school were similar at a level of .991 . With respect to student involvement, the Scheffe post hoc test reported a statistically significant difference in three comparisons. Specifically, the comparison between the Arnold and Bucknell School was .002. The Lucas and Gemrock School comparisons with Bucknell were significant at .039 and .041 level respectively. Consequently, 
these comparisons indicate that the Bucknell's student involvement factor significantly differed with the other schools.

Table 62

Analysis of Variance Test for the Teacher Survey Factors.

\begin{tabular}{llll}
\hline Source & $\underline{\mathrm{df}}$ & $\underline{\mathrm{F}}$ & $\underline{\mathrm{P}}$ \\
\hline Professional practice & 3 & 3.104 & $.028^{*}$ \\
Site based management & 3 & .601 & .615 \\
Collaboration & 3 & 1.917 & .129 \\
Student involvement & 3 & 6.357 & $.001 *$ \\
\hline
\end{tabular}

Note. $* \mathrm{p}<.05$.

Table 63

Case Study Teacher Survey Factors Means by Rank Order.

\begin{tabular}{lccccc}
\hline & \multicolumn{5}{c}{$\underline{\mathrm{M} \text { (Rank Order) }}$} \\
\cline { 2 - 6 } Source & Survey & Gemrock & Lucas & Bucknell & Arnold \\
\hline Professional practice & 3.9 & $4.1(2)$ & $3.8(2)$ & $4.0(1)$ & $4.0(2)$ \\
Site based management & 3.7 & $3.7(4)$ & $3.6(3)$ & $3.8(3)$ & $3.6(3)$ \\
Collaboration & 3.6 & $3.6(3)$ & $3.8(2)$ & $3.7(4)$ & $3.5(4)$ \\
School involvement & 4.1 & $4.3(1)$ & $4.2(1)$ & $3.9(2)$ & $4.3(1)$ \\
\hline
\end{tabular}

The case study comparison in Table 63 suggests that the Gemrock and Arnold Schools have similar Teacher Survey profiles. This appraisal is on the basis that their groups mean for each factor was most similar. For example, in both schools the professional practice and student involvement scores rated above the survey's mean. Their rating for the student involvement factor was equal. The site based management school climate and collaborative teaming factor 
only differed by a tenth of a point. The Gemrock School's mean for these factors was equal to the survey's mean whereas the Arnold School's mean equaled the survey's minus one tenth of a point. In sum, the Gemrock and Arnold School's combined mean for all four factors differed by only three-tenths of a point.

\section{Teacher Interview}

This study devised and used two protocols for conducting semi-structured interviews. The first protocol guided interviews with each school's inclusion plan committee members (Appendix D). The questions related teacher's involvement with strategy plan process, their opinion and knowledge about strategic plan's components, and their evaluation of the plan's impact upon practice. The second protocol guided interviews with at least four other faculty members at each site who did not serve on the planning committee (Appendix E). This protocol only contained questions that relate to their evaluation of the plan's impact upon practice. Using a pattern-matching procedure, the analysis sought themes that related to the school's strategic integration plan's components and the teacher practice in school based decision making. The section below presents these themes.

Team model determines staffing and collaboration. The schools greatly differed by the extent to which collaborative associations occurred between regular and special educators. These interactions did not necessarily correlate with whether the teachers instructed the same students but rather it related to how the special educator affiliated with the team. For example, the Arnold School's regular and special educators each reported that they did not collaborate. The special educator was not a team member and did not share a daily planning time. The Lucas, Bucknell, and Gemrock special educators who were not team members reported the same outcome.

In contrast the teams at the Gemrock, Lucas, and Bucknell Schools that had a special educator as a member reported that they had frequently scheduled interactions with each other. The special educators' responsibilities however differed by the extent to which they determined classroom practice. At Lucas the special educators primarily worked as a consultant and did not prepare student lessons. They primarily were responsible for reading tests aloud, modifying 
instructional materials, and providing students with assistance in the regular classroom. Although the Gemrock and Bucknell special educators conducted these practices, they also were responsible for teaching in a separate setting. These teachers served in a direct role in determining the student's curriculum, whereas the Lucas teachers indirectly determined the instruction by providing support and modifications to regular education's practices.

In response to how students with IEP had an impact upon the staff's roles, the regular education teachers across all four schools talked about various practices that they used. Their discussions, however, did not imply that these practices were new as a result of having a student with an IEP. Their use of such phrases as, "I have always" and "for years my students" supported this notion. The special educators at Gemrock, Bucknell, and Lucas, by comparison, talked about how the restructuring of special education has changed their role. Common to their responses was the feeling of having more responsibilities. At Gemrock, a teacher shared, "I see special education as having two jobs: we teach and then we've got all this other special ed. stuff." At Bucknell one said, "I kind of feel more responsible for these students that are out that I'm not helping them much as I should." Another stated, "We seem to do both at the same time, a job that maybe two teachers would be doing what they are expecting us to do." At Lucas they reported that their responsibilities had greatly changed as this comment summarizes, "I no longer have a classroom and last year I didn't teach any classes."

Team affiliation influences student involvement. All schools reported that all students had related arts, physical education, and lunch with their peers in an integrated school setting. However, not one school assigned all special education students to a regular education team. In other words, all schools assigned some students with IEPs to a special education program rather than a team. Teachers at the Lucas, Bucknell, and Arnold acknowledged that these settings differentiate the students from the general population. At Lucas several related arts teachers suggested that they perceived these settings as creating a stigma: "I don't like to ask kids what team they are in when they get here because I don't want anybody to have to say I am in [the special education] team." 
The teacher's interviews revealed that the schools did not assign teams in the same way. At Gemrock, Arnold, and Lucas the schools assigned the remaining students with IEPs to teams in heterogeneous groups whereas the Bucknell School assigned the majority of students with IEPs to the one team that had a special educator member. Thus in three of the schools, the majority of the general classrooms had a high probability that their classroom represented an integrated setting. This is particularly true for the Lucas School. Except for their seven separate programs all students assigned to a team received their special services in the regular classroom.

Teachers reported that their schools offered a number of extra curricular activities. The Lucas and Arnold teachers mentioned having an organized after lunch and school sports program. At Bucknell interviewees shared about their morning homework program, advisory class, and Ladders student-teacher mentor program. The Gemrock School also had an advisory period, but most teachers reported that they used this as a homework support session rather then a social support program.

Faculty Senate Decision Making. Interviewees overall believed that having faculty senates was beneficial. All schools reported receiving financial support while the teachers at Lucas and Gemrock appreciated having the faculty meet as a group. Several teachers from Arnold School mentioned that the faculty senate gave them a voice and a sense of cohesion.

Each school had committees as a result of faculty senate. However the extent to which these committees sought change varied across the schools. Bucknell and Lucas by far had the most active committee involvement. Teachers easily listed the committees that they had and provided evidence to support how they were active. The Arnold School mentioned that they at one point had many committees but now found many of them as unnecessary. The Gemrock School shared similar opinions. They however attributed the decrease in committees to the faculty senate's inability to implement the proposals they developed. According to several, the administration often did not support their proposals.

The interviews and faculty senate observations noted, that in addition to the schools having different levels of committee involvement the nature of their decisions also differed. 
There were three levels or categories in which the faculty senates made decisions: student, school, and teacher. Each category's label represents who benefits from the decision. For example, the decision to have an Early Bird homework program at Bucknell is of benefit to the students, whereas, the decision to appeal state PEIA proposal is of benefit to the teachers. Table 64 illustrates that at Bucknell and Lucas 44 and 62 percent of the faculty senate's decisions respectfully dealt with concerns that benefit students, whereas 22 and 25 percent of their decisions respectfully dealt with concern that benefit teachers. At Arnold and Gemrock, on the other hand, 20 and zero percent of the faculty senate's decisions respectfully dealt with concerns that benefit students, whereas 60 percent of the decisions at both schools dealt with concerns that benefit teachers. The focus of the faculty senate's decisions therefore differed.

Table 64

Faculty Senate Decision Percentage by Category

\begin{tabular}{lccc}
\hline & \multicolumn{3}{c}{ Group Effected } \\
\cline { 2 - 4 } Site & student & school & teacher \\
\hline Gemrock & .20 & .00 & .60 \\
Bucknell & .44 & .33 & .22 \\
Lucas & .62 & .13 & .25 \\
Arnold & .00 & .40 & .60 \\
\hline
\end{tabular}

Faculty Senate Integration Plans not cause for changes in special education. Interviewees reported changes in special education service delivery but they did not necessarily attribute the strategic plan itself as the impetus to these outcomes. For example one teacher at Lucas reported, "When the plans were first made I felt like they were written for things we were already doing: What I am saying is there were no major changes." At Arnold a teacher stated, "We're very frightened because none of us really understood what exactly, you know, we had to do." The same person later commented, 
It's probably not something that we're even aware that we would have the power to actually make suggestions or maybe even to make some kind of curriculum change within our school to better suit or better service these LD kids.

An Arnold teacher explained their plans this way, "Installing the inclusion plans was an effort that just didn't come to pass and I don't think there was enough push from the Special Education Director to see to it either."

Administrative decisions prescribe change model. Teachers from three of the four schools discussed how their special education service model had changed since the time the state mandated the integration plans but they attributed their outcomes to external forces, not their own efforts. The teachers at the Lucas School reported having the greatest and most recent change. In their second year of implementation, teachers who once taught students with learning disabilities in a separate classroom now serve as consultants in the regular education setting. Interviewees attributed these changes however to their school's need of space, the county's financial restraints, but not to the school's plan.

At Bucknell a teacher at Bucknell mentioned, "We're doing it [inclusion] for the wrong reasons: I think we are doing it a great deal in an effort to keep our special education numbers down in any given class period." In the same vein, the teachers at Gemrock School stated that their principal determined that a team could have no more then three separate resource classes per grade. In both schools the administration limited the number of restrictive settings by defining the special educator's role to include collaborative responsibilities. The teacher's roles in essence influenced the school's level of integration by determining which classes are resource and which are collaborative. However these decisions were administrative. They did not emerge from the strategic plans or from teacher driven decision making.

\section{$\underline{\text { Research Questions }}$}

I. What systemic changes did school's faculty senates make in their restructuring efforts to foster practices for inclusion? 
The greatest changes made to restructure the school's special education model did not come from the faculty senate plans but from the county and school's administrative decisions. According to the interviews at Lucas for example, the county, not the plan, assigned teachers who once taught students with learning disabilities in a separate classroom to now serve as consultants in the regular education setting. At Bucknell, the special educators reported that their county introduced their strategy class around 1986 as a measure to alleviate having all special education students in a self-contained setting. In 1996, ten years later, a teacher reported that the seventh grade teams did not have special education students as they do now.

The Gemrock School reports a similar experience. According to several interviewees, the principal directed the resource teachers to work solely within a collaborative model ten years ago. Five years later the teacher requested to offer more "pull-out" or resource classes. The principal agreed with the stipulation that no more then three classes per grade could offer this separate setting. Although these changes occurred, the school's plan did not direct them. Arnold School's special education model had not undergone any changes.

Within these prescribed models the faculty senates clarified efforts related to staffing, planning, and training at each school. With respect to staffing, the Gemrock School's plan stipulated that an accessible emergency support team and designated room would provide for immediate and appropriate handling of crisis situations. Arnold School's plan required the school to provide additional staff when the regular education's special education population exceeded 20 percent. Bucknell's plan arranged a teacher of behavior disorders and mental impairments to work as a transition person in the regular education setting. Lucas's plan did not include staffing considerations. Each plan addressed scheduling of teacher interaction to establish and maintain effective communication among staff. The Gemrock and Bucknell plan assigned one special educator to have a joint planning time with one team per grade, whereas the Lucas and Arnold plan required the school to provide time for special and regular educators to meet. All four school's plans stated for teachers to participate in county and or school staff development activities. 
The teachers also reported that their faculty senate had been instrumental in the design and implementation of student related activities. For example, the Lucas and Bucknell teachers talked about how their discipline plans provide incentives for positive student behavior. The Bucknell and Gemrock school offered an advisory period and the Lucas School had an exploratory class. Across programs the school had provided to include such topics as study skills, time management, and as one school mentioned, the appropriate treatment toward individuals with disabilities.

II. To what extent did these changes result in increased decision-making for teachers regarding the inclusion of students with disabilities?

Three schools that assigned a special educator to a team increased the number of teachers involved in the decision-making process and accountable for the instruction concerning students with IEPs. For example, the Gemrock teacher interviews reported that their teams had a great deal of flexibility in determining which classes would serve under a collaborative model. They also expressed a satisfaction about having a resource classroom as an option. Although the administration allows each team to offer three separate settings one team only offered two. This suggests that the teachers based their decision on student need.

Lucas school's restructuring to eliminate their learning disability resource classroom caused several regular educators to have students that previously attended a separate setting. These changes thereby increased their level of involvement with the student's program of study. The consultants, on the other hand, continue to work with these students but their orientation of decision-making changed from what to teach to how to support the teaching in the general program. Their instructional decisions became in direct relationship with and relative to the context of the general classroom.

Interviewees at the Arnold School suggested that their level of decision making did not increase nor decrease, but remained the same. It is noteworthy that this school also had undergone the least change. To this end, the school has the same special education delivery model since it opened 13 years ago. The teachers at Bucknell did not necessarily say that their 
level of decision making changed but they clearly communicated that their responsibilities increased. It is noteworthy that in the teachers' comments they shared an awareness of the school's effort to increase the inclusion of students by reassigning students to grade appropriate lunch and related arts classes. These examples however were not on the basis of teacher decisions but rather related to administrative practices.

With respect to the teacher survey, the professional practice factor had a total mean score of 3.9. On a five-point scale, a high score on this scale reflects higher levels of teacher's professional practices as in congruency with West Virginia's Integrative Initiative. On the response scale the school's group score represents the term "sometimes." Gemrock, Lucas, and Arnold score by rank order had the highest mean in comparison to the other factors. Each of their scores rated above 4.0 or as "usually" on the response scale. These relatively high scores support the notion that teachers perceive their classroom level decisions to support the inclusion of students with disabilities.

In sum, the changes brought on by the restructuring of the school's special education delivery model increased the number of teachers involved in the decision-making process regarding the inclusion of students with disabilities. This is not to say that the teacher could decide whether or not to have an integrative school model but rather that they made more instructional decisions concerning students with IEPs as the number of students increased in the regular education setting.

III. What was the relationship between schools' inclusion ratios and faculty's perceived role of participatory decision making involvement?

On the basis of the observational data and school records, Arnold, and Gemrock School had the least number of students assigned 60 percent or more of their day to a separate setting, whereas Bucknell and Lucas had the greatest percentage. The Teacher Survey data supports this difference. Bucknell School that appeared to have the highest ratio of student with IEPs in a separate setting is also the school that demonstrates significant difference on factor scores. 
With respect to the school's perceived role in decision making, the Teacher Survey did not demonstrate significant differences. The interview analysis, however suggest that the schools differed. The teachers at Lucas and Bucknell reported that faculty senates had several committees and that each committee was instrumental in bringing about school change. The observations of their faculty senate meeting's practices also documented how the faculty senate spent a great deal of their meeting's time on the reports from the different committees. At both schools, committee proposed motions that the faculty senate enacted. The faculty senate also provided time for the committees to meet before and or after the faculty met as a group. It is evident by these activities that faculty senate valued their committee's contributions and that the teachers viewed their efforts as having an impact upon school practice.

At Arnold and Gemrock School the faculty senate had far fewer committees. At their faculty senate meetings the Arnold School at best heard two committee reports, and all of the Gemrock School's committees reported no new business. Not one committee at either school submitted a proposal for the faculty senate's review. These school's meetings spent the greatest amount of time listening to the principal. Teachers provided comments and reactions to these announcements but decisions were nonetheless driven by the administration. It also did not appear that the faculty had leverage nor an invitation to determine change but rather the announcements asked them to make such proposals happen.

These findings suggest that the relationship between a school's inclusion ratio and the faculty's perceived role of school-based decision making involvement is complex. At Bucknell and Lucas Schools, where more students spend 60 percent or more of their day in a separate setting, the faculty senate appeared more involved in committee-based decision making. The faculty at Arnold and Gemrock Schools, where a lower percentage of students attends separate settings for 60 percent or more of their day, appeared less involved in committee-based decision making activities. It is of question whether these difference in levels of committee involvement suggest that the teacher's perceived participatory role in decision making differ. 
At Bucknell and Lucas the interviews and faculty senate observations reveal that 44 and 62 percent of the faculty senate's decisions respectfully dealt with concerns that benefit students, whereas 22 and 25 percent of their decisions respectfully dealt with concern that benefit teachers. At Arnold and Gemrock, on the other hand, 20 and zero percent of the faculty senate's decisions respectfully dealt with concerns that benefit students, whereas 60 percent of the faculty senate decisions at both schools dealt with concerns that benefit teachers. The focus of the decisions across schools differed.

This pattern suggests that schools with a greater level of integration have fewer faculty senate committees, spend more time discussing the agenda presented by administration rather than on teacher driven proposals, and the majority of their decisions dealt with concerns that benefit the teachers. Schools with lower levels of integration had a greater number of faculty senate committees, spent more faculty senate time on discussing teacher driven proposals, and the majority of their decisions dealt with concern that benefit students.

IV. To what extent did the general and special education teacher's perceptions agree regarding their involvement in the special education delivery decision making process?

The schools greatly differed by the extent to which collaborative interactions occurred between regular and special educators. In teams where the regular and special education teachers routinely shared a common planning, the interview analysis reported that teachers shared a common perception about determining and implementing a student with IEPs program of study. The level of agreement therefore related to the extent that special and regular teachers interacted with each other.

It is noteworthy that the special educators who worked in collaborative settings at Gemrock, Bucknell, and Lucas described how they developed knowledge about the regular educator's teaching style and expectations. In other words, their discussions dealt with how regular educator's way of practice influenced how they made decisions about students with IEPs. Furthermore, they shared how these decisions contrasted in kind with the decisions that they made in a separate classroom setting. In the resource room they directly determined and 
controlled classroom practice whereas in the collaborative setting they conformed to the regular educator's classroom practice.

The interviews with the regular educators, however, did not include mention of how they changed their practices other then by having a special educator in the room. Furthermore, they talked about the special educators in terms of their personality and ability to get along within the team. These comments suggest that the relationship is not reciprocal. The special educator primarily adapted their decisions and practices to conform with the regular educator's mode of operation. The special and regular educator's perceptions about their roles were in agreement. The special educators determined how to meet student needs to be successful with the practices determined by the regular education teacher or program. 


\section{Chapter V}

\section{Discussion and Recommendations}

This study examined West Virginia's reform efforts to understand how faculty senate's site based management practices effect school restructuring to facilitate inclusion. Several interests prompted this topic's selection. First, this is the first time that a reform, at the national level, emphasizes a goal that gives recognition to individuals with disabilities. Of consequence, we know little about how the Individuals with Disabilities Education Act (IDEA) and effort to support inclusive schooling impact education when presented within this context. Second, the goal is to build a restructured, interfaced coordinated service delivery system that deals more effectively with student diversity. In West Virginia each school responded by developing and implementing a Strategic Integration Plan that essentially details how each school adopts the principles of the Individuals with Disabilities Education Act on a systemic level. This process provides insight into the levels by which special and regular educators confront their differences and rethink conventional methods of practice. Finally, today's reform strategy seeks change by combining a top down and bottom up approach. West Virginia's efforts provide an opportunity to examine this undertaking and to determine the extent to which this strategy provides schools with a method to envision and practice the spirit of the reform.

A theoretical framework was established to guide the purpose of this study. From a literature review this study identified several theoretical propositions to highlight how current reform's combined components champion a significance. These key components in turn served as the underpinning that informed the study's focus, method of investigation, and process of data examination. The statements below summarize these factors and propositions contained therein:

\section{Factors:}

\section{Reform Strategy.}

- A top down change strategy provides an effective method for disseminating reform mandates (Goertz, 1986, 1988; Grossman, Kirst, Negash, \& SchmidtPosner, 1985; Kaye, 1985). 
- A top down change strategy alone can not assure that schools carry out such changes in the classroom (Firestone, 1990; Fullan, 1994; Goodlad, 1992; Policy Analysis for California Education, 1986).

- A bottom up change strategy provides an effective method for increasing teacher participation (Taylor \& Bogotch, 1994; Taylor \& Teddlie, 1992; Weiss, 1992; Wohlsetter, Smyer \& Mohrman, 1994).

- A bottom up change strategy, alone does not lead to changes in classroom practice (Elmore, 1993; Hallinger, Murphy \& Hausman, 1991; Taylor \& Bogotch, 1994; Taylor and Teddlie, 1992; Wohlsetter, Smyer \& Mohrman, 1994).

Special Education as a change agent.

- From a philosophical vantage point, IDEA's principles and practice for providing a FAPE in a LRE create a contingency requiring educators to conduct an ethical deliberation of schooling (Kauffman \& Hallahan, 1995; Lieberman, 1996; Paul \& Ward, 1996; Stainback \& Stainback, 1990, 1992).

- From a pragmatic vantage point, IDEA's principles and practice for providing an IEP in a LRE create a contingency requiring educators to redefine the school's model of a professional bureaucracy (Skrtic, 1991a, 1991b, 1995).

\section{$\underline{\text { Propositions }}$}

$\underline{\text { Reform's inclusive agenda }}$

- Combined top down, bottom up strategies create a more comprehensive and coherent model for change (Firestone, Fuhrman \& Kirst, 1990; Fullan, 1994; Peters \& Waterman, 1982).

\section{$\underline{\text { Rationale }}$}

- Mandates from above guide the central direction of change and protect the core value it intends to achieve. Decision-making from below provides flexibility and encourages teacher ownership to facilitate goal implementation (Fullan, 1994; Peters \& Waterman, 1982). 
- Today's student-centered initiatives coupled with decentralized decision making create a comprehensive, multifaceted, systematic change process (Goertz, Floden and O'Day, 1996; Lavely \& McCarthy, 1995; Schrag, 1993).

\section{$\underline{\text { Rationale }}$}

- By adopting school wide student centered practices, teachers break their relative autonomy and make necessary for the coordination of teams and individuals to support each other (Duchnowski, Townsend, Hocutt, \& McKinney, 1995; Stainback \& Stainback, 1990a, 1990b, 1990c, 1996; Villa \& Thousand, 1990).

- Student centeredness challenges teachers to question their standardization of practice and to seek new instructional approaches that create a classroom learning atmosphere in which students of varying abilities and interests can achieve their potential (Stainback \& Stainback, 1996).

From these patterns of ideas from above, the study postulated that the degree to which faculty senate members engage in developing strategic plans for inclusion correlates with the extent to which their practices reflect a change. Stated differently, this study sought to examine whether schools with a higher perceived participatory role in decision making achieve a different level of inclusion then that of schools with a lower perceived participatory role in decision making.

\section{$\underline{\text { Findings }}$}

In this study a pattern emerged. Each case study profile's reveals similar results (a literal replication) and contrary results for predictable reasons (a theoretical replication, Yin, 1984). From a systemic point of view, the impetus for change in each case was largely attributed to how the larger system initially redefined the teachers' positions within the organization. The study's conclusions therefore did not find that the degree to which faculty senate members engaged in developing strategic integration plans correlated with the extent to how their structural model of schooling ultimately changed. This is not to say that the schools that were studied did not undergo a restructuring process; rather the faculty senate was not responsible for redefining the delivery model of service. The plan's staffing model instead reflects the degree to which the 
system induced change and not the degree to which the faculty senate engaged in the plan's development.

An understanding of the bureaucratic nature of schooling provides insight to interpreting these findings. It is known that the schools arrange and define a teacher's position within the organization based on expertise. While the teacher's level of acquired training decreases the organization's need to regulate their work it also reinforces the teachers to perceive their role as important and interdependent to the system's operations. The teacher's sense of professionalism consequently diverts their attention from envisioning a model that questions their position's validity. It is therefore predictable that the restructuring of the school's staffing patterns resulted from changes introduced by the greater system and not by the faculty senate's plans.

In each of the case studies, however, the faculty senates served as an internal force that pushed up on the changes that external forces sent down. Their plans supported yet tailored how change was implemented. Because each plan differently defined how teachers were to interact, the four case studies ultimately reveal that schools have unique set of characteristics that effect how change is internalized. In other words, each school operated under the same guidelines put forth by the Federal, Individual with Disabilities Education Act, and State, Integrative Schools Initiative mandate, yet each sought different practices to achieve the same goal. From a change strategy perspective, this phenomenon illustrates how top down mandates coupled with school based decision making creates a relationship that is complex, nonlinear, and yet complementary. The mandates from above guide the central direction of change and protect the core value it intends to achieve while the decision making from below provides flexibility and encourages teacher ownership to facilitate goal implementation.

In three of the case studies, the schools restructured their service delivery model by redefining the special educator's role. Several teachers were assigned to a regular education team to provide collaborative support within in the regular education setting. Because the schools did not hire additional teachers to fulfill this role, the schools essentially decreased the number of separate settings by reassigning the students and special educators to integrated classrooms. 
Opposed to creating add-ons, the schools merged existing programs. Consequently these efforts advanced the system to some degree to become a more cohesive, coordinated model by interfacing teacher responsibilities. It is noteworthy that the case studies' special education enrollment and county percentage of students receiving special education services did not correlate with the level of integration the schools achieved. Two schools that had a similar number of students with IEPs, one school maintained seven separate classroom settings, whereas the other only had two. These findings reveal that goal achievement is not contingent upon factors, such as student enrollment, over which schools have little control. It instead suggests that outcomes relate to how the schools coordinated their service delivery system to become more cohesive model.

The degree to which the schools achieved a comprehensive, multifaceted level of change however is of suspect. Although three schools increased their level of integration by assigning the students to the regular classroom setting and the special educator to their team, more than half of the school's other special educators continue to work in separate settings and do not have team membership. This is problematic because across the four case studies a pattern emerged whereby the teacher's level of collaboration related to their team affiliation and classroom assignment. The highest level of interaction occurred between staff who worked together in the same classroom. Teachers assigned to the same teams likewise had a high level of interaction. Teachers not assigned to a team however primarily worked alone regardless if they shared student responsibility. These findings clearly demonstrate that the school's staffing patterns greatly impact teacher's level of collaboration. Furthermore, by assigning a special educator to a team the school not only changed that teacher's role and responsibilities but a lesser extent increased the other team member's involvement in determining student placement.

Within the teams a pattern emerged with regard to the types of decisions the teachers made and the degree to which classroom practice changed. In the one school where the special educator collaboratively taught with a regular educator the teacher shared a greater level of reciprocity in determining classroom practice than that in the two schools where the special 
educator shared consultative services with the regular educator. Across the four case studies however the regular educators reported that their classroom's increase in students with IEPs did not change their practice. The special educators who worked in integrated settings on the other hand reported that their practices changed from determining what to teach to how to support the other's teachings. These findings suggest that the increased level of integration did not result in having an equally compelling impact on whether classroom practice changed.

The reason the data failed to reflect an increased change in classroom practice is difficult to ascertain. The survey data across the four schools report that teachers perceived to have a higher level of professional practice in comparison to the factors that related to their perceived levels of participation in site base management and collaboration. Perhaps teachers do not perceive the increased level of integration as an impetus that changed the classroom's composition of student need. Although the literature supports that students with IEPs have similar needs to peers who also have difficulty, it nonetheless calls into question how and the degree to which the teacher's notion of a disability imparts the need to change practice. It may be that the teacher's repertoire of practice accommodates student difference. On the other hand, the degree to which teachers seek change may be limited by a perceived need to maintain a notion of standard. It is of question whether the integrated classrooms meet student need or if their practices warrant change.

The lack of reported change in practice may also relate to how each school's plans commonly noted goals and objectives that related to staffing, planning, and training needs to facilitate an integrative model of schooling. The focus of these items was administrative in nature and primarily dealt with issues that promoted the organizational aspects of change. In contrast the plans gave limited attention to activities that related to how teachers at the classroom level facilitate an inclusive environment. For example, the plans did not detail how teachers adapt, modify, and support instruction to meet individual student need. The strategic plans likewise included minimal concerns that promote student socialization, participation, and extracurricular involvement. 
The lack of respect to these items may relate to how the teacher's perceive their role in determining decisions that impact teacher practice. The concerns addressed in the plans are impersonal in the sense that they define teacher opportunity such as the availability of joint planning time. In contrast, items not addressed are personal in that they describe behaviors that teachers must practice. The rationale used to understand why the greater system and not the faculty senate plans created the changes that reorganized the school's staffing pattern may be pertinent. From a change strategy point of view, the bureaucratic structure of schooling may thwart teacher's ability and propensity to make decisions that systematically define the quality of teacher practice. The bureaucracy arranges and defines the teacher's position within the organization in order to maintain a stable environment. This condition pragmatically impedes the teachers' ability to determine individual's mode of practice, employment, or status. The teacher's level of expertise also loosely couples the teachers within the organization to allow them to work directly with students and less with their peers. As a result, teachers only collectively control their colleagues' practice and lack the standpoint to redefine each other's role within the larger system.

The purpose of this study ultimately sought to examine whether schools with a higher perceived participatory role in decision making achieve a different level of inclusive practices then that of schools with a lower perceived participatory role in decision making. The conclusions demonstrate that the school's level of inclusion had a relationship with the faculty senate's level of involvement with committee decision making and types of decisions the teachers made. The findings however did not ascertain whether this relationship demonstrates a difference in levels of participation but only that there is a difference in the type of decisions.

The emerged pattern reveals that the two case studies with a greater level of integration had fewer faculty senate committees. Their faculty senates spent more time discussing an agenda presented by administration and less time on teacher driven proposals. The majority of their decisions also dealt with concerns that benefit teachers. The two schools with lower levels of integration on the other hand had a greater number of faculty senate committees. They spent 
more faculty senate time on discussing teacher driven proposals and the majority of their decisions dealt with concerns that benefit students.

These findings suggest that the school's level of integration influences the dynamics of the school's decision making practices. In each case study the majority of the teachers are assigned to team and each team has the opportunity to meet daily during a common planning period. The data supports that these team's decisions primarily concerned their student and classroom practice. The focus of these decisions therefore was to benefit the student. In schools with higher levels of inclusion, it is reasonable to assume that the student composition within the teams has greater diversity and thereby crates less variability across programs. This diversity in turn creates the need for the teams to engage in decision making to address a variety of different concerns. As a result, the teams may decrease faculty senate's need to engage in these types of decisions. In other words, if the team's decisions bring benefit to students that have a greater diversity of need, the role their faculty senates have less need to engage in student related concerns and can focus more on making decisions that benefit the teachers and school.

In contrast the schools with a lower level of inclusion have greater homogeneity within the classroom and a greater level of student diversity across programs. In teams where there is less student diversity the team's decision making process concerns students with fewer differences. As each team concerns different student needs, the variance across programs increases. For example, the team of special educators deal with a different set of student concerns in comparison to the team's decisions that do not have students with IEPs. As a result the school decreases the likelihood that the programs share the same mode of operation. These differences in turn may give rise to the need of faculty senates to seek methods that micromanage practice across programs. In other words, the level of program variability or seclusion fragment the organization's mode of operation into a series of different units and thereby cause the faculty senates to engage in more student related decisions in response to the school's needs to seek cohesion. 


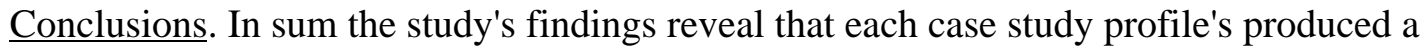
literal replication of similar results as well as a theoretical replication of contrary results for predictable reasons. A summary of these findings is listed below.

1. The degree to which faculty senate members engaged in developing strategic integration plans did not correlate with the extent to how their structural model of schooling ultimately changed. The primary impetus for change instead was largely attributed to how the larger system initially redefined the teachers' positions within the organization.

2. Three of the case studies restructured their service delivery model by redefining the special educator's role. The system restructured the staff patterns by merging existing programs. By interfacing teacher responsibilities, the outcomes consequently advanced the system to some degree to become a more cohesive, coordinated model.

3. Schools have unique set of characteristics that effect how change is internalized. In each case the faculty senates' integration plans supported yet tailored how change was implemented. The faculty senate thereby served as an internal force that pushed up on the changes that external forces sent down.

4. The faculty senates' integration plans primarily addressed staffing, planning, and training needs to facilitate an integrative model of schooling and gave limited attention to activities that related to the teacher's classroom practice and student involvement.

5. The case studies' special education enrollment and county percentage of students receiving special education services did not impact the school's level of integration.

6. The school's staffing patterns greatly impact teacher's level of collaboration. The levels of collaboration achieved is relative to the teacher's team affiliation and classroom model assignment. 
7. The special educator who collaboratively taught with a regular educator shared a greater level of reciprocity in determining classroom practice than that of the special educators who provided consultative services with the regular educator.

8. More than half of the school's special educators continue to work in separate settings and do not have team membership. Special educators not affiliated with a team had the lowest level of interaction with others even if teachers shared student responsibility.

9. The faculty senates in schools with higher levels of integration made different types of decisions than that of faculty senates in schools with lower levels of integration.

10. Schools where faculty senates engage in decision making regarding school and teacher related concerns had a higher level of integration then that of schools where faculty senates engage in decision making regarding student concerns.

Limitations. Although a repeated pattern emerged among the case studies, the validation of the findings warrants a replication of study. The process, however, needs to recognize that the study's primary focus examined West Virginia's reform efforts. As a result this state specific framework questions the degree to which this study may be replicated in other states. Such practice would require a need to revise the instruments' foci in accordance to that particular state's policy mandates. Each case study was a middle school. In this setting, the majority of the staff are members of teams. Each team teaches the same students and shares a planning period to facilitate collaborative relationships. This organizational structuring differs from the elementary and high school settings where teachers are not assigned to teams. The generalization of findings therefore may not replicate in these other settings. Finally, the data regarding each case studies' special education only includes students with IEPs in the areas of learning disabilities, behavior disorders, and mild and moderate mental impairments. The results therefore are limited to the mild and moderate special education population and do not include students in the severe and multiple or gifted education programs. 


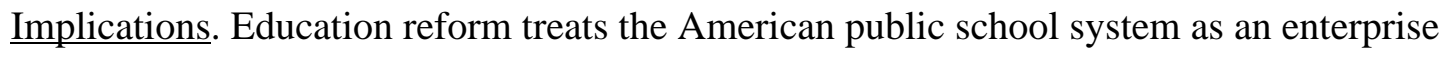
needing continual reshaping toward the achievement of excellence and equity. These initiative's distinct and compelling efforts consequently provide several insights to our knowledge about change. In this study, their successes and shortcomings demonstrate how education is a complex, multifaceted organization. In order to best understand this phenomenon research practice needs to continue to develop equally sophisticated methods and instruments that appropriately take into consideration the dynamic nature of schooling. Furthermore, each setting or school has a unique set of characteristics that have an impact on how change is internalized. Our research design must have the capability that provides the level of sensitivity that can appreciate and identify these nuances that make each school unique.

In today's reform, mandates from above send schools guiding principles that favor decentralized practices. In theory, because these efforts combine previous reform's top-down and bottom-up change strategies, they provide a change model that is comprehensive. The findings of this study however suggest that the bureaucratic nature of schooling continues to have an impact on how change translates into practice. To overcome these barriers top down mandates must initially provide the effort to restructure the staffing patterns within the organization if the goal is to change the nature in which teachers interact. Furthermore, it is not enough to examine only practice or policy: the complexity of schooling requires a simultaneous understanding of both. Our methods of study in turn need to inform policy and practice in a manner that is meaningful to each.

Because the emphasis of change focuses on the needs of all students, it is questionable how well our policies and practice incite teachers to consider ideas that challenge their own instructional practice. In this study, the majority of teachers addressed individual student need in the regular classroom setting by adapting and modifying instructional materials and approach. What is lacking in our knowledge is whether best practice needs to rethink the traditional curriculum model. In other words, instead of altering existing practice, it is of question whether we need to ultimately revamp practice and adopt a new instructional approach. Furthermore, this 
study also suggests that the teachers' area of content specialization influences how they perceive their role in site based management. In the teacher survey and interviews, the comparison of special educators, general educators, and related arts teachers' responses differed. Although such findings warrant further understanding, they also imply the need for future study to consider the teacher's role as an important variable that has an impact on outcomes. Finally, as schools continue to merge programs in effort to build a restructured, interfaced coordinated service delivery system, research must also continue to identify best practice from a systemic point of view and take into consideration the needs of this model.

The study's outcomes also provide several implications for future teacher education and school administration training programs. In order to adequately prepare educators to effectively engage in site based management decision making, training programs need to develop teacher competency in the area of collaboration and group decision making. Such topics may include, the art of working on committees, effective communication skills, and methods for linking program development to classroom practice. Furthermore, teacher training programs need to support teacher awareness of how site based management advances their ability to shape school practice. By acknowledging and developing their notion of empowerment, teacher training programs may better facilitate teachers to assume a more active role in school base decision making. School administrative training programs in turn need to prepare our future leaders in how to support teachers to engage in site based decision making activities. By using a holistic, school centered perspective administrators can improve their skills in how to promote, facilitate, and effectively achieve purposeful change at the school level through site based management techniques.

In sum, the notion equity and excellence must transcend all aspects of the reform process. First, we need to continue to restructure our schools to promote teachers to share expertise. While site based management theoretically provides each faculty member an equal opportunity to shape and to define best practice, policy must continue to seek new methods to support this goal achievement. Second, in order to assure that all teachers create an atmosphere that strives to achieve equity and excellence for their students, research and policy must continue to identify 
practices that address the needs of all students. These endeavors make necessary to produce methods that provide on-going, formative evaluation processes that inform both practice and policy. Ultimately, policy and practice need to continue to identify supports that strive for excellence in a manner that gives parity to the concerns of the individual student as well as to the individual teacher. From this parity we need to identify new practices that challenge the traditional conventions of schooling and provide education with a comprehensive and coherent model for achieving deep structural reform. 


\section{$\underline{\text { Reference }}$}

Bacdayan, A. W. (1994). Time-denominated achievement cost curves, learning differences and individualized instruction. Economics of Education Review, 13, 43-53.

Banerji, T. R., \& Dailey, R. A. (1995). A study of the effects of an inclusion model on students with specific learning disabilities. Journal of Learning Disabilities, 28(8), 511-522.

Bierlein, L. A. (1993). Controversial issues in educational policy. Newbury Park, CA: Sage.

Boyd, W. L. (1987). Public education's last hurrah? Schizophrenia, amnesia, and ignorance in school politics. Educational Evaluation and Policy Analysis, 9 (2), 85-100.

Boyd, W. L. (1990). Balancing control and autonomy in school reform: The politics of Perestroika. In J. Murphy (Ed.), The educational reform movement of the 1980s: Perspectives and cases. (pp. 85-96). Berkeley: McCutchan Publishing Corporation.

Braaten, S., Kauffman, J. M., Braaten, B., Polsgrove, L., \& Nelson, C. M. (1988). The regular education initiative: Patent medicine for behavior disorders. Exceptional Children, 55, 21-27.

Brown, B. W., \& Saks, D. H. (1981). The microeconomics of schooling. In D. C. Berliner (Ed.), Review of research in education, vol. 9. Washington DC: American Educational Research Association.

Burello, L. C., \& Wright, P. T. (1993). Strategies for inclusion of behaviorally challanged students. The Principal Letters, 10.

Butera, G., Dempsey, V., Dennis, R., Steele, S., \& Webb-Dempsey, J. (1996). The School Climate Survey: Tracking change in Professional Development Schools. Unpublished manuscript, West Virginia University.

Campbell, D. T. (1969). Reforms as experiments. American Psychologist, 24, 409-429.

Carnegie Forum on Education and the Economy. (1986). A nation prepared: Teachers for the 21st century. New York: Author. 
Chase, V., \& Pope, E. (1993, February). Model for mainstreaming: The systemic approach. Paper presented at the Learning Disabilities of America Conference, San Francisco. Christmas, O. L. (1992). The Michigan non-mandated aide pilot project. Lansing: Michigan State Department of Education.

Committee for Economic Development. (1985). Investing in our children. New York: Committee for Economic Development.

Committee for Economic Development. (1987). Children in Need. New York: Committee for Economic Development.

Conley, D. T. (1993). Roadmap to restructuring: policies, practices, and the emerging visions of schooling. University of Oregon: Clearinghouse on Educational Management.

Corbett, H. D., \& Wilson, B. (1990). Testing, reform and rebellion. Norwood, NY: Ablex.

Council for Children with Behavioral Disorders. (1989). Position statement on the regular education initiative. Behavioral Disorders, 14, 201-208.

Danielson, L. C., \& Malouf, D. B. (1994). Federal policy and educational reform: Achieving better outcomes for students with disabilities. In J. E. Ysseldyke \& M. L. Thurlow (Eds.). Educational outcomes for students with disabilities. (pp. 11-19). New York: Haworth Press.

David, J. L. (1989a). Restructuring in progress: Lessons from pioneering districts. Washington DC: National Governors' Association.

David, J. L. (1989b). Synthesis of research on School-Based Management. Educational Leadership, 48(8), 45-47, 50-53.

David, J. I. (1991) Restructuring and technology: Partners in change. Phi Delta Kappan, 73(1), 37-40, 78-80.

Dillman, D. A. (1978). Mail and telephone surveys: The total design method. New York: John Wiley \& Sons. 
Duchnowski, A., Townsend, B., Hocutt, A., \& Mckinney, J. (1995). Designing studies that are sensitive to the complexity of inclusion: Creating a knowledge base. In J. L. Paul, H. Rosselli \& D. Evans (Eds.), Integrating school restructuring and special education reform, (pp. 373-388). Fort Worth, TX: Harcourt Brace \& Company.

Duttweiler, P. C., \& Mutchler, S. E. (1990). Organizing the educational system for excellence: Harnessing the energy of people. Austin, TX: Southwest Educational Development Library.

Education Commission of the States. (1983). Action for excellence. Denver: Education Commission of the States.

Elmore, R. F. (1993). School decentralization: Who gains? who loses? In J. Hannaway \& C. Carnoy (Eds.), Decentralization and school improvement (pp. 33-54). San Francisco: JosseyBass.

Etheridge, C. P, Horgan, D., Valesky, T., Hall, M. L., \& Terrell, L. (1994). Challenge to change: The Memphis experience with school-based decision making. Washington DC: National Education Association of United States.

Evans, D., Panacek-Howell, L. (1995). Restructuring education: National reform in regular education. In J. L. Paul, H. Rosselli \& D. Evans (Eds.), Integrating school restructuring and special education reform, (pp. 30-42). Fort Worth, TX: Harcourt Brace \& Company.

Excellence: A fifty state survey. (1985, February 11) Education Week.

Firestone, W. A. (1990). Continuity and incrementalism after all: State responses to the excellence movement. In J. Murphy (Ed.), The educational reform movement of the 1980s: Perspectives and cases (pp. 143-165). Berkeley: McCutchan Publishing Corporation.

Firestone, W. Fuhrman, S., \& Kirst, M. (1990). An overview of education reform since 1983. In J. Murphy (Ed.), The educational reform movement of the 1980s: Perspectives and cases. (pp. 349-363). Berkeley: McCutchan Publishing Corporation.

Fuchs, D., \& Fuchs, L. S. (1991). Framing the REI debate: Abolitionists versus conservationists. In J. W. Llyod, N. N. Singh, \& A. C. Repp (Eds.), The regular education 
initiative: Alternative perspectives on concepts, issues, and models (pp. 241-255). Sycamore, IL: Sycamore.

Fuchs, D., \& Fuchs, L. (1994). Inclusive school movement and the radicalization of special education reform. Exceptional Children, 60, 249-309.

Fullan, M. G. (1994). Coordinating top-down and bottom-up strategies for educational reform. In R. J. Anson (Ed.), Systemic reform: Perspectives on personalizing education (pp. 724). Washington, DC: U.S. Government Printing Office.

Furhman, S., Clune, W., \& Elmore, R. (1986). Research on education reform: Lessons on implementation of policy. Teachers College Record, 90(2), 237-258.

Gartner, A., \& Lipsky, D. K. (1987). Beyond special education: Toward a quality system for all students. Harvard Educational Review, 57(4), 367-395.

Gerber, M. M. (1988). Tolerance and technology of instruction: implications or special education reform. Exceptional Children, 54, 308-14.

Gerber, M. M. (1996). Reforming special education: Beyond 'inclusion'. In C. Christensen \& F. Rizvi (Eds.), Disability and the dilemmas of education and justice (pp. 156174). Philadelphia, PA: Open University Press.

Gerber, M. M., \& Semmel, M. I. (1984). Teacher as imperfect test: Reconceptualizing the referral process. Educational Psychologist, 19, 137-148.

Gerber, M. M., \& Semmel, M. I. (1985). The microeconomics of referral and reintegration: Towards a new paradigm of special education evaluation. Studies in Educational Evaluation, 11, 13-29.

Glaser, B. G. V. \& Strauss, L. L. (1967). The discovery of grounded theory: Strategies for qualitative research. Chicago: Aldine.

Goertz, M. E. (1986). State educational standards: A 50 state survey. Princeton, NJ: Educational Testing Service.

Goertz, M. E. (1988). State educational standards in the 50 states: An update. Princeton, NJ: Educational Testing Service. 
Goertz, M. E., Floden, R. E., \& O'Day, J. (1996). Studies of educational reform: Systemic reform. (Report No. ORAD 96-132). Washington DC: U.S. Department of Education. (ERIC Documentation Reproduction Service No. ED 1.302

Goodlad, J. (1992). On taking school reform seriously. Phi Delta Kappan, 73(3), 232-38.

Goodlad, J. I., \& Lovitt, T. C. (Eds.). (1993). Integrating general and special education. New York: Macmillan.

Goodman, L. V. (1976). A bill of rights for the handicapped. American Education, 12(6), 6-8.

Green, J. (1987). The next wave: A synopsis of recent education reform reports. Denver: Education Commission of the States.

Grossman, P., Kirst, M., Negash, W., \& Schmidt-Posner, J. (1985). Curriculum change in California comprehensive high schools: 1982-83 to 1984-85. Berkeley: Policy Analysis for California Education (PACE), University of California.

Gutek, G. L. (1991). Thomas Jefferson: Advocate of republican education. In Cultural foundations of education: A biographical introduction (pp. 148-171). New York: Macmillan.

Guthrie, J. W., \& Kirst, M. W. (1988). Conditions of education in California 1988: Policy analysis for California education. (Policy paper No. 88-3-2). Berkeley CA: Authors.

Guthrie, J. W., \& Koppich, J. E. (1993). Examining contemporary education reform efforts in the United States. In H. Beare, \& W. L. Boyd (Eds.), Restructuring schools: An international perspective on the movement to transform the control and performance of schools (pp. 51-68). Washington, DC: The Falmer Press.

Hallahan, D. P., \& Kauffman, J. M. (1977). Categories, labels, behavioral characteristics: ED, LD, and EMR reconsidered. Journal of Special Education, 11, 139-149.

Hallinger, P., Murphy, J., \& Hausman, C. (1991). Conceptualizing school restructuring: Principals' and teachers' perceptions. Paper presented at the Annual Meeting of the American Educational Research Association, Chicago. 
Hocutt, A., \& McKinney, J. D. (1995). Moving beyond the regular education initiative: National reform in special education. In J. L. Paul, H. Rosselli, \& D. Evans (Eds.), Integrating

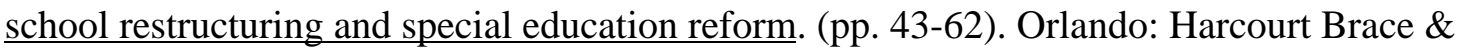
Company.

Holmes Group. (1986). Tomorrow's teachers: A report of the Holmes Group. East Lansing, MI: Authors.

Hoy, W., \& Miskel, C. (1991). Educational administration: Theory, research, practice. (4th ed.). New York: McGraw-Hill.

Ingwerson, D. W. (1990). Personal reflections of shared decision making: A superintendent's view: Learning to listen and trust each school faculty. The School Administrator, 47(8), 8-11.

Jenkins, J. R., \& Horner, A., (1989). Students' preferences for service delivery: Pull-out, in-class in integrated models. Exceptional Children, 55, 516-523.

Jordan, K. F., \& McKeown, M. P. (1990). State fiscal policy and education reform. In J. M. Murphy (Ed.), The educational reform movement of the 1980s: Perspectives and cases. (pp. 97-120). Berkeley: McCutchan Publishing Corporation.

Kauffman, J. M., Cullinan, D., \& Epstein, M. H. (1987). Characteristics of students placed in special programs for the seriously emotionally disturbed. Behavior Disorders, 12, 175184.

Kauffman, J. M., Gerber, M., M., \& Semmel, M. I. (1988). Arguable assumptions underlying the regular education initiative. Journal of Learning Disabilities, 21(1), 6-11.

Kauffman, J. M., \& Hallahan, D. P. (1993). Toward a comprehensive delivery system for special education. In J. I. Goodlad, \& T. C. Lovitt (Eds.), Integrating general and special education. (pp. 73-102). New York: Macmillan.

Kauffman, J. M., \& Hallahan, D. P. (1995). The illusion of full inclusion. Austin, TX: Pro-Ed. 
Kaye, L. (1985). Making the grade? Assessing school districts progress on SB 813. Sacramento: California Tax Foundation.

Kirst, M. (1984). Who controls our schools: American values in conflict. New York: Freeman.

Kirst, M. W. (1987). PEER: An interview with Michael Kirst. Phi Delta Kappan, 60(2), $161-164$.

Kennedy, R. (1993). Goals 2000: Educate America Act: Report together with additional and minority views. Congress Report from the Committee on Labor and Human resources. Calendar No. 106. 103D Congress 1st Session. Report 103-85.

Keogh, B. K. (1988). Improving services for problem learners: Rethinking and restructuring. Journal of Learning Disabilities, 21(1), 19-22.

Lally, K. (1991). Changing the old guard: States, turn toward helping rather then regulating, The School Administrator, 48(3), 8-12.

Lavely, L., \& McCarthy, M. A. (1995). Early intervention in the context of school reform and inclusion. In J. L. Paul, H. Rosselli, \& D. Evans (Eds.), Integrating school restructuring and special education reform (pp. 79-104). Fort Worth, TX: Harcourt Brace \& Company.

Lieberman, L. (1990). REI revisited ... again. Exceptional Children, 56, 561-562.

Lieberman, M. L. (1996). Preserving Special Education...for those who need it. In W. C. Stainback \& S. B. Stainback (Eds.), Controversial issues confronting special education: Divergent perspectives (2nd ed., pp. 16-27). Boston: Allyn and Bacon.

Lilly, M. S. (1987). Lack of focus on special education in literature on educational reform. Exceptional Children, 53 (4), 325-329.

Lincoln, Y. S., \& Guba, E. G. (1985). Naturalistic inquiry. London: Sage. Lipsky, D. K., \& Gartner, A. (1991). Restructuring for quality. In J. W. Llyod, N. N. Singh, \& A. C. Repp (Eds.), The regular education initiative: Alternative perspectives on concepts, issues and models (pp. 43-56). Sycamore, IL: Sycamore. 
Lipsky, D. K., \& Gartner, A. (1996a). Inclusion, school restructuring, and the remaking of American society. Harvard Educational Review, 66(4), 762-796.

Lipsky, D. K., \& Gartner, A. (1996b). Inclusive education and school restructuring. In W. C. Stainback, \& S. B. Stainback (Eds.), Controversial issues confronting special education: Divergent perspectives (pp. 3-15). Boston: Allyn and Bacon.

Local School Involvement Act, West Virginia Code $§ 18-20-3$, (1990 \& supp. 1995).

Logan, K. R., Bakeman, R., \& Keefe, E. B. (1997). Effects of instructional variables on engaged behavior with disabilities in the general classrooms. Exceptional Children, 63(4), 481498.

Lutz, F. W., \& Maddirala, J. (1988). Stress, burnout in Texas teachers and reform mandated accountability. Paper presented at American Educational Research Association annual meeting.

National Association of State Boards of Education. (1992). Winners all: A call for inclusive schools. Alexandria, VA: Author.

Neill, D., \& Medina, N. (1989). Standardized testing: Harmful to educational health. Phi Delta Kappan, 70(9), 688-97.

Malen, B., Ogawa, R. T., \& Krantz. (1989, May). What do we know about school based management? A case study of the literature: A call for research. Paper presented at the conference on choice and control in America education, University of Wisconsin, Madison.

McLesky, J., \& Waldron, N. (1995). Inclusive elementary programs: Must they cure students with learning disabilities to be effective? Phi Delta Kappan, 76, 300-304.

McNeil, L. M. (1986). Contradictions of control: School structure and school knowledge.. New York: Routledge \& Kegan Paul/Methuen.

Merriam-Webster's ninth new collegiate dictionary. (1990). Springfield, MA: MerriamWebster. 
Meyen, E. L. (1995). Legislative and programmatic foundations of special education. In E. L. Meyen \& T. M. Skrtic (Eds.), Special education and student disability: An introduction. (4th ed., pp. 33-75). Denver: Love Publishing.

Mintzberg, H. (1979). The structuring of organizations: A synthesis of the research. Englewood Cliffs, NJ: Prentice Hall.

Murphy, J. T. (1980). Getting the facts: A fieldwork guide for evaluators and policy analysis. Santa Monica, CA: Goodyear Publishing.

Murphy, J. (1990). The educational reform movement of the 1980s: Perspectives and cases. Berkeley: McCutchan Publishing Corporation.

Murphy, J. (1991). Restructuring schools: Capturing and assessing the phenomena. New York, NY: Teachers College Press.

Murphy, J. \& Beck, L. G. (1995). School-based management as school reform: Taking stock. Thousand Oaks, CA: Corwin Press.

Myles, B. S., \& Simpson, R. L. (1992). General educators' mainstreaming preferences that facilitate acceptance of students with behavioral disorders and learning disabilities. Behavior Disorders, 17, 305-315.

National Association of State Directors of Special Education. (1992). NASDSE's commitment to America 2000 educational goals. Washington DC: Author.

National Commission on Excellence in Education. (1983, April). A nation at risk: The imperative of educational reform. Washington, DC: US. Government Printing Office.

National Commission on Excellence in Educational Administration (1987). Leaders for American schools. Tempe, AZ: University Council on Educational Administration.

National Governors' Association. (1986). Time for results: The governors' 1991 report on education. Washington DC: National Governors' Association.

National Science Board. (1983). Educating Americans for the 21st century. Washington, DC: National Science Board. 
Odden, A., \& Marsh, D. (1987). How state education reform can improve secondary schools. Part II: Background and technical appendices. Berkeley: Policy Analysis for California Education (PACE), University of California.

Odden, A., \& Marsh, D. (1988). How comprehensive reform legislation can improve secondary schools. Phi Delta Kappan, 69(8), 593-598.

Odden, A., \& Marsh, D. (1990). Local response to the 1980s state education reforms: New patterns of local and state interaction. In J. Murphy (Ed.), The educational reform movement of the 1980s: Perspectives and cases (pp. 167-186). Berkeley: McCutchan Publishing Corporation.

Olson, L. (1989). Governors say investment in children can curb "long-term costs" for states. Education Week, 8(22), 10.

Pascal, P. (1990). Managing on the edge. New York, NY: Touchstone.

Paul, J., \& Rosselli, H. (1995). Integrating the parallel reforms in general and special education. In J. L. Paul, H. Rosselli, \& D. Evans (Eds.), Integrating school restructuring and special education reform (pp. 188-213). Fort Worth, TX: Harcourt Brace \& Company.

Paul, J. L., Rosselli, H., \& Evans, D. (1995). Integrating school restructuring and special education reform. New York, NY: Harcourt Brace College Publishers.

Paul, P. V., \& Ward, M. E. (1996). Inclusion paradigms in conflict. Theory into Practice, $\underline{35}(1), 4-11$.

Peters, T. J., \& Waterman, R. H. (1982). In search of excellence: Lessons for America;s best-run companies. New York: Harper \& Row.

Policy Analysis for California Education. (1986). Conditions of Education in California, 1986-87. Berkeley CA.: Author.

Pugach, M., \& Lilly, M. S. (1984). Re conceptualizing support services for classroom teachers: Implications for teacher education. Journal of Teacher Education, 35(5), 48-55.

Pugach, M., \& Sapon-Shevin, M. (1987). New agendas for special education policy: What the national reports haven't said. Exceptional Children, 53 (4), 295-299. 
Pugach, M. C., \& Warger, C. L. (1993). Curriculum considerations. In J. I. Goodlad \& T. C. Lovitt (Eds.), Integrating general and special education (pp. 125-148). New York: Macmillan Publishing Company.

Putt, A. D., \& Springer, A. F. (1989). Policy research: Concepts, methods, and applications. Englewood Cliffs, NJ: Prentice Hall.

Robbins, S. P. (1983). Organization theory: The structure and design of organizations. Englewood Cliffs, NJ: Prentice Hall.

Rossman, G. B., \& Salzman, J. (1994). Evaluating inclusive education programs: A survey of current practice. A paper prepared for the National center on Educational Restructuring and Inclusion invitational conference on inclusive education, Wingspread (WI) Conference Center.

Sage, D. D., \& Burrello, L. C. (1994). Leadership in educational reform: An administrator's guide to changes in special education. Baltimore: Paul Brookes Publishing Company.

Sailor, W. (1991). Special education in the restructured school. Remedial and Special Education, 12(6), 8-22.

Sapon-Shevin, M. (1992). Celebrating diversity. In Stainback \& W. Stainback (Eds.), Curriculum considerations in inclusive classrooms: Facilitating learning for all children (pp. 1936). Baltimore: Brookes.

Sapon-Shevin, M. (1995). Why gifted students belong in inclusive schools. Educational Leadership, 52(4), 64-70.

Schaffner, C. B., \& Buswell, E. B. (1996). Ten critical elements for creating inclusive and effective school communities. In S. Stainback, \& W. Stainback (Eds.), Inclusion: A guide for educators (pp. 49-66). Baltimore MD: Paul H. Brookes Publishing Company.

Schattman, R. (1992). The Franklin Northwest Supervisory Union: A case study of an inclusive school system. In R. Villa, J. Thousand, W. Stainback, \& S. Stainback (Eds.), 
$\underline{\text { Restructuring for caring effective education: An administrative guide to creating heterogeneous }}$ schools (pp. 143-159). Baltimore MD: Paul H. Brookes Publishing Company.

School Law of West Virginia. (1995). Charlottesville, VA: The Mitchie Company.

Schrag, J. A. (1993). Restructuring schools for better alignment of general and special education. In J. I. Goodlad, \& T. C. Lovitt (Eds.), Integrating general and special education (203-228). New York: Macmillan.

Schumacher, S., \& McMillan, J. H. (1993). Research in education: A conceptual introduction. New York, NY: HarperCollins College Publishers.

Schumm, J. S., \& Vaughn, S. (1991). making adaptations for mainstreamed students: General classroom teacher's perception. Remedial and Special Education, 12, 18-27.

Scruggs, T. E., \& Mastropieri, M. A. (1996). Teacher perceptions of mainstreaming/inclusion, 1985-1995: A research synthesis. Exceptional Children, 61(1), 59-74.

Sedlak, M. W., Wheeler, C. W., Pullin, D. C., \& Cusick, P. A. (1986). Selling students short: Classroom bargains and academic reform in the American high school. New York: Teachers College Press.

Semmel, M. I., Abernathy, T. V., Butera, G., \& Lesar, S. (1991). Teacher perceptions of the regular education initiative. Exceptional Children, 58 (1), 9-25.

Senge, P. (1990). The fifth discipline. New York, NY: Doubleday.

Shaw, S. F., Biklen, D. Colon, S., Dunn, J., Kramer, J., \& DeRoma-Wagner, V. (1990).

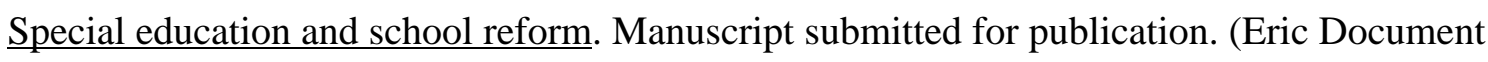
Reproduction Service No. ED 332 674)

Singer, J. D., \& Butler, J. A. (1987). The Education for All Handicapped Children Act: Schools as agents of social reform. Harvard Educational Review, 57(2), 125-152.

Skrtic, T. M. (1991a). The special education paradox: Equity as the way to excellence. Harvard Educational Review, 61(2), 148-206.

Skrtic, T. M. (1991b). Behind special education: A critical analysis of professional culture and school organization. Denver, CO: Love Publishing. 
Skrtic, T. M. (1995). The organizational context of special education and school reform.

In E. L. Meyen, \& T. M. Skrtic (Eds.), Special Education and student disability: An introduction

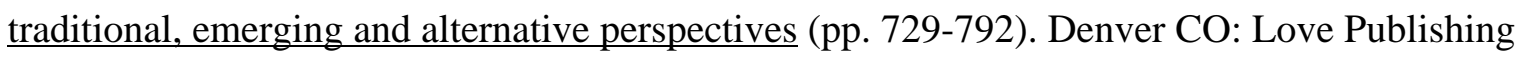
Company.

Skrtic, T. M. (1995). The organizational context of special education and school reform. In E. L. Meyen, \& T. M. Skrtic (Eds.), Special education and student disability: An introduction. (4th ed., pp. 609-674). Denver: Love Publishing.

Spradley, J. P. (1979). The ethnographic interview. Orlando, FL: Harcourt Brace Jovanovich College Publishers.

Stacey, R. (1992). Managing the unknowable. San Francisco, CA: Jossey-Bass.

Stainback, S. B., \& Stainback, W. (1984). A rationale for the merger of special and regular education. Exceptional Children, (51)2, 102-111.

Stainback, S., \& Stainback, W. (1990a). Facilitating support networks. In W. Stainback \& S. Stainback (Eds.), Support networks for inclusive schooling: Independent integrated education (pp. 25-36). Baltimore: Paul H. Brookes Publishing Company.

Stainback, S., \& Stainback, W. (1990b). Inclusive schooling. In W. Stainback \& S. Stainback (Eds.), Support networks for inclusive schooling: Independent integrated education (pp. 3-23). Baltimore: Paul H. Brookes Publishing Company.

Stainback, S. \& Stainback, W. (Eds.). (1992). Curriculum considerations in inclusive classrooms: Facilitating learning for all students. Baltimore: Brookes.

Stainback, S., \& Stainback, W. (1996). Schools as inclusive communities. In W. Stainback \& S. Stainback (Eds.), Controversial issues confronting special education: Divergent perspectives (2nd ed., pp. 29-43) Boston: Allyn \& Bacon.

Stainback, W., \& Stainback, S (1990c). Support facilitators that work. In W. Stainback \& S. Stainback (Eds.), Support networks for inclusive schooling: Independent integrated education (pp. 37-48). Baltimore: Paul H. Brookes Publishing Company. 
Stainback, W. \& Stainback, S. (Eds.). (1990). Support networks for inclusive schooling: Interdependent integrated education. Baltimore: Brookes.

Stainback, W., \& Stainback, S. (1996). Rationale for inclusive schooling. In S. Stainback \& W. Stainback (Eds.), Inclusion: A guide for educators (pp. 3-15). Baltimore: Paul H. Brookes Publishing Company.

Struaber, S. K., Stanley, S., \& Wagenknecht, C. (1990). Site-based management at Central-Hower. Educational Leadership, 47(7), 64-66.

Taylor, D. L. \& Bogotch, I. E. (1994). School-level effects of teachers' participation in decision making. Educational Evaluation and Policy Analysis, 16(3) 302-319.

Taylor, D. L. \& Teddlie, C. (1992). Restructuring and the classroom: A view from a reform district. Paper presented at the Annual Meeting of the American Educational Research Association.

Thurlow, M. L., Ysseldyke, J. E., \& Greenen, K. M. (1995). Future directions in the education of students with disabilities. In J. E. Ysseldyke \& M. L. Thurlow (Eds.). Educational outcomes for students with disabilities. (pp. 193-206). New York: Haworth Press.

Turnbull, H. R. \& Turnbull, A. P. (1978). Free appropriate public education: Law and implementation. Denver: Love.

Twentieth Century Fund Task Force on Federal Educational Policy. (1983). Making the grade. New York: Twentieth Century Fund.

Tyack, D. (1993). School governance in the United States: Historical puzzles and anomalies. In J. Hannaway \& M. Carnoy (Eds.), Decentralization and school improvement. (pp. 1-32). San Francisco: Jossey-Bass.

Underwood, J. (1989). State legislative responses to educational reform literature. In L. S. Lotto and P. W. Thurston, (Eds.), Recent advances in educational administration, Vol. 1 Greenwich, CT: JAI Press.

Underwood, J. K. \& Mead, J. F. (1995). Legal aspects of special education and pupil services. Boston: Allyn and Bacon. 
U.S. Congress. (1993). Goals 2000: Educate America Act. (Report from the Senate Committee on Labor and Human Resources, July 13, 1993). Washington, DC: Author.

U.S. Congress, Committee on Education and Labor, Select Subcommittee on Education. Hearings. 93rd Congress, 1st session, (1993).

U.S. Department of Education. (1987). Ninth Annual Report to the Congress on the implementation of the Education of the Handicapped Act. Washington, DC: Author.

U.S. Department of Education. (1990). To assure the free appropriate public education of all children with disabilities. Thirteenth Annual Report to the Congress on the implementation of the Individuals with Disabilities Education Act. Washington, DC: U.S. Government Printing Office.

U.S. Department of Education. (1991). America 2000: An education strategy source book. Washington, DC: Author.

U.S. Department of Education. (1995). To assure the free appropriate public education of all children with disabilities. Seventeenth Annual Report to the Congress on the implementation of the Individuals with Disabilities Education Act. Washington, DC: U.S. Government Printing Office.

U.S. Senate. (1993). Senate report 103-85 to accompany S. 1150. Washington, DC: U.S. Government Printing Office.

Van Meter, E. J. (1991). The Kentucky mandate: School-based decision making. NASSP Bulletin, 75, 52-62.

Villa, R., \& Thousand, J. S. (1990). Administrative supports to promote inclusive schooling. In W. Stainback \& S. Stainback (Eds.), Support networks for inclusive schooling: Independent integrated education (pp. 151-166). Baltimore: Paul H. Brookes Publishing Company.

Wang, M., \& Walberg, H. (1988). Four fallacies of segregationism. Exceptional Children, 55, 128-137. 
Weber, M. (1947). The Theory of Social and Economic Organizations. Talcott Parsons (ed.), A. M. Henderson and Talcott Parsons (trans.). New York: Free Press.

Weick, K. E. (1976). Educational organizations as loosely coupled systems. Administrative Science Quarterly p. 1-19.

Weick, K. E. (1983).Educational organizations as loosely coupled systems. In J. V. Baldridge \& T. Deal (Eds.), The dynamics of organizational change in education (pp. 15-37). Berkeley CA: McCutchan Publishing.

Weiss, C. (1992). Shared decision making about what? A comparison of schools with and without teacher participation. A paper presented at the Annual Meeting of the American Education Research Association.

West Virginia Department of Education. (1994). A strategic planning guide for West Virginia Faculty Senates. Charleston, WV: Author.

West Virginia Department of Education. (1997). Exceptional students in West Virginia's county school districts: Selected enrollment and financial information. Charleston, WV: Author.

Will, M. C. (1986). Educating children with learning problems: A shared responsibility. Exceptional Children, 52, 411-415.

Wise, A. (1988). The two conflicting trends in school reform: Legislative learning revisited. Phi Delta Kappan, 86(1), 61-121.

Wohlsetter, P., Smyer, R., \& Mohrman, S. A. (1994). New boundaries for school-based management: The high involvement model. Educational Evaluation, 16(3), 268-286.

Yell, M. L. (1995). Least restrictive environment, inclusion, and students with disabilities: A legal analysis. The Journal of Special Education, 28(4), 389-404.

Yin, R. K. (1984). Case Study Research: Design and methods. Newbury Park: Sage Publications.

Ysseldyke, J. E., Algozzine, B., \& Thurlow, M. L. (1992). Critical issues in special education. (2nd ed.). Boston: Houghton Mifflin. 
Zigmond, N., Jenkins, J., Fuchs, D., Deno, S., \& Fuchs, L. S. (1995). When students fail to achieve satisfactorily: A reply to Mcleskey and Waldron. Phi Delta Kappan, 77, 303-306. 


\section{APPENDIX A \\ SCHOOL DEMOGRAPHIC PROTOCOL}

This instrument examines eleven demographic features that characterize West Virginia's schools. The information for each question below reflects data obtained from the West Virginia School Report Cards and the Office of Special Education Programs and Assurances. The purpose is to identify and rank schools to determine which school will be examined by scatterplot regression analysis. The information will remain anonymous and confidentiality will be maintained.

School Name:

Key Coding

\section{Student Information}

1. Student population total 1995-1996 school year :

2. Total number of students with a written IEP 1995-1996 school year:

(a) Number of students who's primary identification is learning disabilities:

(b) Number of students who's primary identification is mentally impaired:

(c) Number of students who's primary identification is behavior disorders:

(d) Number who's primary identification is severely/profoundly impaired:

(e) Number of students who's primary identification is other health impaired:

(f) Number who's primary identification is deafness and/or blindness:

\section{School Information}

3. Average class size 1995-1996 school year:

4. Attendance rate 1995-1996 school year:

5. Promotion rate 1995-1996 school year:

6. Amount spent per pupil 1995-1996 school year:

7. Pupil teacher ratio 1995-1996 school year:

8. Pupil administrator ratio 1995-1996 school year:

9. Number of students with IEPs who spend $100 \%$ of instructional time in regular classroom: 
(a) Number of students with IEPs who spend more than $80 \%$ of instructional time in regular classroom setting during the 1991-2, 1992-3, 1993-4, 1994-5, 1995-6 school year:

(b) Number of students with IEPs who spend 60 to $79 \%$ of instructional time in regular classroom setting during the 1991-2, 1992-3, 1993-4, 1994-5, 1995-6 school year

(c) Number of students with IEPs who spend 40 to $59 \%$ of instructional time in regular classroom setting during the 1991-2, 1992-3, 1993-4, 1994-5, 1995-6 school year:

(d) Number of students with IEPs who spend less then $39 \%$ of instructional time in regular classroom setting during the 1991-2, 1992-3, 1993-4, 1994-5, 1995-6 school year:

\section{Teacher Information}

10. Number of Regular Educators 1995-1996 school year:
(a) Average years of experience:
(b) Percentage with Bachelor's:
(c) Percentage with Bachelor's +15 :
(d) Percentage with Master's:
(e) Percentage with Master's + 15:
(f) Percentage with Master's + 30:

(11) Number of Special Educators 1995-1996 school year:
(a) Average years of experience:
(d) Percentage with Master's:
(b) Percentage with Bachelor's:
(e) Percentage with Master's + 15:
(c) Percentage with Bachelor's + 15: (f) Percentage with Master's + 30: 


\section{APPENDIX B \\ STRATEGIC PLAN PROTOCOL}

School :

County:

This instrument examines six components of a school's Strategic Plan for the Appropriate Integration of Exceptional Students in the Regular Classroom. The development of each question below directly relates to the suggestions and guidelines described in, A strategic Planning Guide for West Virginia Faculty Senates. The purpose, therefore, is to identify how each school's components relate to this guide's recommendations. The information will remain anonymous and confidentiality will be maintained.

\section{Mission Statement}

Write the school's mission Statement below:

1. Identify the following three components of the school's mission statement:

Who is the audience (e.g., for whom does the school perform it primary function?)

What is the action (e.g., how does the school perform its primary function?)

What is the aim (e.g., what is the primary function, purpose or outcomes of the school)

Why is this important (e.g., why are these functions purposeful?) 
2. Match the mission statement with the following West Virginia's Integrated Initiative beliefs:

(a). Quality education reflects our diverse society and supports and promotes the success of all students.

(b). Education is a shared responsibility of families, educators and the community.

(c). Interaction with others fosters the life-long learning process.

(d). Each student's potential is better realized when a spectrum of educational opportunities occurs with age-appropriate peers in home school settings.

\section{Goals}

3. List the goals related to the Office of Special Education Programs and Assurances' goals:

(a). Provide technical assistance designed to promote a unified system that fosters integration.

(b). Establish and maintain positive partnerships with families, communities, local schools and legislators that support and enhance quality integration sensitive to the individual differences of all students.

(c). Provide comprehensive training that supports integrated education. 
(d). Utilize student-based funding that encourages integrated education.

(e). Develop and implement an accountability system to measure the outcomes of the Integrated Education Initiative.

4. List any additional goals not included above.

\section{Needs}

5. List the needs related to the Office of Special education Programs and Assurances' goals:

(a). Technical Assistance Needed

(b). Partnership Establishment Needed

(c). Comprehensive Training Needed

(e). Student-Based Funding Needed

(f). Accountability System Needed

6. list any additional needs not identified by the goals above. 


\section{Objectives and Activities}

7. List the objectives and activities as they relate to the areas listed below:

(a). Leadership and Support (e.g., goal dissemination, committee development, training, community involvement)

(b). Administrative Responsibilities and Staff Supervision (e.g., role defining, staff planning, scheduling, teaming, resource identification)

(c). IEP Development (e.g., grading and evaluation practices, collaborative decision-making, planning, transition, family participation, curriculum supports, inclusion defining)

(d). Collaborative Teamwork (e.g., planning, support identification, interagency networking, resource sharing, grade transitions, communication, )

(e). Professional Practices (e.g., policy development, related service staffing, curricular adaptations, instructional strategies, student groupings, socialization, behavior management)

(f). Student Activities (e.g., accessibility, socialization, participation, extracurricular involvement) 
(g). Student Interaction with Peers (e.g., peer support systems, program development)

8. List any additional objectives and activities not included above.

\section{Evaluation}

9. List the evaluation activities as they relate to the areas listed below and label using all of the following words that apply: Format: summative, formative; Orientation: process, outcome, impact; Resource: survey, records, observation, checklist, evaluation; Basis: judgment, performance)

(a). Leadership and Support

(b). Administrative Responsibilities and Staff Supervision

(c). IEP Development

(d). Collaborative Teamwork 
(e). Professional Practices

(f). Student Activities

(g). Student Interaction with Peers

10. List any additional evaluation activities that did not relate to these areas.

Additional Comments: 


\section{APPENDIX C}

\section{TEACHER SURVEY}

The following statements concern important teaching and student issues that you either currently face or may face in the future. As a teacher, your point of view regarding these issues is crucial. Please respond to each item by circling the response that is most descriptive of your experiences in your school. For questions about which you feel ambivalent, please circle the number that most closely reflects your opinion. Your participation is entirely voluntary and you do not have to respond to every question. I assure you that the information you provide will be treated confidentially. Please do not put any identifying marks on this questionnaire.

\begin{tabular}{|ccccc|}
\hline Never & Rarely & Sometimes & Usually & Always \\
1 & 2 & 3 & 4 & 5 \\
\hline
\end{tabular}

1. Teachers in my school tend to share a common view about school, teaching and learning.

2. Instructional staff ensure interaction of students with special needs with non disabled peers in all activities.

3. Teachers collaborate to make material and environmental adaptations.

4. Students with disabilities are involved in extracurricular activities (i.e., clubs, dances).

5. When faced with a mandate (state, county) our school takes a proactive stance on how it will be implemented.

6. Faculty members have the opportunity to contribute to decision-making about how money is spent.

7. Related service staff provide services in general education classrooms.

8. Teams meet weekly to plan instructional support services for all students.

9. Teachers adapt instructional strategies in academic content areas to meet (IEP) objectives.

10. IEP objectives reflect interaction with non disabled peers.

$\begin{array}{lllll}1 & 2 & 3 & 4 & 5 \\ 1 & 2 & 3 & 4 & 5\end{array}$

5

5


\begin{tabular}{lllll}
\hline Never & Rarely & Sometimes & Usually & Always
\end{tabular}

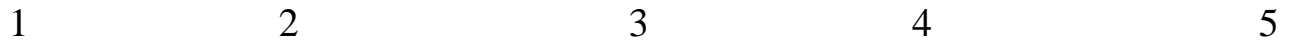

11. Remedial programs and other support services are available at my school for students who are not experiencing success.

12. Teams collaborate to provide related services (i.e., therapies) in inclusive settings.

13. Teachers develop age appropriate materials to address student level of performance.

14. Teachers implement positive behavior managemen strategies with support of other team members.

15. All students participate in music, art and gym classes. $\quad \begin{array}{lllllll}1 & 2 & 3 & 4 & 5\end{array}$

16. Administrators in my school are committed to $\quad \begin{array}{lllllll}1 & 2 & 3 & 4 & 5\end{array}$ enhancing their professional knowledge and skills.

17. Teachers in my school participate in the decisions about teachers' assignments to duties outside the classroom.

18. The school develops and disseminates a mission statement that reflects the philosophy that all children can learn.

19. The design of progress reports reflects my school's mission.

20. Students with disabilities' instructional programs incorporate interaction with non disabled students.

21. All students participate in general education classes.

22. Teachers collaborate to adapt learning objectives for students within the context of core curriculum.

23. The school philosophy supports the need for ongoing inservice training, staff development and technical assistance.

24. IEP meetings use a transdisciplinary approach.

25. Decisions about how money is spent are consistent with our school mission. 


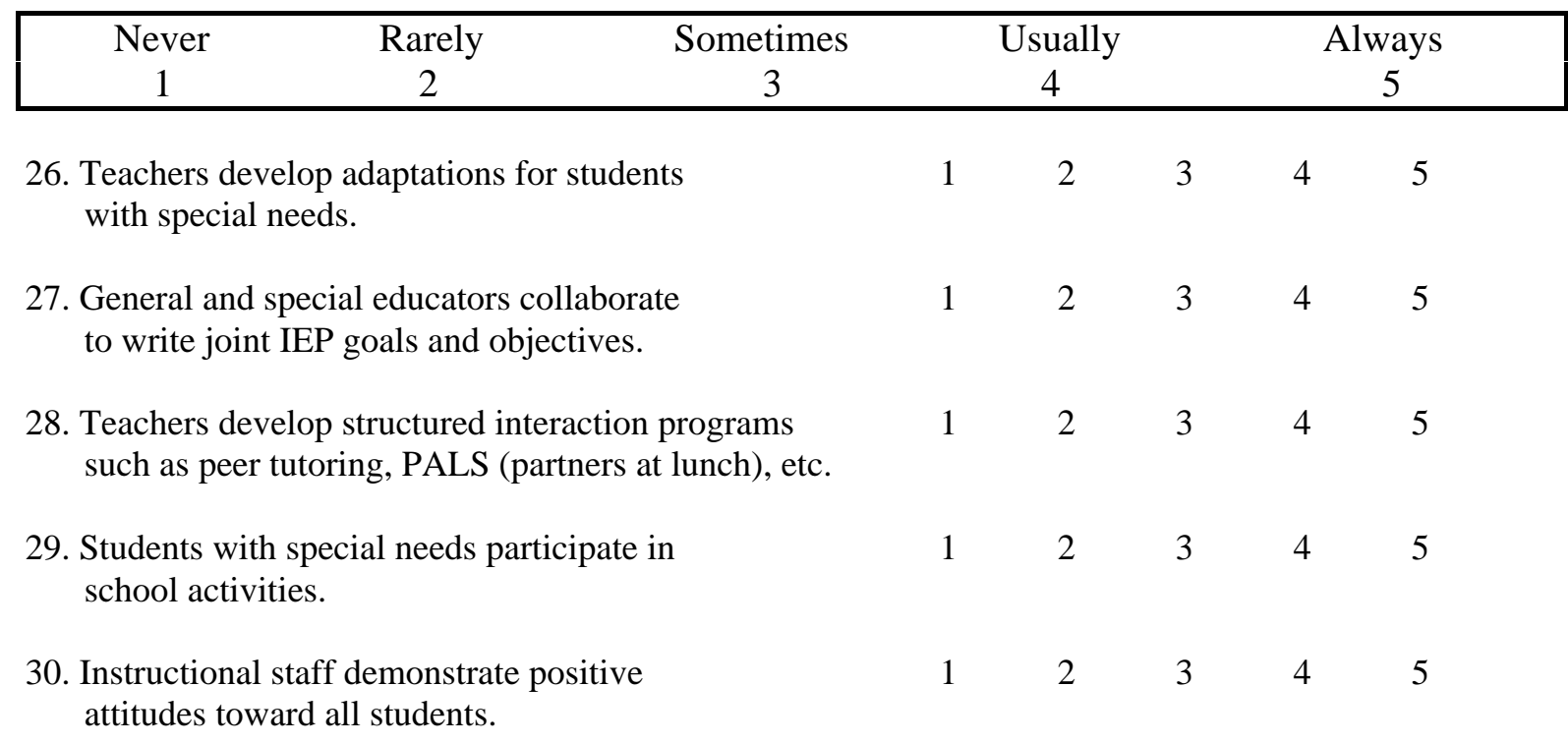

Please answer the following questions about yourself so that I can better interpret survey responses. Thank you.

How many years have you taught?

How many years have you taught in this school?

Describe your role in the school, including the grades and subjects you teach. (i.e., Math 7th gr.).

Do you instruct students that have IEPs? __ Yes __ No

What is the highest degree you currently hold? _ BA _ _ MA _ D Doctorate

Thank you for completing the survey. Please offer any comments or suggestions. 


\section{APPENDIX C-1}

Teacher Survey Factor Component

The first scale, Professional Practice, includes eight items. The reliability alpha was .7357. Items in this scale reflected to the professional practices that support an inclusive schooling environment. Several items referenced the teachers' philosophical beliefs and attitudes toward teaching all children, including children with disabilities. Items referred to the teacher's perception about their school's mission and how the mission related to their own belief structure. Other items concerned the extent to which teachers adapt instructional strategies and materials to support student individual need. A high score on this scale reflect higher levels of teacher's professional practices as in congruency with West Virginia's school inclusion mission.

\section{Professional Practice Factor Mean and Standard Deviation}

Item $\underline{\mathrm{M}} \quad \underline{\mathrm{SD}}$

1. Teachers in my school tend to share a common view about school, teaching and learning.

$\underline{\mathrm{SD}}$

2. Instructional staff ensure interaction

of students with special needs with nondisabled peers in all activities.

9. Teachers adapt instructional strategies in academic content areas to meet IEP objectives.

13. Teachers develop age appropriate materials to address student level of performance.

18. The school develops and disseminates a mission statement that reflects the philosophy that all children can learn.

26. Teachers develop adaptations for students with special needs.

28. Teachers develop structured interaction programs such as peer tutoring, PALS (partners at lunch), etc.

30. Instructional staff demonstrate positive attitudes toward all students. 
The School Site Based Management Climate scale contained eight items and had a reliability alpha of .7750 . This scale referred to the way schools make administrative policy decisions. These decisions include developing school budgets, designing student progress reports, and assigning teacher duties outside the classroom. They reference the extent to which administrative decisions reflect the school's mission and the degree to which the decision making process involved teacher participation. A high score on this scale reflects a school climate where administrative decisions support West Virginia's school site based management mission. $\underline{\text { School Site-Based Management Climate Factor Mean and Standard Deviation }}$ Item

$\underline{M} \quad \underline{\text { SD }}$

5. When faced with a mandate (state, county) 3.85 .7694 our school takes a proactive stance on how it will be implemented.

6. Faculty member have the opportunity to contribute to decision-making about how money is spent.

8. Teams meet weekly to plan instructional support services for all students.

14. Teachers implement positive behavior management $\quad 4.04$ strategies with support of other team members.

16. Administrators in my school are committed to enhancing their professional knowledge and skills.

17. Teachers in my school participate in the decisions about teachers' assignments to duties outside the classroom.

19. The design of progress reports reflects my school's mission.

23. The school philosophy supports the need for ongoing inservice training, staff development and technical assistance.

25. Decisions about how money is spent are consistent with our school mission. 
The third scale, Collaborative Teaming, consisted of six items. It had a reliability alpha of .6593. This scale references teacher engagement in collaborative teaming as it relates to achieving a common goal to support inclusive practices for students with disabilities. Items reflect teacher working relationships and reference the extent the teachers share team ownership in planning and delivering specially designed instruction. Items also reflect how policy translates into creating a positive, supportive school climate. For example, items refer to how support services provide aide to students having difficulty. The items also measure how collaborative planning activities relate to teacher's own implementation of individualized instructional practices. A high score on this scale suggest that teachers perceive participating in a higher level of shared decision making practices to address student individual need.

\section{Collaborative Teaming Factor Mean and Standard Deviation}

Item $\underline{\mathrm{M}}$

$\underline{\mathrm{SD}}$

3. Teachers collaborate to make material 3.66

.7237 and environmental adaptations.

7. Related service staff provide services in general education classrooms.

12. Teams collaborate to provide related services (i.e., therapies) in inclusive settings.

22. Teachers collaborate to adapt learning objectives for students within the context of core curriculum.

24. IEP meetings use a transdisciplinary approach.

27. General and special educators collaborate to write joint IEP goals and objectives.

The final scale, Student Involvement, contained seven items. The reliability alpha was .6935. Items in this scale refer to activities designed to facilitate positive student peer interactions and the extent teachers perceive that the school activities involve students with disabilities. Items 
reference student involvement in school programs including extra curricular activities, academic and non academic classes and to how teachers ensure all activities involve the interaction of all students. This scale also measures issues related to student behavior management and student personal management of self-advocacy. It also includes Individual Education Plan (IEP) goals and objectives concerning student interactions and activity participation. A high score on this scale reflects teacher perceiving student with disabilities having a high level of involvement in school activities and interaction among their peers.

$\underline{\text { Student Involvement Factor Mean and Standard Deviation }}$

Item $\quad \underline{M} \quad \underline{S D}$

4. Students with disabilities are involved in extracurricular activities (i.e., clubs, dances).

10. IEP objectives reflect interaction with nondisabled peers.

11. Remedial programs and other support services are available at my school for students who are not experiencing success.

15. All students participate in general education classes. $\quad 4.65$ .5657

20. Students with disabilities' instructional programs .6766 incorporate interaction with nondisabled students.

21. All students participate in music, art and gym classes.

29. Students with special needs participate in school activities. 


\section{APPENDIX D}

\section{TEACHER INTERVIEW: SCHOOL-BASED PLANNING TEAM MEMBERS}

This instrument examines fourteen areas of interest that relate to West Virginia's strategic plans for managing the integration of exceptional students in the regular classroom. I am interested in your opinion about this topic. All information will be kept confidential, and no names will be used. Your participation in this interview is voluntary, and you do not have to respond to every question posed.

School:

Position:

\section{School-Based Planning Team}

1. List the members of the School-Based Planning Team and indicate the number of years they have served as members of the school's faculty and their positions in the school:

2. How were the members of the School-based Planning Team determined?

3. What was their role and responsibility on the School-based Planning Team?

\section{Strategic Plan Meetings}

4. Describe the timeline used to develop the plan.

5. Where and how often did the committee meet? How long was each meeting?

6. Did everyone attend all of the meetings? If not, how did this effect the planning process?

7. What procedures did the committee use to conduct the meeting? 


\section{Strategic Planning Process}

8. Did the committee include the participation of members from outside the school's faculty (e.g., parents, special education administrators, teachers form other schools)? How

9. What resources did the committee use to devise the plan?

10. How were revisions made? why?

11. How did the committee includes the concerns of other faculty members? What were some of these concerns?

\section{Mission Statement}

12. Is the statement different from previous mission statement? If so how? Do other documents have a different statement?

13. Who sees the statement? Is it posted in the school? Is it printed on other school publications?

14. How well does this statement represent your beliefs? the beliefs of the school?

\section{Goal Statements}

15. Are these new goals?

16. Do these goals different from other school goals? If so how?

17. Are they goals for the entire faculty? (why or why not) 


\section{Needs Assessment}

18. Who was involved in the needs assessment process? How was this process conducted?

19. What formal and informal assessments were used? (Was judgment based data collected and how? Was performance-based data collected? If so what did you use? test results? promotion and/or retention rates? grievance and lawsuits?

20. How did these assessments serve to analyze external and internal conditions that may effect mission statement implementation?

21. Were any needs identified and not included in the strategic plan? If so, why?

22. How did you prioritize the needs?

\section{Objectives \& Activities}

23. How did the committee determine the objectives and activities?

24. Do they represents needs of the entire faculty? If so, how?

25. Were any of these activities new? If so, how? Why?

\section{Plan Implementation}

26. How was the strategic planning process for the inclusion of students with disabilities been infused within the school's overall restructuring of services provided to all students?

27. During the plan's development what barriers were encountered? How were they overcome? 


\section{Process Evaluation}

28. Who evaluates the plan's effectiveness? How is it done?

29. Have activities been carried out as planned?

30. Have the activities undertaken been consistent with the overall goals of the effort?

31. What worked well and what have been keys to success?

\section{Outcome Evaluation}

32. Have the goals and objectives been met?

33. What has happened as a result of meeting those objectives? Who has been effected?

34. What activities influenced the achievement of the goals identified in this plan?

35. Have any products been developed as a result of this plan?

\section{Impact Evaluation}

36. Have the project activities' accomplishments resulted in any long term effects? If so, specify.

37. What indicators reflect best practice for inclusion? 
38. Is follow-up data available? If so, what changes do they reflect?

39. Have any school or district policies been changed or modified as a result? If so, specify.

40. What positive outcomes have been demonstrated for student? teachers? the school?

\section{Staffing}

41. Have the roles of staff changed? How is their role used to effectively support all students?

42. How are students group within and among classrooms? Is this practice different from before the plans?

43. Have any scheduling changes been made as a result of these plans? If so, what changes were made? Why?

\section{Collaboration}

44. Are times provided for collaborative teaming? If so, how, when, why?

45. Describe the collaborative models used in your school.

46. What barriers conflict with collaborative practices?

\section{Training}

47. What training was provided as a result of these plans? Has it been effective, Why or why not? 
48. What additional training is still needed?

49. How do teachers meet student's individual needs in the general classroom? Has this practice changed? How?

50. In sum, how has the training, the planning process, and plan's components effected current practice from your point of view? for a student's point of view and from the faculty's view?

Additional Comments: 


\section{APPENDIX E}

\section{TEACHER INTERVIEW}

This instrument examines seven areas of interest that relate to West Virginia's strategic plans for managing the integration of exceptional students in the regular classroom. I am interested in your opinion about this topic. All information will be kept confidential, and no names will be used. Your participation in this interview is voluntary, and you do not have to respond to every question posed.

School:

Position:

\section{Plan Implementation}

1. How was the strategic planning process for the inclusion of students with disabilities been infused within the school's overall restructuring of services provided to all students?

2. What barriers does it encounter? How are they overcome?

\section{Process Evaluation}

3. How do you evaluate the plan's effectiveness? Has it changed anything from your point of view? from the faculty's point of view?

4. What activities have been carried out? Were they meaningful to you? Why or why not?

5. Are the activities undertaken been consistent with the overall goals of the effort and of your practices? 


\section{Outcome Evaluation}

6. What the goals and objectives have been met? How?

7. What has happened as a result of meeting those objectives? Who has been effected?

8. What activities influenced your practices?

9. Have any products been developed as a result of this plan?

\section{Impact Evaluation}

10. Have the activities' accomplishments resulted in any long term effects? If so, specify.

11. What indicators reflect best practice for inclusion?

12. Are these practices different from approach use previously? If so, how?

13. Have any school or district policies been changed as a result? If so, specify.

14. What positive outcomes have been demonstrated for student? teachers? the school? 


\section{Staffing}

15. Have staff roles changed? How is their role used to effectively support all students?

16. How are students grouped within and among classrooms? Is this a new practice?

17. Have any scheduling changes been made as a result of these plans? If so, How? Why?

\section{Collaboration}

18. Are times provided for collaborative teaming? If so, how, when, why?

19. What collaborative models do you use?

20. What barriers conflict with collaborative practices?

\section{Training}

21. What training was provided as a result of these plans? Was it effective, Why?

22. What additional training is still needed?

23. How do teachers meet student's individual needs in the general classroom? Has this practice changed over time? How? 
24. In sum, how has the training, the planning process, and plan's components effected current practice from your point of view? for a student's point of view and from the?

25. What other changes would you like to see occur? 


\section{APPENDIX F}

\section{CONTENT ANALYSIS PROTOCOL}

This instrument examines six components of each school's Strategic Plan Protocol for identification and comparison purposes. Each letter below corresponds to the letter's statements contained in the Strategic Plan Protocol.

I. Mission Statement: Identify the following three components of the school's mission statement:

Case Study 2 3 4 Audience

$\underline{\text { Action }}$

$\underline{\text { Aim }}$

$\underline{\text { Importance }}$

2. Mark X if the mission statement correlates with West Virginia's Integrated Initiative beliefs: Case Study 12 3 4
(a)
(b)
(c)
(d)

II. Goals: Mark X if goals relate to the Office of SEPA's goals:

Case Study

12

3

4

(e)

(f)

(g)

(h)

(i) 
III. Needs: Mark X if the needs relate to the Office of SEPA's goals:

\begin{tabular}{lllll} 
Case Study & 1 & 2 & 3 & 4 \\
\hline
\end{tabular}

(j)

$(\mathrm{k})$

(1)

(m)

(n)

IV. Objectives and Activities: Mark X if the objectives and activities relate.

\begin{tabular}{lllll} 
Case Study & 1 & 2 & 3 & 4 \\
\hline
\end{tabular}

(o)

(p)

(q)

$(\mathrm{r})$

(s)

(t)

(u)

V. Evaluation: Mark X for the evaluation activities that apply and label using the following words to describe their Format: summative, formative; Orientation: process, outcome, impact; Resource: survey, records, observation, checklist, evaluation; Basis: judgment, performance.

1

2 3

4

(w)

(x)

(y)

(z)

(AA)

(BB)

(CC) 


\section{Curriculum Vitae HOLLY ANN PAE}

\section{EDUCATION}

Ed.D.

May, 1999

M.A.

1991

B.A.

1987

Language Certificate

1986
West Virginia University

Doctoral Candidate: Special Education (Major)

Education Administration (Minor)

Morgantown, West Virginia

West Virginia University

Special Education

Specific Learning Disabilities (certification)

Morgantown, West Virginia

Denison University

Art History

Granville, Ohio

Nanjing University

Chinese Language Program

People's Republic of China

PROFESSIONAL PUBLICATIONS (note my name has changed from Klein to Pae)

Pae, H. (1998). West Virginia University's teacher training inclusion efforts. (in review).

Butera, G., Klein, H. (Pae), McMullan, L., \& Wilson, B. (1998). A statewide study of FAPE and school discipline policies. Journal of Special Education, 32(2), 108-114.

Lombardi, T., Klein, H. (Pae), \& Savage, L. (1998). Expanding and enriching a teacher training program to better meet special education needs: A strand approach. International Journal of Special Education, 13(2), 1-15.

Butera, G., Dempsey, V., Conti, A., McMullan, L., Pae, H., \& Pavlovic, S. (1998). 1998 Energy Express Evaluation: Design and findings. Governor's Cabinet on Children and Families. Charleston, West Virginia.

Butera, G., Metheny, A., Klein, H. (Pae), \& Wilson, B. (1997). Wade Elementary: Energy Express case study report. In 1996 Energy Express evaluation: Design and findings Governor's Cabinet on Children and Families. Charleston, West Virginia.

Butera, G., Klein, H. (Pae), Metheny, A., \& Wilson, B. (1997). Frametown: Energy Express case study report. In 1996 Energy Express evaluation: Design and findings Governor's Cabinet on Children and Families. Charleston, West Virginia. 
Butera, G., Belcastro, R., Friedland, B., Henderson, J., Jackson, C., Klein, H. (Pae), McMullan, L., \& Wilson, B. (1996). Suspension, discipline and disabilities: Perspectives from practice. Special Education Leadership Review, 3(1), 77-90.

Monongalia County Schools Division of Special Education. (1995). Team effort applying motor skills: Project team report. Unpublished Manual.

\section{PROFESSIONAL PRESENTATIONS}

1999 Special education competencies in general teacher training programs: Design and initial feedback. Council for Exceptional Children Annual Convention. Charlotte, North Carolina

1999 Building Community on behalf of low income West Virginian school children: Energy Express. American Education Research Association. Montreal, Canada.

1997 Reforming a special education leadership program: Participant reactions and program outcomes. Teacher Education Division of the Council for Exceptional Children Annual Conference. Savannah, Georgia.

1997 Invited Speaker, West Virginia University's teacher training inclusion efforts. Phi Delta Kappa Leadership Skill Institute, Inclusion: Its Impact and Ramifications on Education. West Virginia University, West Virginia.

1996 IEP process and school discipline policies: Special and general education intersect. West Virginia Federation Council for Exceptional Children Annual Conference. Huntington, West Virginia.

1996 West Virginia teachers \& administrators speak out about suspension. Research and Development Colloquium Series. West Virginia University, Morgantown, West Virginia.

1996 West Virginia teachers \& administrators speak out about suspension. Continuing Education Conference for Social Workers. Charleston, West Virginia.

1996 Restructuring general teacher training: Strands in special education, multiculturalism, and technology. Council for Exceptional Children Annual Convention. Orlando, Florida.

1995 How professionals view suspension. American Association on Mental Retardation. Lancaster, Pennsylvania.

1995 Suspension: Perspectives and practitioners. West Virginia Federation of Council for Exceptional Children Annual Conference. Parkersburg, West Virginia. 